\author{
UNIVERSIDADE DE SÃO PAULO \\ ESCOLA DE ENGENHARIA DE SÃO CARLOS \\ DEPARTAMENTO DE ENGENHARIA MECÂNICA
}

\title{
OTIMIZAÇÃO ESTRUTURAL DE PROTÓTIPOS FABRICADOS PELA TECNOLOGIA FDM UTILIZANDO O MÉTODO DOS ELEMENTOS FINITOS
}

\section{Wagner José de Almeida}

Dissertação de Mestrado apresentada à Escola de Engenharia de São Carlos, da Universidade de São Paulo, como parte dos requisitos para a obtenção do título de Mestre em Engenharia Mecânica.

ORIENTADOR: Prof. Dr. Jonas de Carvalho

São Carlos

2007 


\section{AGRADECIMENTOS}

Ao Prof. Dr. Jonas de Carvalho, orientador, meu respeito e admiração, pela cooperação e paciência.

À secretária de Pós-Graduação em Engenharia Mecânica, Ana Paula, que sempre esteve presente e por auxiliar nas questões burocráticas.

Aos funcionários da Secretaria do SEM, que sempre estiveram dispostos ao atendimento.

Aos amigos da pós-graduação, pelo companheirismo.

Aos meus Pais e minha noiva, pelo incentivo e ajuda nos momentos difíceis.

E a Deus, nosso Criador, pela Vida. 


\section{SUMÁRIO}

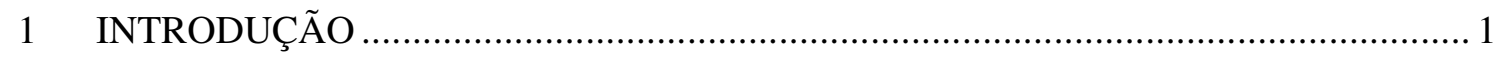

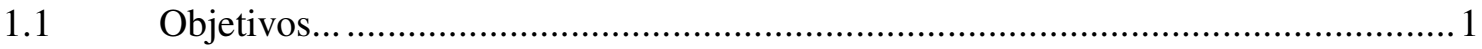

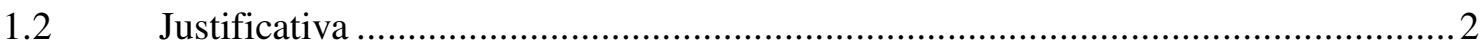

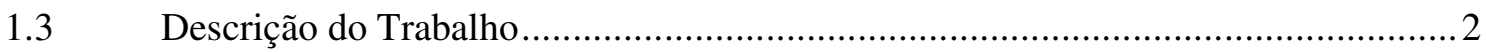

2 PROTOTIPAGEM RÁPIDA - FUNDAMENTAÇÃO TEÓRICA ……………................5

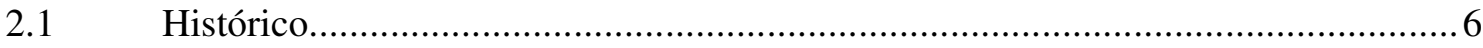

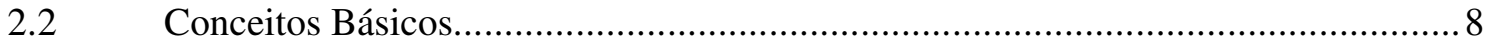

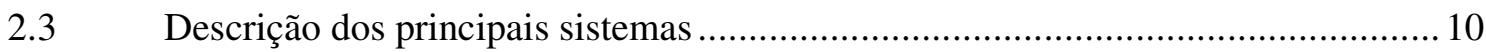

2.3.1 Estereolitografia (SLA, Stereolithography) …………….....................................11

2.3.2 Manufatura de Objetos em Lâminas (LOM, Laminated Object Manufacturing) ....12

2.3.3 Impressão a Jato de Tinta (IJP) - PolyJet da Objet .................................................14

2.3.4 Impressão a Jato de Tinta (IJP) - InVision da 3D Systems ....................................15

2.3.5 Sinterização Seletiva a Laser (SLS, Selective Laser Sintering).................................16

2.3.6 Modelagem por Deposição de Material Fundido (Fused Deposition Modeling -

FDM)

2.3.7 Base de Cura Sólida (SGC, Solid Ground Curing) ............................................ 18

2.3.8 Dimensional Printing (3DP) - Impressão Tridimensional .....................................18

2.3.9 Conformação Próxima ao Formato Final via Laser (LENS, Laser Engineered Net

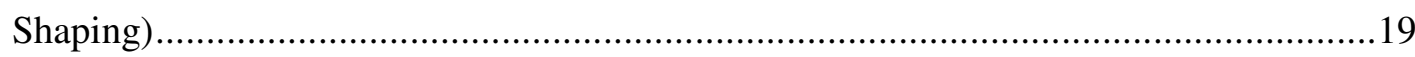

2.3.10 Comparativo de processos 3D Print ………………………………………...20

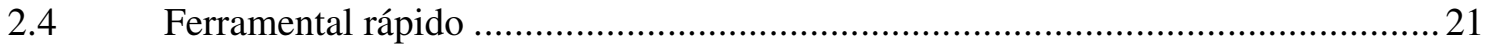

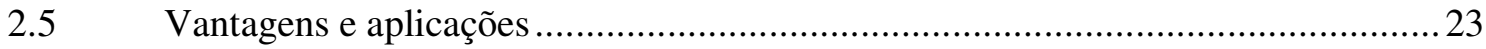

3 OTIMIZAÇÃO ESTRUTURAL DE PROTÓTIPOS ………………...........................2

3.1 Parâmetros a serem considerados...........................................................................2

3.2 Módulo de elasticidade e propriedades do material ................................................39

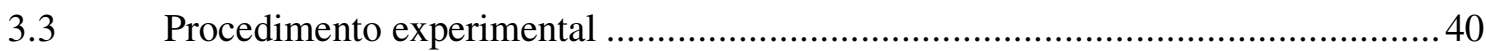

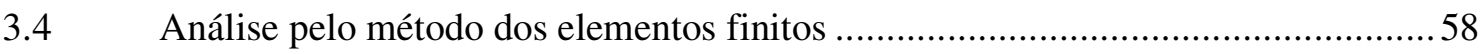

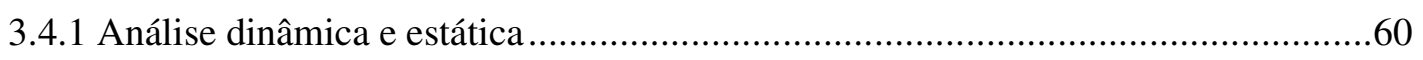

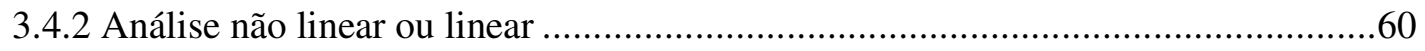

3.4.3 Pré-Processamento ...................................................................................62 


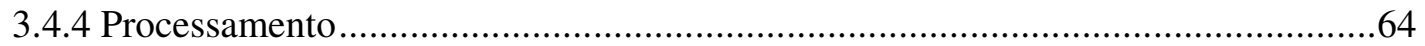

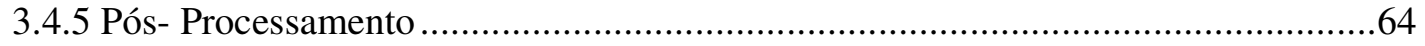

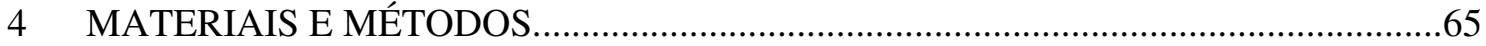

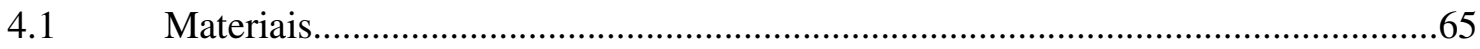

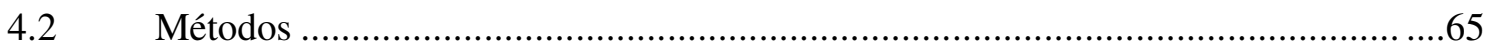

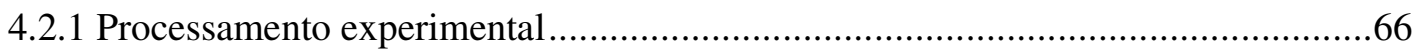

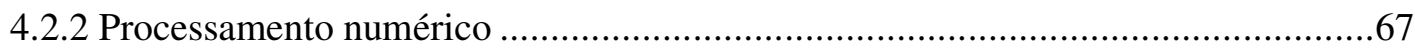

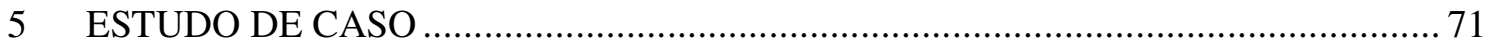

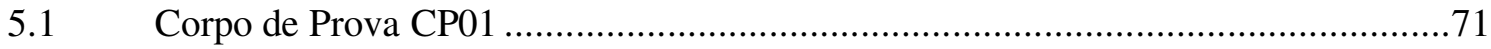

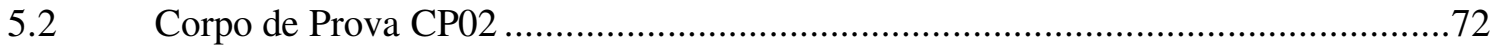

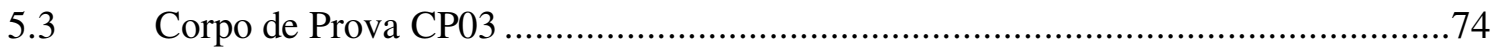

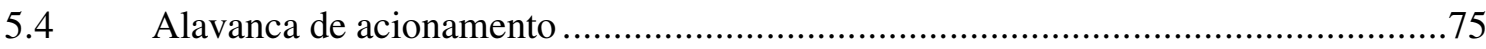

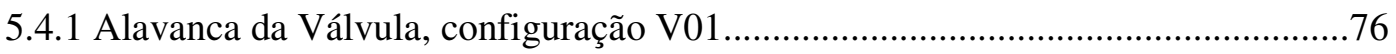

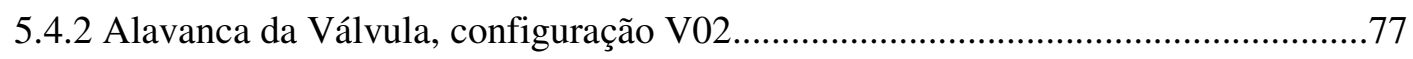

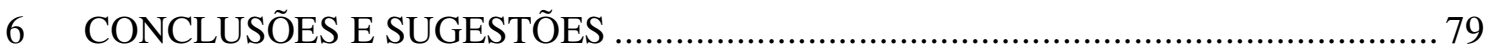

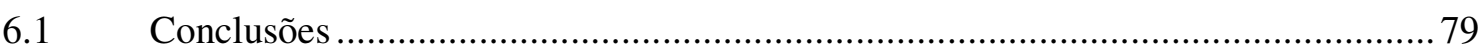

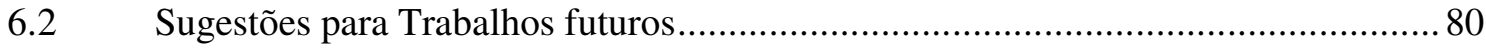

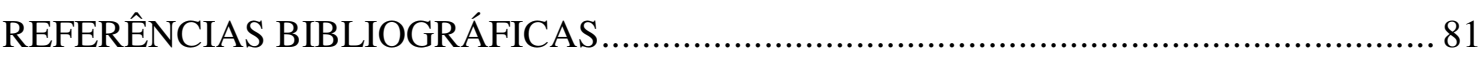

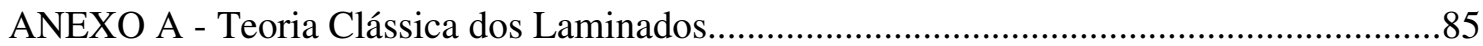

Caracterização mecânica por métodos experimentais.................................................96

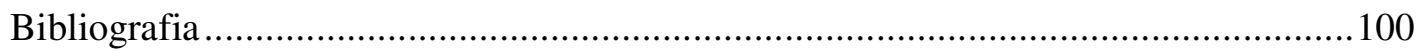




\section{LISTA DE FIGURAS}

Figura 1 - Conceito da manufatura por camada.

Figura 2 - Custo de alteração de projeto ao longo de ciclo de desenvolvimento do produto

Figura 3 - Princípio do processo SLA

Figura 4 - Princípio do processo LOM

Figura 5 - Princípio da Tecnologia PolyJet

Figura 6 - Princípio de funcionamento do processo InVision

Figura 7 - Princípio do processo SLS

Figura 8 - Princípio do processo FDM

Figura 9 - Princípio do processo 3DP

Figura 10 - Tempo médio de construção dos protótipos

Figura 11 - Nível alto, baixo, mediana e média dimensional de precisão

Figura 12 - Representação esquemática de uma camada de material sendo depositado no processo FDM com alguns dos parâmetros de controle

Figura 13 - Resultados comparativos entre peças injetadas e prototipadas em FDM

Figura 14 - Fatores de influência no processo de Prototipagem Rápida

Figura 15 - Tipo de construção de poucas camadas aproximando estruturas de formas complexas

Figura 16 - Tipo de construção de muitas camadas melhores aproximando estruturas de formas complexas

Figura 17 - Alteração da densidade no interior da camada

Figura 18 - Influência da densidade interna da peça

Figura 19 - Deposição de material em espessura fina

Figura 20 - Parâmetros de processo FDM de alto e baixo nível 
Figura 21 - Efeito da porosidade no rendimento e resistência à compressão para estruturas FDM

Figura 22 - Efeito da porosidade no módulo de compressão para estruturas FDM

Figura 23 - Fabricação de um protótipo com o processo visto minimamente e a decisão do sistema de suporte usado

Figura 24 - Vista de seção transversal com peça construída em ABS e orientação de 0/90

Figura 25 - Processo de pré-processamento em FDM

Figura 26 - Método dos elementos finitos

Figura 27 - Graus de liberdade

Figura 28 - Geração do modelo CAD

Figura 29 - Geração da malha

Figura 30 - Restrições e carregamentos

Figura 31 - Exemplo de comportamento de material

Figura 32 - Exemplo de resultados de deslocamentos

Figura 33 - Dimensões em milímetros do corpo de prova de tração - Tipo I

Figura 34 - Dimensões em milímetros do corpo de prova de flexão - Método I

Figura 35 - Estado de tensões (direção axial) para trajetórias a $0^{\circ}$..

Figura 36 - Estado de deformações (axial) para trajetórias a $0^{\circ}$

Figura 37 - Estado de tensões (direção axial) para trajetórias a $90^{\circ}$.

Figura 38 - Estado de deformações (axial) para trajetórias a $90^{\circ}$

Figura 39 - Estado de tensões (direção axial) para trajetórias a $+-45^{\circ}$

Figura 40 - Estado de deformações (axial) para trajetórias a +-45

Figura 41 - Máxima tensão para CP01.

Figura 42 - Máximo deslocamento para CP01.

Figura 43 - Máxima tensão para CP02 
Figura 44 - Máximo deslocamento para CP02

Figura 45 - Máxima tensão para CP03

Figura 46 - Máximo deslocamento para CP03

Figura 47 - Conjunto Válvula

Figura 48 - Máxima tensão para V01

Figura 49 - Máximo deslocamento para V01

Figura 50 - Máxima tensão para V02

Figura 51 - Máximo deslocamento para V02 


\section{LISTA DE TABELAS}

Tabela 1 - Classificação dos processos de Prototipagem Rápida baseados no estado inicial da matéria-prima

Tabela 2 - Valores adotados para fatores mais relevantes no processo

Tabela 3 - Influência da porosidade no comportamento mecânico da peça

Tabela 4 - Valores encontrados nos ensaios de tração dos protótipos

Tabela 5 - Valores encontrados nas simulações dos s ensaios de tração dos protótipos

Tabela 6 - Especificações e Resultados Corpo de Prova CP01

Tabela 7 - Especificações e Resultados Corpo de Prova CP02

Tabela 8 - Especificações e Resultados Corpo de Prova CP03

Tabela 9 - Especificações e Resultados Alavanca V01

Tabela 10 - Especificações e Resultados Alavanca V02 


\section{RESUMO}

\section{ALMEIDA, WAGNER J. Otimização estrutural de protótipos fabricados pela tecnologia}

FDM utilizando o método dos elementos finitos. 2007. 100 p. Dissertação (Mestrado).

Escola de Engenharia de São Carlos, Universidade de São Paulo, 2007.

Este trabalho tem como objetivo principal a otimização dos protótipos fabricados pelo processo FDM (Fused Deposition Modeling) em procedimento baseado na análise do comportamento estrutural dos protótipos variando as estratégias de preenchimento das camadas. Para atingir tal objetivo, corpos de prova com diferentes orientações de preenchimento foram ensaiados experimentalmente e os resultados foram verificados em análise estrutural por elementos finitos.

Foram verificados o caráter ortotrópico do material do protótipo e a validade do uso da Teoria Clássica dos Laminados na simulação de seu comportamento. Os conceitos e metodologia de análise foram validados em estudos de casos, mostrando a viabilidade de sua aplicação na obtenção de protótipos funcionais.

Palavras-chave: Prototipagem Rápida, FDM, Manufatura Rápida, Otimização, Protótipos, Elementos finitos, Materiais Compósitos. 


\begin{abstract}
ALMEIDA, WAGNER J. Structural optimization of FDM prototypes based on finite element analysis. 2007. 100 p. Dissertação (Mestrado). Escola de Engenharia de São Carlos, Universidade de São Paulo, 2007.

The objective of this work is to develop an optimization procedure for FDM prototypes. This procedure is based on the structural analysis of the prototypes within different slice filling paths. In order to reach this objective, experimental tests with different filling trajectories are conducted and the results are used in structural analysis by finite element method. The orthotropic behavior of the prototype material and the use of the Classical Laminate Theory in the numerical simulation were validated. The results were applied in different case studies, showing the viability of its application in the design of functional prototypes.
\end{abstract}

Keywords: rapid prototyping; FDM; rapid manufacturing; optimization; prototypes; finite element method, composite materials. 


\section{INTRODUÇÃO}

A imposição do mercado para o lançamento de novos produtos, bem como alterações em projetos anteriores, tem exigido das empresas mudanças em seus processos de desenvolvimento, segundo as quais, estabelecer práticas eficazes e rápidas é condição para permanecer competitivo. Alguns exemplos de trabalhos realizados nesse sentido podem ser citados como o time-to-market e o gerenciamento de mudanças, demonstrado pela indústria de computadores pessoais para a qual a estratégia é submeter às empresas concorrentes a uma intensa competitividade, eliminando as mais fracas, considerando-se também o ciclo de vida dos produtos como preocupação importante, o que leva algumas empresas a estabelecerem cronogramas de nascimento e encerramento da vida útil do item a ser lançado.

\subsection{OBJETIVOS}

Este trabalho tem como objetivo principal a otimização dos protótipos fabricados pelo processo FDM (Fused Deposition Modeling) a partir da análise do comportamento estrutural dos protótipos variando as estratégias de preenchimento das camadas. Para atingir tal objetivo, corpos de prova com diferentes orientações de preenchimento serão ensaiados experimentalmente e os resultados serão utilizados em análise estrutural por elementos finitos.

Traz ainda como objetivos secundários:

- verificar o caráter anisotrópico dos protótipos fabricados pela tecnologia FDM e a possibilidade de considerá-lo material ortotrópico nas análises computacionais;

- verificar a possibilidade do uso da Teoria Clássica dos Laminados na modelagem e simulação numérica dos protótipos. Essa validação será feita experimentalmente em ensaios de tração e flexão. 


\subsection{JUSTIFICATIVA}

Existe hoje comercialmente uma grande quantidade de máquinas e tecnologias de prototipagem rápida utilizados para a confecção de protótipos (RP - Rapid Prototyping) ou produtos finais. A utilização destas máquinas e tecnologias deu origem ao que hoje tem sido conhecido como manufatura rápida (RM - Rapid Manufacturing) ou ferramental rápido (RT Rapid Tooling). Cada tecnologia produz protótipos com diferentes características e aplicações, devendo o usuário conhecer limitações e características de cada processo. Como os métodos são diferentes, os materiais são diferentes e as aplicações são distintas é necessário que sejam feitos estudos que possibilitem o uso adequado das tecnologias disponíveis para suprir necessidades existentes ou ainda aprimorar e desenvolver as tecnologias atuais.

É neste sentido que este trabalho pretende contribuir, uma vez que visa otimizar os protótipos baseados em requisitos estruturais e construídos pela tecnologia FDM. Esta otimização fornecerá ao projetista uma importante ferramenta no momento da construção do protótipo, podendo inclusive viabilizar o uso da peça, inicialmente um protótipo, como peça final.

\subsection{DESCRIÇÃO DO TRABALHO}

Para fundamentar o trabalho é realizada inicialmente uma revisão da literatura a com relação às principais tecnologias de prototipagem rápida, apresentada no Capítulo 2. Procurou-se não se aprofundar demasiadamente em todos os tópicos, uma vez que o assunto tem sido bastante disseminado e já existe farta literatura a respeito. Em seguida foi realizada uma revisão mais específica a respeito dos parâmetros de processo para otimização dos protótipos, em particular aqueles produzidos pela tecnologia FDM, apresentada no Capítulo 3. 
Neste capítulo é apresentada a metodologia que abrange os efeitos, vantagens e desvantagens durante o planejamento e projeto de cada etapa, desde o modelamento da peça, escolha e quantificação das variáveis de processo, passando pela análise de materiais até a fabricação do protótipo.

No capítulo 4, materiais e métodos, é descrito o procedimento experimental para a confecção dos corpos de prova e ensaios. Os resultados experimentais são também utilizados para validar numericamente os modelos que serão utilizados, através de simulações por elementos finitos.

No capítulo 5, verifica-se a aplicação dos procedimentos de otimização em dois estudos de caso: inicialmente o ensaio de flexão com os diferentes ângulos de preenchimento. Esta simulação é importante para validar o procedimento e o modelo matemático utilizado na simulação numérica. Em seguida, o procedimento de otimização é aplicado em um dispositivo tipo válvula, de uso comercial, para verificação da melhoria do comportamento mecânico advindo da otimização. Neste caso a análise é feita com relação aos deslocamentos máximos, uma vez que os níveis de tensão aplicados estão bem abaixo daqueles de falha do material.

O capítulo 6 apresenta as principais conclusões e sugestões para continuidade deste tema de pesquisa e trabalhos futuros.

No Anexo A são apresentados os conceitos relativos à Teoria Clássica dos Laminados. 


\section{PROTOTIPAGEM RÁPIDA - FUNDAMENTAÇÃO TEÓRICA}

Frente ao panorama do mercado atual, várias ferramentas têm sido utilizadas para minimização de custos e melhoria da competitividade no desenvolvimento de produtos. Dentre estas ferramentas, destacam-se as tecnologias de prototipagem rápida, utilizadas como ferramentas auxiliares em diferentes fases do processo de desenvolvimento do produto. Segundo Terry Wohlers (1992), prototipagem rápida pode ser definida como: “A fabricação de uma peça física e tridimensional a partir de uma descrição numérica (tipicamente um modelo $\mathrm{CAD} 3 \mathrm{D}$ ) por meio de um processo rápido, altamente automatizado e totalmente flexível”. Segundo ainda este autor, a Prototipagem Rápida pode ser dividida em:

- convencional ou subtrativa (métodos $\mathrm{CNC}$ ), em que a partir de um bloco se remove, por usinagem, a parte não desejada de material;

- aditiva ou processo camada-por-camada (layer-by-layer) que atualmente é a mais aceita, uma vez que o protótipo é gerado por deposição de camadas geradas a partir do modelo sólido por um programa específico para o fatiamento (slicing), conforme figura 1.

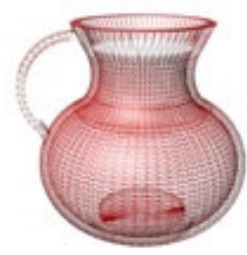

Modelo gerado em CAD

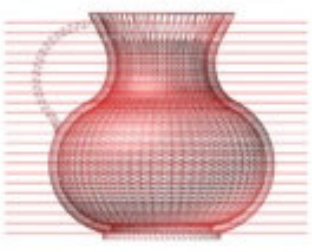

Modelo em "slices" (fatiado pelo software)

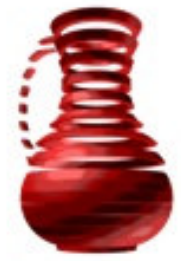

Geraçăo de camadas pelo processo de prototipagem rápida

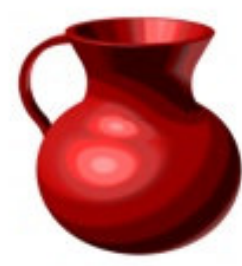

Peça final

Figura 1 - Conceito da manufatura por camada (Carvalho, 2004). 


\subsection{HISTÓRICO}

Conforme citado por ADLER (2005), os sistemas de prototipagem rápida surgiram inicialmente em 1987 com o processo da estereolitografia (StereoLithography - SL), tecnologia original da empresa americana 3D Systems ${ }^{\circledR}$, processo o qual solidifica as camadas (layers) de resina foto-sensível através de uma fonte de laser. O primeiro sistema de prototipagem disponível comercialmente, SLA-1, foi um precursor da máquina SLA - 250, que se tornou bastante popular nos anos 90. Após a empresa 3D Systems iniciar a comercialização de máquinas SL nos EUA, as empresas japonesas NTT Data e Sony/D-MEC passaram a comercializar suas versões de máquinas de estereolitografia em 1988 e 1989, respectivamente. Em seguida, em 1990, a empresa Eletro Optical Systems - EOS na Alemanha passou a comercializar o sistema conhecido como Stereos, também baseado em estereolitografia.

Logo após vieram as tecnologias conhecidas como Fused Deposition Modeling (FDM) da empresa americana Stratasys, Solid Ground Curing (SGC) da israelense Cubital e Laminated Object Manufacturing (LOM), todas em 1991. A tecnologia FDM faz a extrusão de filamentos de materiais termoplásticos camada por camada, só que utilizando um cabeçote de fusão do material e não por cabeçote laser. A SGC, também trabalha com resina fotosensível a raios UV, no entanto, solidifica cada camada numa única operação a partir da utilização de máscaras criadas com tinta eletrostática numa placa de vidro. O processo LOM se caracteriza por solidificar e cortar folhas de papel (atualmente folhas de termoplásticos reforçados com fibras) usando laser controlado por computador. Os sistemas de sinterização (Selective Laser Sintering - SLS) da empresa americana DTM e o sistema Soliform de estereolitografia da japonesa Teijin Seiki tornaram-se disponíveis em 1992, usando calor gerado pelo laser para fundir pós metálicos, podendo ser utilizado diretamente para obtenção de matrizes de injeção. Em 1993, a americana Soligen comercializou o produto conhecido por 
Direct Shell Production Casting (DSPC), que utiliza um mecanismo de jato de tinta para depositar líquido agregante em pós cerâmicos para produção de cascas. Estas "cascas” podem ser utilizadas na produção de moldes e peças injetadas em alumínio, processo este desenvolvido e patenteado pelo MIT (Massachussets Institute of Technology).

Em 1994 muitas outras tecnologias e sistemas surgiram:

- $\quad$ ModelMaker da empresa americana Sanders Prototype, usando sistema de jato de cera (ink-jet wax);

- $\quad$ Solid Center da empresa japonesa Kira Corp., utilizando um sistema laser guiado e um plotter XY para produção de moldes e protótipos por laminação de papel.;

- $\quad$ Sistema de estereolitografia da empresa Fockele \& Schwarze (Alemanha);

- $\quad$ Sistema EOSINT, da empresa alemã EOS, baseado em sinterização;

- $\quad$ Sistema de estereolitografia da empresa japonesa Ushio

O sistema Personal Modeler 2100 da empresa BPM (Ballistic Particle Manufacturing) Technology (EUA) foi vendido comercialmente a partir de 1996. A máquina produz peças a partir de um cabeçote a jato de cera. No mesmo ano a empresa Aaroflex (EUA) passou a comercializar o sistema SOMOS em estereolitografia da multinacional DuPont, e a empresas Stratasys (EUA) lançou seu produto Genisys, baseado em extrusão, similar ao processo de FDM, mas utilizando sistema de prototipagem desenvolvido no Centro de Desenvolvimento IBM (IBM's Watson Research Center). No mesmo ano, após oito anos comercializando produtos em esterolitografia, a empresa 3D Systems (EUA) comercializou pela primeira vez seu sistema Actua 2100, baseado em impressão 3D. O sistema deposita materiais em cera camada por camada através de 96 jatos.

Existem ainda outras tecnologias de diversas empresas que após terem sido apresentadas, seja em função de suas características técnicas ou da concorrência de mercado não se encontram mais disponíveis. Empresas como a Light Sculpting (EUA), Sparx AB 
(Suécia) e Laser 3D (França) desenvolveram e implementaram sistemas de prototipagem, mas não tiveram impacto industrial. Nos EUA, atualmente somente uma empresa estrangeira, a israelense Cubital, mantém escritórios de venda (Wohlers, 1998).

\subsection{CONCEITOS BÁSICOS}

Conforme descrito por GORNI (2001), as tecnologias de prototipagem rápida mais recentes têm se mostrado altamente inovadoras, permitindo, com tecnologias e materiais diferentes, obter protótipos de um modelo ou de um molde de maneira rápida e precisa. Possibilitam a obtenção de modo automático, de qualquer forma e em dimensões finais, com complexidade que não permitiriam sua obtenção em máquinas convencionais de usinagem, ou tornariam sua execução demorada ou complexa em centros de usinagem numericamente controlados. Além disso, em certos casos, estas técnicas permitem a obtenção de matrizes capazes de produzir uma quantidade pequena ou curtos ciclos de peças, ideal para o emprego na produção de lotes pilotos. Tal tecnologia possibilita que as empresas possam desenvolver produtos mais rapidamente (menor time to market) e com menor custo para o projeto como um todo, e, principalmente, com um acréscimo na qualidade por meio de uma melhor avaliação do projeto. Leva também a uma diminuição das incertezas e riscos. É o caso do ferramental, por exemplo, cujo risco de perda por falhas no projeto diminui drasticamente e também, do produto que, uma vez tornado físico pode ser melhor avaliado por grupos multidiciplinares antes da decisão de dar continuidade ao seu desenvolvimento.

Os sistemas de prototipagem rápida geram a peça protótipo a partir da união gradativa de líquidos, pós ou folhas. Camada por camada, a partir de seções transversais da peça obtidas de modelo 3D, as máquinas de prototipagem rápida produzem peças em plásticos, madeira, cerâmica ou metais. 
Os dados para as máquinas de prototipagem são gerados em sistemas CAD no formato STL, que aproxima a superfície do modelo sólido por pequenos triângulos ou facetas. Quanto menores esses triângulos, melhor a aproximação da superfície, se complexa, ao custo naturalmente de maior tamanho do arquivo STL e tempo de processamento.

Uma vez gerado o arquivo STL, as demais operações são executadas pelo próprio software da máquina de prototipagem rápida, os quais basicamente, além de operações de visualização, geram seções transversais do modelo a ser construído. Tais dados são então descarregados para a máquina que irá depositar as camadas sucessivamente até que a peça seja gerada. Segundo Wohlers (1998), o custo das mudanças de projeto ao longo do ciclo de desenvolvimento do produto, aumenta aproximadamente em cerca de uma ordem de magnitude conforme se passa de uma fase para a seguinte conforme indicado na figura 2.

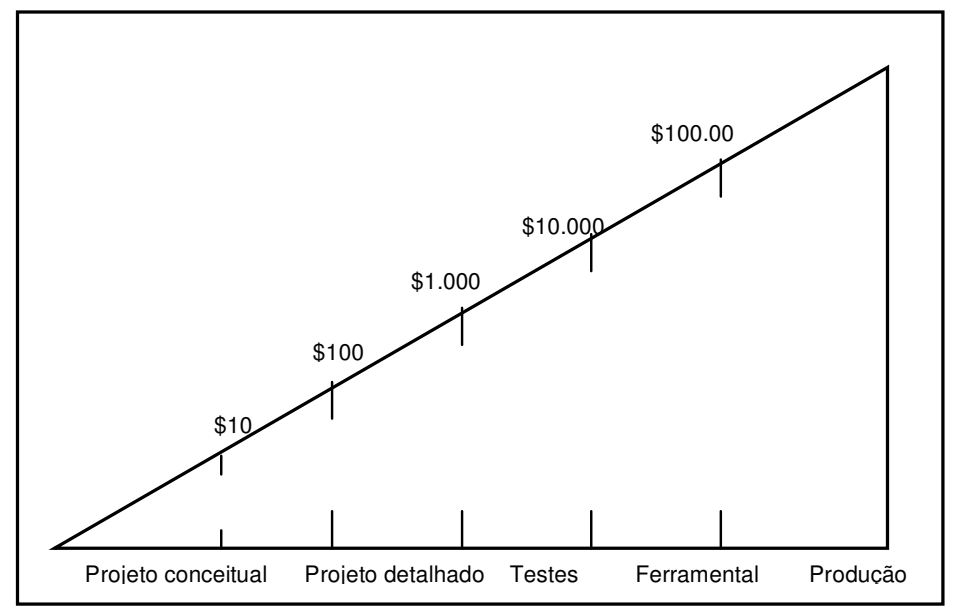

Figura 2 - Custo de alteração de projeto ao longo de ciclo de desenvolvimento do produto (Wohlers, 1998).

Tais métodos são bastante peculiares, trabalhando de forma similar à realidade física, uma vez que agregam e ligam materiais, camada a camada, de forma a constituir o objeto desejado. Atualmente há pelo menos sete diferentes técnicas de prototipagem rápida disponíveis comercialmente. Uma vez que tais tecnologias estão sendo cada vez mais usadas em aplicações não relacionadas diretamente com prototipagem, é preferível designá-las pelas 
expressões fabricação sólida com forma livre (Free form Fabrication - FFF), manufatura em camadas.

Pode-se dizer que, nos processos de prototipagem rápida, são realizadas cinco etapas básicas:

- Criação de um modelo CAD da peça que está sendo projetada;

- Conversão do arquivo CAD em formato STL, próprio para as máquinas de prototipagem;

- Fatiamento do arquivo STL em finas camadas transversais ou slicing: é a divisão do modelo sólido, por meio de um software, em seções transversais (slices) para a deposição do material. A escolha do plano é feita através do software, e deve levar em consideração a seqüência de construção da peça. O modelo sólido é transformado em laminas e durante a sua fabricação, as mesmas são depositadas sequencialmente, gerando o modelo sólido;

- Construção física do protótipo;

- Limpeza e acabamento do protótipo.

\subsection{DESCRIÇÃO DOS PRINCIPAIS SISTEMAS}

VOLPATO et al (2007), descreve que os sistemas de prototipagem rápida de maior utilização comercial atualmente são mostrados na Tabela 1:

- SLA (Stereolithography - estereolitografia): usa a polimerização de resina líquida por meio de uma fonte de laser.;

- SLS (Selective Laser Sintering - sinterização a laser): usa a polimerização de resinas em pó por meio de uma fonte de laser;

- LOM (Laminated Object Manufacturing): usa a sobreposição de laminas cortadas a laser.

- FDM (Fused Deposition Modeling): usa a extrusão a quente de material em filamentos; 
- SGC (Solid Ground Curing): usa resinas líquidas, como a SLA, porém expondo toda a seção por vez à fonte de laser.

- 3DP (3 Dimensional Printing): usa material em pó depositado por impressão jato de tinta

A seguir é apresentada a descrição dos processos, salientando o princípio e algumas das suas principais características.

Tabela 1 - Classificação dos processos de RP baseada no estado inicial da matéria-prima (Volpato, 2007).

\begin{tabular}{|c|c|c|}
\hline Baseado em Líquido & Baseado em Sólido & Baseado em Pó \\
\hline $\begin{array}{l}\text { Estereolitografia - SLA } \\
\text { (Stereolithography) }\end{array}$ & $\begin{array}{l}\text { Modelagem por Fusão e } \\
\text { Deposição - FDM (Fused } \\
\text { Deposition Modeling) }\end{array}$ & $\begin{array}{l}\text { Sinterização Seletiva a Laser - SLS } \\
\text { (Selective Laser Sintering) }\end{array}$ \\
\hline $\begin{array}{l}\text { Impressão a Jato de } \\
\text { Tinta - IJP (Ink Jet } \\
\text { Printing) - PolyJet }\end{array}$ & $\begin{array}{l}\text { Manufatura Laminar de Objetos - } \\
\text { LOM (Laminated Object } \\
\text { Manufacturing) }\end{array}$ & $\begin{array}{l}\text { Sinterização a Laser (Laser } \\
\text { Sintering) - EOSINT da EOS }\end{array}$ \\
\hline IJP - InVision & $\begin{array}{l}\text { Tecnologia de RP com Papel - } \\
\text { PLT (Paper Lamination } \\
\text { Technology) } \\
\text { IJP - ThermoJet }\end{array}$ & $\begin{array}{l}\text { Impressão Tridimensional - 3DP } \\
\text { (3 Dimensional Printing) - } Z \\
\text { Corporation } \\
\text { Fabricação da Forma Final a Laser - } \\
\text { LENS (Laser Engineered Net } \\
\text { Shaping) }\end{array}$ \\
\hline & IJP - Benchtop & 3DP - ProMetal \\
\hline
\end{tabular}

\subsubsection{ESTEREOLITOGRAFIA (SLA, STEREOLITHOGRAPHY)}

Processo pioneiro, patenteado em 1986, que deflagrou a revolução da prototipagem rápida. Os modelos tridimensionais são construídos a partir de polímeros líquidos sensíveis à luz, que se solidificam quando expostos à radiação ultravioleta. O modelo é construído sobre uma plataforma situada imediatamente abaixo da superfície de um banho líquido de resina epóxi ou acrílica. Uma fonte de raio laser ultravioleta, com alta precisão de foco, traça a primeira camada, solidificando a seção transversal do modelo e deixando as demais áreas líquidas. A seguir, um elevador mergulha levemente a plataforma no banho de polímero 
líquido e o raio laser cria a segunda camada de polímero sólido acima da primeira camada. $\mathrm{O}$ processo é repetido sucessivas vezes até o protótipo estar completo. Uma vez pronto, o modelo sólido é removido do banho de polímero líquido e lavado. Os suportes são retirados e o modelo é introduzido num forno de radiação ultravioleta para ser submetido a uma cura completa. Uma vez que a estereolitografia foi a primeira técnica bem sucedida de prototipagem rápida ela se tornou um padrão de avaliação (benchmarking) para as demais, que surgiram (e continuam surgindo) posteriormente.

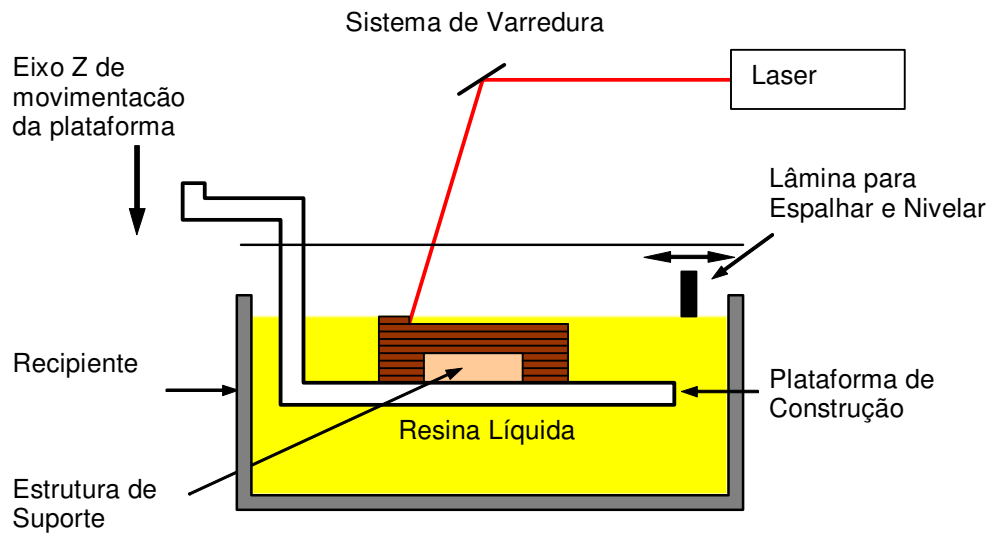

Figura 3 - Princípio do processo SLA (Volpato, 2007).

\subsubsection{MANUFATURA DE OBJETOS EM LÂMINAS (LOM, LAMINATED OBJECT}

\section{Manufacturing)}

Nesta técnica, camadas de material, na forma de tiras revestidas de adesivo, são "coladas" umas às outras formando o protótipo. O material original consiste de bobinas de papel laminado com cola ativada pelo calor. Um rolo coletor avança a tira de papel sobre a plataforma de construção, onde há uma base feita de papel e fita com espuma nas duas faces. A seguir, um rolo aquecido aplica pressão para fixar o papel à base. Uma fonte de raio laser com alta precisão de foco corta o contorno da primeira camada sobre o papel e então 
quadricula a área em excesso, ou seja, o espaço negativo do protótipo. Esse quadriculado rompe o material extra, tornando fácil sua remoção durante o processamento posterior. Esse material em excesso proporciona um excelente suporte para projeções, saliências e seções com paredes finas durante o processo de construção. Após o corte da primeira camada a plataforma é abaixada, liberando o caminho para que o rolo coletor avance a tira de papel e exponha material novo. Então a plataforma se eleva até um ponto ligeiramente inferior à altura original, o rolo aquecido liga a segunda camada a primeira e a fonte de raio laser corta a segunda camada. Este processo é repetido tantas vezes quantas forem necessárias para construir a peça, a qual apresentará textura similar à de madeira. Uma vez que os modelos são feitos de papel, eles devem ser selados e revestidos com tinta ou verniz para evitar eventuais danos provocados pela umidade. Os mais recentes desenvolvimentos deste processo permitem o uso de novos tipos de materiais, incluindo plástico, papel hidrófobo e pós cerâmicos e metálicos. Estes materiais, em fomato de pó, geram no final do processo uma peça "verde" que deve ser posteriormente sinterizada para que alcance máxima resistência mecânica.

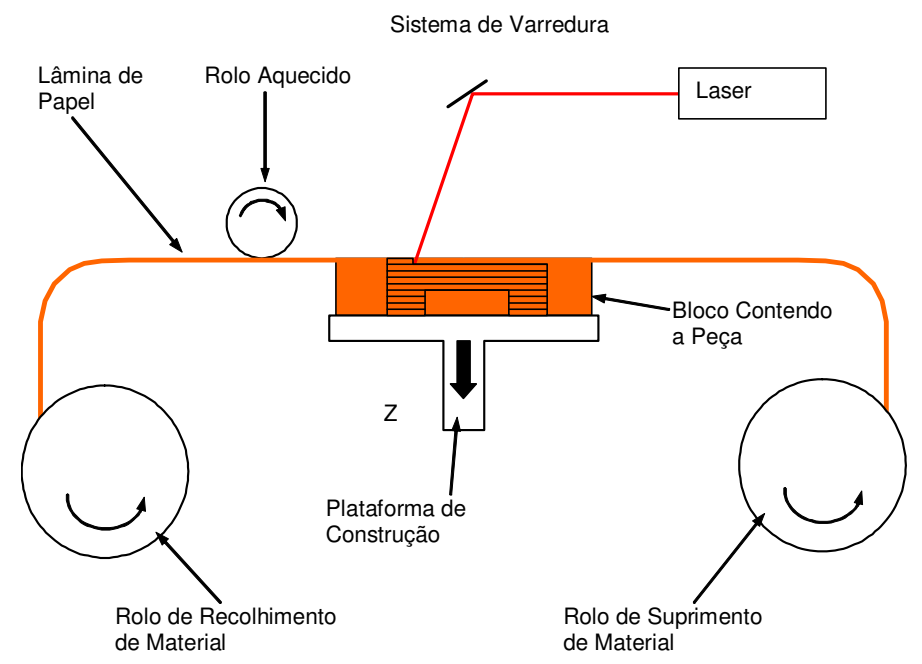

Figura 4 - Princípio do processo LOM (Volpato, 2007). 


\subsubsection{ImPressão A Jato de Tinta (IJP) - PolyJet da ObJET}

A tecnologia denominada de PolyJet é relativamente recente e foi desenvolvida pela empresa Objet Geometries Ltd, de Israel, fundada em 1998. Esta tecnologia também trabalha com resinas fotocuráveis, mas difere consideravelmente do princípio da SLA. O princípio da PolyJet é utilizar um sistema tipo jato de tinta para depositar a resina em pequenas gotas sobre uma bandeja e, imediatamente após a deposição, lançar uma luz UV para a cura da camada (Figura 5). A segunda geração da PolyJet utiliza uma resolução de 600 x 300 dpi, com uma possibilidade de espessura de camada de somente 16 microns. O sistema de deposição trabalha com oito cabeças de jato de resina e um sistema de controle que permite que estas trabalhem de forma sincronizada e harmônica. Esta tecnologia utiliza dois materiais diferentes para a fabricação, uma resina para a peça e um material tipo gel, também foto curável, para o suporte. Após o término do processo, o material de suporte é facilmente removido com um jato d'água misturado com componente solúvel ou mesmo manualmente. A resina é totalmente curada durante o processo de deposição não sendo necessária pós-cura da peça. Segundo o fabricante, este equipamento pode ser utilizado em ambiente de escritório, pois as resinas utilizadas vêm em cartuchos selados e as peças são totalmente curadas durante o processo.

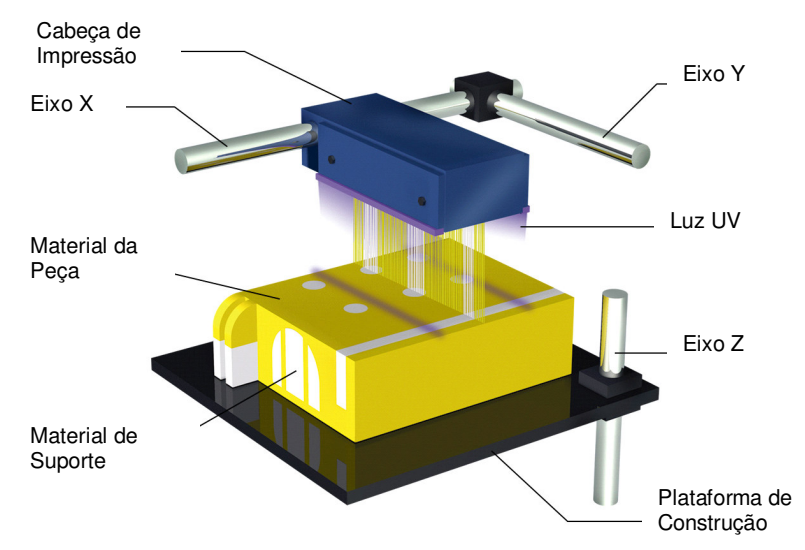

Figura 5 - Princípio da Tecnologia PolyJet (Volpato, 2007). 


\subsubsection{IMPRESSÃO A JATO DE TINTA (IJP) - INVISION DA 3D SYSTEMS}

A empresa 3D Systems Corporation também apresentou recentemente um processo que deposita um material foto curável em pequenas gotas e aplica uma luz ultravioleta para a cura da camada. A tecnologia também foi classificada como pertencente à família Multi-Jet Modeling por esta empresa, que inclui outro processo trabalhando com material sólido (tipo cera). O material utilizado é depositado em forma de pequenas gotas, similar ao que ocorre no processo de uma impressora jato de tinta. Após a deposição da camada sobre a plataforma onde a peça será construída, no caso da primeira camada, ou sobre as camadas já depositadas, uma luz ultravioleta é aplicada para sua cura. Neste processo também é necessária a criação de suporte para apoiar as regiões desconectadas da peça. O material do suporte é diferente do material utilizado para a peça. O material utilizado na produção da peça é resina epóxi fotossensível com 30\% de cera e o material utilizado para confecção do suporte tem propriedades semelhantes à da cera. Para acelerar o processo de fabricação é utilizado um cabeçote com vários jatos de impressão. Um dos equipamentos disponíveis no mercado utiliza um cabeçote com 352 jatos. A empresa classifica este processo como modelador conceitual.

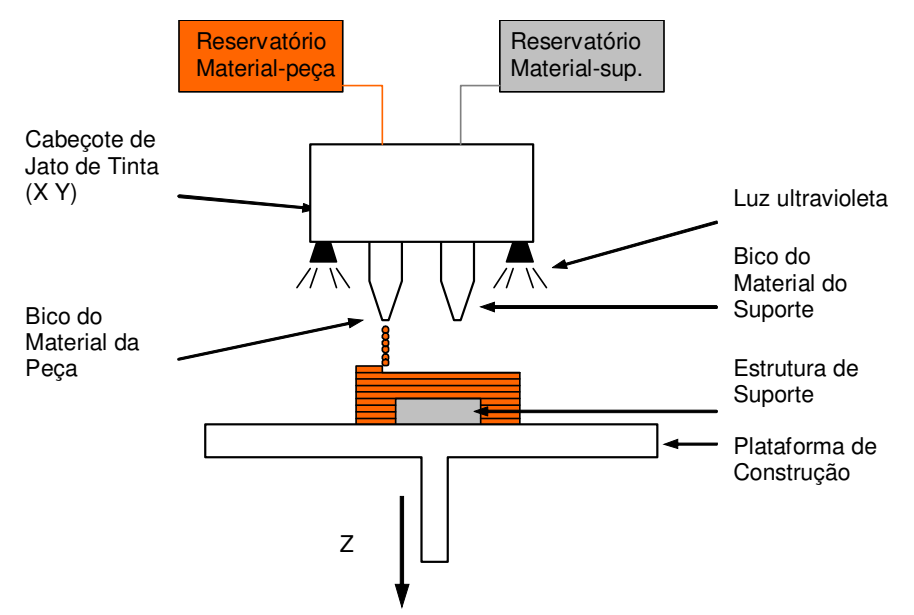

Figura 6 - Princípio de funcionamento do processo InVision (Volpato, 2007). 


\subsubsection{Sinterização Seletiva A LASER (SLS, SElective LaSER SinTERING)}

Esta técnica, patenteada em 1989, usa um raio de laser para fundir, de forma seletiva, materiais em pó, tais como nylon, elastômeros e metais, num objeto sólido. As peças são construídas sobre uma plataforma, a qual está imediatamente abaixo da superfície de um recipiente preenchido com o pó a ser fundido por calor. O raio laser traça a primeira camada, sinterizando o material. A plataforma é ligeiramente abaixada, reaplica-se o pó e o raio laser traça a segunda camada. O processo continua até que a peça esteja terminada. O pó em excesso ajuda a dar suporte ao componente durante sua construção, e caracterizando este processo por sua boa resistência devido à presença de Poliamida.

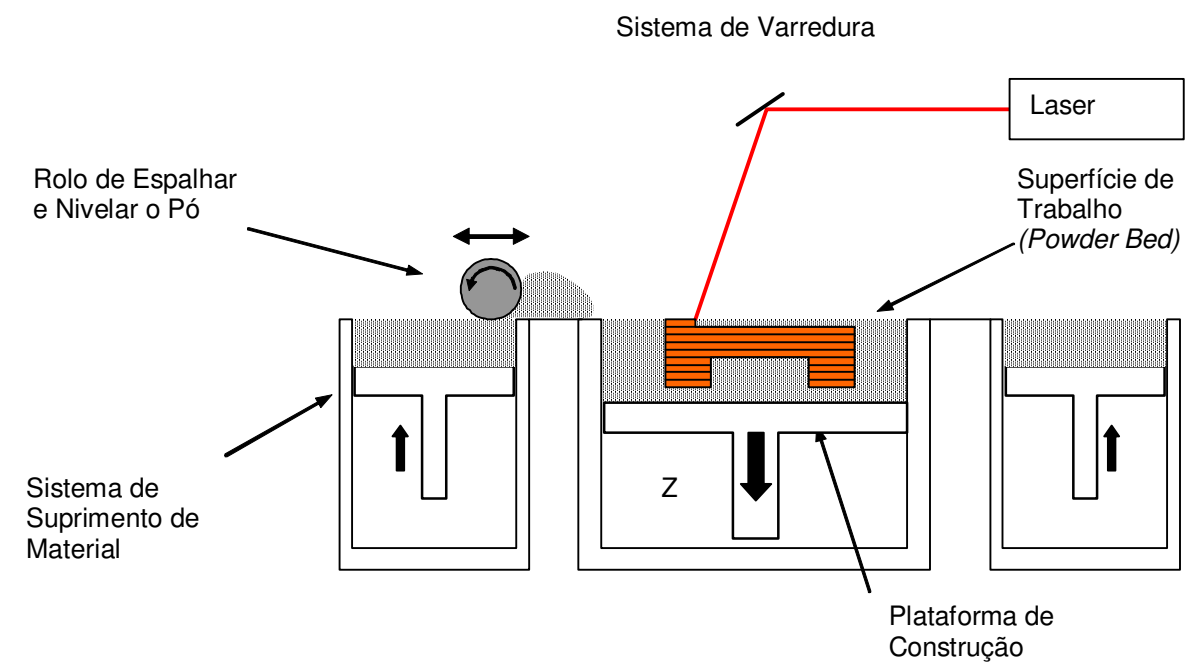

Figura 7 - Princípio do processo SLS (Volpato, 2007). 


\subsubsection{Modelagem POR Deposição de MATERIAl Fundido (Fused DEPOSITION MODELING - FDM)}

Neste processo, filamentos de resina termoplástica aquecida são extrudadas a partir de uma matriz de extrusão (head) que se move num plano X-Y. A matriz de extrusão controlada deposita filamentos de material sobre a plataforma de construção, formando a primeira camada do componente. A plataforma é mantida sob uma temperatura inferior à do material extrudado, de forma que a resina termoplástica endureça rapidamente. Após esse endurecimento a plataforma se abaixa da espessura da camada e a matriz de extrusão deposita uma segunda camada sobre a primeira. O processo é repetido até a construção total do protótipo. São construídos suportes durante o processo para dar sustentação ao protótipo durante sua fabricação. Tais suportes são fixados ao protótipo usando um segundo material, mais fraco, ou uma junção perfurada. As resinas termoplásticas adequadas a esse processo incluem poliéster, polipropileno, ABS, Policarbonatos, elastômeros e cera usada no processo de fundição por cera perdida. Este processo necessita de um cuidado maior durante o tempo de preparo para o processamento por parte do projetista e/ou operador do equipamento.

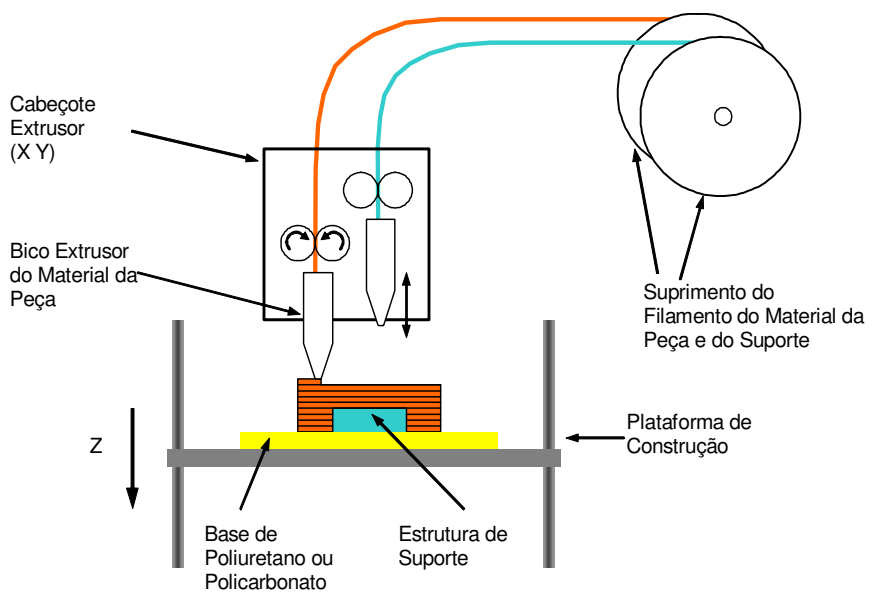

Figura 8 - Princípio do processo FDM da Stratasys, Inc. (Volpato, 2007). 


\subsubsection{Base de Cura Sólida (SGC, Solid Ground Curing)}

É um processo bastante similar a estereolitografia, pois ambos usam radiação ultravioleta para endurecer, de forma seletiva, polímeros fotossensíveis. Contudo, ao contrário da estereolitografia, este processo cura uma camada inteira de uma vez. Em primeiro lugar, a resina foto-sensível é borrifada sobre a plataforma de construção. A seguir, a máquina gera uma foto-máscara (como um estêncil) correspondente à camada a ser gerada. Esta fotomáscara é impressa sobre uma placa de vidro acima da plataforma de construção, usando-se um processo similar ao das fotocopiadoras. A seguir a máscara é exposta à radiação ultravioleta, a qual passa apenas através das porções transparentes da máscara, endurecendo seletivamente as porções desejadas de polímero correspondentes à camada atual. Após a cura da camada, a máquina succiona por vácuo o excesso da resina líquida e borrifa cera em seu lugar para dar suporte ao modelo durante sua construção. A superfície superior é fresada de forma a ficar plana e o processo é repetido para construir a próxima camada. Assim que a peça fica pronta é necessário remover a cera nela presente, através de sua imersão num banho de solvente. Essas máquinas são de grande porte e podem produzir modelos de grandes dimensões.

\subsubsection{Dimensional PRinting (3DP) - IMPRESSÃo Tridimensional}

Processo que utiliza material em forma de pó, similar ao processo SLS, mas com o diferencial que este contém um aglutinante (sílica, latex, a base d'água) depositado por impressão tipo jato de tinta. Um rolo espalha e nivela o material e a cabeça de impressão deposita o aglutinante de acordo com a geometria 2D da camada em processo. Este processo também não precisa de suporte, pois o material não processado ao redor da peça atua como um suporte natural. Adicionalmente, várias peças podem ser fabricadas em sobreposição em 
uma operação. As peças fabricadas por este processo geralmente necessitam de uma etapa de pós-processamento para aumentar a resistência ou acabamento superficial. Este pósprocessamento varia de acordo com o material utilizado. Na obtenção de peças metálicas geralmente é necessária a queima do aglutinante e sinterização em um forno a alta temperatura. No caso de utilizar material à base de celule pode ser aplicado um banho de uma resina ou então com um elastômero que torna o protótipo bastante flexível. Aparentemente não há limitação quanto aos materiais que podem ser utilizados neste processo, sendo comum a utilização com cerâmica, metais, polímero e material a base de celulose.

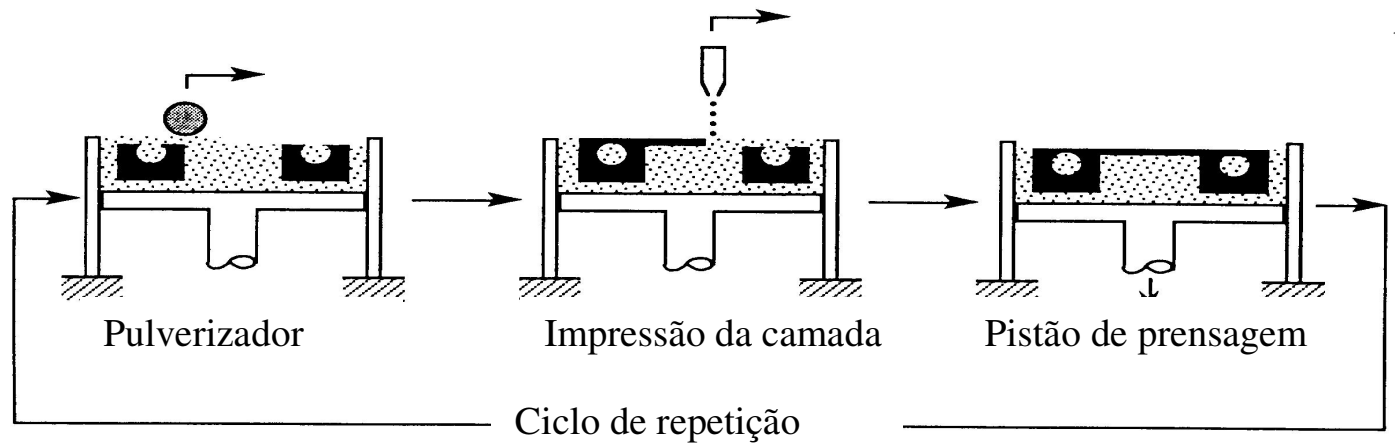

Figura 9 - Princípio do processo 3DP (Volpato, 2007).

\subsubsection{CONFOrMaÇão Próxima Ao Formato Final Via LaSER (LENS,}

\section{LASER ENGINEERED NET SHAPING)}

Processo relativamente novo, cuja vantagem é produzir protótipos de metal densos, com boas propriedades metalúrgicas e sob velocidades razoáveis de construção. Define-se por um gerador de raio laser de alta potência o qual é usado para fundir pó metálico fornecido coaxialmente ao foco do raio laser, através de um cabeçote de deposição. $\mathrm{O}$ raio laser passa através do centro do cabeçote e é focado para um pequeno ponto através de uma lente ou conjunto e lentes. Uma mesa X-Y é movida por varredura de forma a gerar cada camada do 
objeto. $\mathrm{O}$ cabeçote é movido para cima à medida que cada camada é completada. $\mathrm{O}$ raio laser pode ser conduzido até a área de trabalho através de espelhos ou fibra ótica. Os pós metálicos são fornecidos e distribuídos ao redor da circunferência do cabeçote por gravidade ou através de um gás portador inerte pressurizado. Mesmo nos casos em que não há necessidade de uma corrente de gás para transportar o pó metálico é necessário haver uma corrente de gás inerte para proteger a poça de metal líquido do oxigênio atmosférico, de forma a garantir as propriedades metalúrgicas e promover melhor adesão entre camadas através de melhor molhamento superficial. Podem ser usados pós de diversas ligas metálicas, tais como aço inoxidável, inconel, cobre, alumínio e titânio. A potência do gerador de raio laser varia conforme o material usado, taxa de deposição e outros parâmetros, podendo oscilar desde algumas centenas até 20.000 watts ou mais. Os protótipos produzidos requerem usinagem para acabamento, apresentando densidade plena, boa microestrutura e propriedades similares ou melhores à peça obtida por processos convencionais.

\subsubsection{COMPARATIVO DE PROCESSOS 3D PRINT}

Em estudos realizados por Grimm (2003), foram realizadas comparações entre diferentes tecnologias 3D Print na construção de três protótipos (aparelho celular, bola, ventilador). Apenas para enriquecer este trabalho, é citada abaixo uma breve descrição dos resultados obtidos. Mais detalhes poderão ser encontrados no trabalho original (Grimm, 2003). 


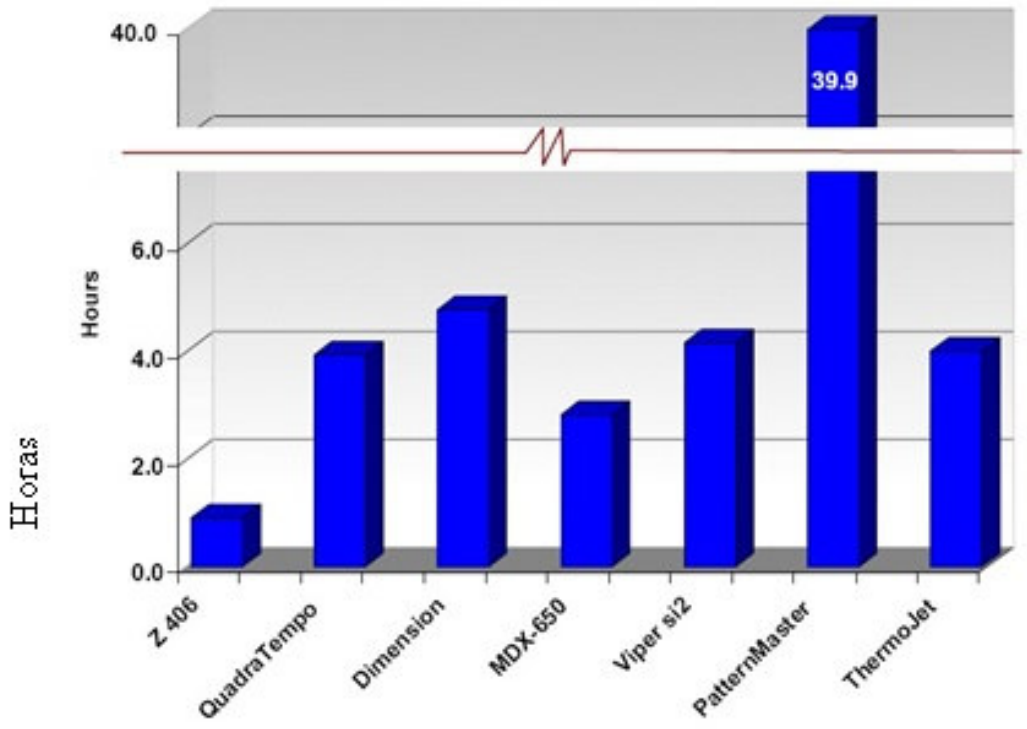

Figura 10 - Tempo médio de construção dos protótipos (Grimm, 2003).

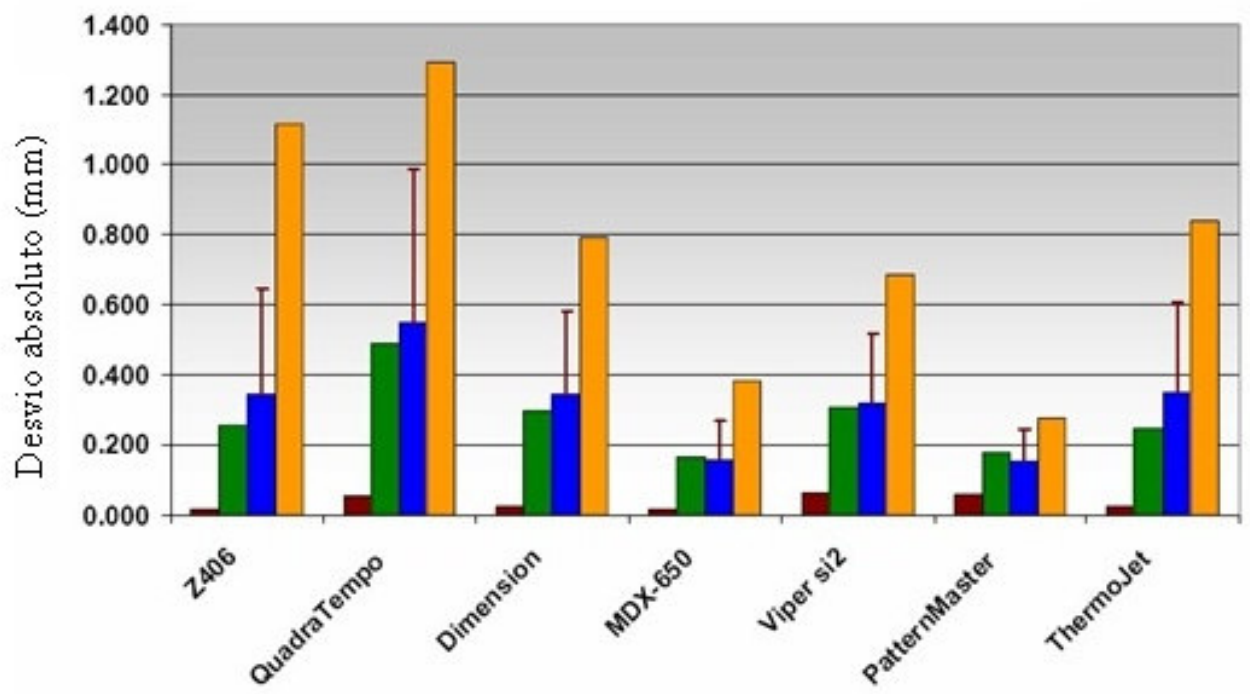

Figura 11 - Nível alto, baixo, mediana e média dimensional de precisão (Grimm, 2003).

\subsection{FERRAMENTAL RÁPIDO}

Gorni (2001) cita que, mais recentemente as técnicas de prototipagem rápida tem sido aplicadas na fabricação de ferramentas, técnica conhecida como ferramentaria rápida ou 
ferramental rápido (do inglês Rapid Tooling). Estas técnicas podem ser divididas em duas classes principais:

- A primeira delas, mais usada atualmente, é a ferramentaria indireta, que consiste em se utilizar os protótipos rápido como modelos (masters) para se produzir moldes e matriz. Essas ferramentas podem ser utilizadas em diferentes processos de manufatura:

- Vazamento a vácuo: esta técnica, a mais simples e antiga dentro da ferramentaria rápida, consiste em suspender um modelo positivo feito por prototipagem rápida num tanque cheio de silicone líquido ou borracha vulcanizável à temperatura ambiente (RTV rubber, room-temperature, vulcanizing rubber). Após cura, o elastômero (ferramental) é cortado em duas metades, removendo-se o modelo feito por prototipagem rápida. $\mathrm{O}$ molde de borracha resultante pode ser usado para se vazar até um número limitado, geralmente na casa de algumas dezenas, de poliuretano do modelo original. Uma variante deste processo utiliza moldes de borracha para se produzir ferramental metálico. Neste caso os moldes de borracha são preenchidos com aço ferramenta em pó mais um ligante a base de epóxi. Assim que o ligante sofre cura a ferramenta "verde" de metal é removida do molde de borracha, sendo posteriormente sinterizado. Nesta etapa o metal apresenta apenas $70 \%$ de seu valor original de densidade, requerendo uma infiltração com cobre para que a peça apresente um valor de densidade mais próximo de um componente maciço. Essas ferramentas apresentam precisão muito boa, mas seu tamanho é limitado a um valor máximo de $25 \mathrm{~cm}$.

- Moldagem por Injeção: podem-se produzir moldes para moldagem por injeção feitos de um compósito de metal e cerâmica. Neste processo, é produzido inicialmente um modelo positivo da peça a ser moldada. A seguir esse modelo é revestido com níquel, o qual é reforçado com um material cerâmico rígido. As duas metades do molde são 
separadas para se remover o modelo, obtendo-se então um molde que pode produzir alguns de milhares de peças injetadas.

- No segundo caso, estão os processos de ferramentaria direta, que permitem produzir diretamente ferramental com alta dureza diretamente de arquivos CAD. Devido às dificuldades na obtenção de ferramentais com qualidades equivalentes àquelas fabricadas por usinagem. Acredita-se que ainda serão necessários alguns anos para que essas técnicas se tornem plenamente comerciais. Como exemplo, pode-se citar alguns desenvolvimentos são bastante promissores:

- Sinterização de pós metálicos: processo que sinteriza seletivamente grânulos de aço revestidos de polímero de forma a produzir um molde metálico. A seguir o molde é colocado num forno onde o ligante polimérico é queimado e a peça é infiltrada com cobre. O molde resultante pode produzir até 50.000 peças injetadas.

- Direct AIM: nesta técnica, machos produzidos por estereolitografia são usados com moldes para injeção tradicionais de metal normalmente empregados na produção de peças de PEAD, PEBD, PS, PP e ABS. Pode-se produzir até 200 peças com boa precisão. Contudo, são requeridos tempos de ciclo relativamente longos (da ordem de cinco minutos) para se permitir que a peça moldada resfrie o suficiente de forma a não "colar" no macho feito por estereolitografia.

\subsection{VANTAGENS E APLICAÇÕES}

Segundo Quatter Design, dentre as inúmeras vantagens do uso do processo de prototipagem rápida, pode-se citar a facilidade dos projetistas em criar rapidamente protótipos físicos ainda na fase conceitual do desenvolvimento, ao invés de figuras bidimensionais. Esses modelos apresentam diversos usos e constituem um auxílio visual excelente durante a 
discussão prévia do projeto com colaboradores ou clientes. Além disso, o protótipo pode permitir testes prévios como, por exemplo, ensaios em túnel de vento para componentes aeronáuticos ou análise fotoelástica para se verificar pontos de concentração de tensões na peça. Gorni (2001), ainda ressalta que, de fato as economias de tempo e de custos proporcionada pela aplicação das técnicas de prototipagem rápida na construção de modelos sejam da ordem de 70 a 90\%. Apesar da reconhecida importância da Prototipagem Rápida no processo de desenvolvimento de produtos, o Brasil ainda é totalmente dependente de equipamentos e insumos importados, o que torna a tecnologia de alto custo, inviabilizando seu uso por grande parte de nossas empresas. Dessa forma, é de importância estratégica para nosso país que instituições de ensino e pesquisa, empresas privadas e agências governamentais, se unam em um esforço conjunto para o desenvolvimento de tecnologias e equipamentos nacionais, propiciando assim um ganho significativo de qualidade no desenvolvimento de novos produtos nos próximos anos. As vantagens da prototipagem rápida estão principalmente em poder, de forma muito rápida, transformar arquivos de modelos 3D em protótipos rápidos para testar e avaliar sua resistência, ergonomia e sua possibilidade de produção, sem a necessidade da construção de qualquer tipo de ferramental.

Complementando, Gorni (2001) cita que as técnicas de Prototipagem Rápidas têm sido aplicadas com sucesso na fabricação de protótipos funcionais e ferramentas para produção em baixa escala. A produção de protótipos funcionais é ainda um processo caro e que consome muito tempo e na maioria das vezes são feitos manualmente por pessoas especializadas. De acordo com HILTON (1998), o uso das técnicas de Prototipagem Rápida na fabricação de ferramentas pode reduzir em $75 \%$ o seu tempo de desenvolvimento, como também reduz o custo de desenvolvimento do produto. Um exemplo é a utilização de tecnologias de Prototipagem Rápida para suprir na fabricação de brinquedos, as necessidades de produção em larga escala do mesmo produto em um tempo limitado, possibilitando o 
desenvolvimento de novos produtos para cada época do ano. Peças produzidas através de técnicas de Prototipagem Rápida são cada vez mais usadas para produção de pré-séries e produção de alto e baixo volume.

As mesmas técnicas de prototipagem rápida podem ser usadas para a fabricação de ferramentais, ou seja, a fabricação automática de ferramentas para uso na produção em série. A produção de ferramentas é uma das etapas mais lentas e caras no processo de manufatura, em função da qualidade extremamente alta que se exige delas. Ferramentas geralmente apresentam geometrias complexas e precisam ser dimensionalmente precisas, em torno de centésimos de milímetro. Além disso, elas devem ser duras, resistentes ao desgaste e apresentar baixa rugosidade. Por isso matrizes e moldes são tradicionalmente feitos por usinagem $\mathrm{CNC}$, eletroerosão ou mesmo manualmente. Todos esses processos são caros e demorados, o que torna a implementação das técnicas de prototipagem rápida muito bem vinda. Com estes recursos é permito também a obtenção de peças com mesmo nível de qualidade da produção em série, na chamada manufatura rápida. De fato, a prototipagem rápida é o melhor processo de manufatura possível quando é necessário produzir pequenos lotes de peças e ou no caso de componentes complexos. O termo "rápido" associado a esses processos é relativo. A construção de alguns protótipos pode levar de 3 a 72 horas, dependendo do tamanho e complexidade do objeto. Ainda assim esses processos são bem mais rápidos que os métodos tradicionais, tais como usinagem, que podem requerer dias ou mesmo meses para fabricar um único protótipo.

A prototipagem rápida apresenta como limitação o volume do protótipo, o qual varia em torno de $0,125 \mathrm{~m}^{3}$ ou até menos, dependendo do equipamento disponível. Ainda é difícil fazer protótipos de metal, embora se acredite que isso deverá mudar num futuro próximo com o desenvolvimento da técnica. No momento as técnicas convencionais de manufatura ainda 
são mais econômicas que as de prototipagem rápida em se tratando de modelos de metal.

Dentre as principais vantagens associadas ao uso da prototipagem rápida pode-se citar:

- proporciona modelos físicos para revisões críticas de projeto;

- executa rapidamente os protótipos para testes funcionais, antes da fabricação do ferramental;

- gera ferramentas de produção precisas e elimina o caro retrabalho das ferramentas;

- aumenta a comunicação entre marketing, design, manufatura e suprimento;

- facilita grupos de análise e os estudos de viabilidade industrial;

- reduz dramaticamente o tempo e custo de desenvolvimento de produto;

- possibilita a obtenção do produto para a comercialização à frente dos competidores. 


\section{OTIMIZAÇÃO ESTRUTURAL DE PROTÓTIPOS}

Neste capítulo serão apresentados os principais parâmetros e aspectos operacionais que serão considerados quando da construção dos protótipos, visando estabelecer os procedimentos a serem seguidos no processo de otimização estrutural. As considerações serão feitas com a utilização do processo FDM, objeto deste trabalho.

\subsection{PARÂMETROS A SEREM CONSIDERADOS}

Conforme descrito por SABOURIN (1997), no processo FDM, os suportes gerados para sustentação das peças são construídos utilizando um segundo bico, o qual faz a extrusão do material suporte em um ângulo menor que $45^{\circ}$ em relação ao plano horizontal. Desta forma o material é direcionado para deposição em uma trajetória horizontal resultando comportamento anisotrópico da peça. Os principais parâmetros construtivos das peças no processo FDM são:

- Largura do fio depositado (road width): é a dimensão que o bico FDM deposita de material, podendo variar de $0,1778 \mathrm{~mm}(0,007$ polegadas $)$ com bico modelo $\mathrm{T} 12$ a 0,3556 $\mathrm{mm}(0,014$ polegadas $)$ com bico $\mathrm{T} 16$, por exemplo, para o equipamento FDM8000 - Stratasys.

- Distância entre filamentos (air gap): termo usualmente definido como espaço existente entre os filamentos ou rasters. Como padrão aplica-se o valor zero, podendo, porém ser ajustado, o valor positivo significa maior espaço e valor negativo significa menor espaço. Variando este parâmetro para um valor negativo (-0,003 polegadas) obtêm-se peças mais densas e robustas.

- Temperatura de construção: temperatura de aquecimento do filamento para o modelo, sendo um parâmetro para controle da viscosidade do material derretido. 
- Orientação de preenchimento das camadas: refere-se à direção das trajetórias de deposição do material. A Figura 12 ilustra esquematicamente os diferentes parâmetros citados em protótipos construídos com diferentes orientações e quantidade de camadas. (AHN et al, 2002).

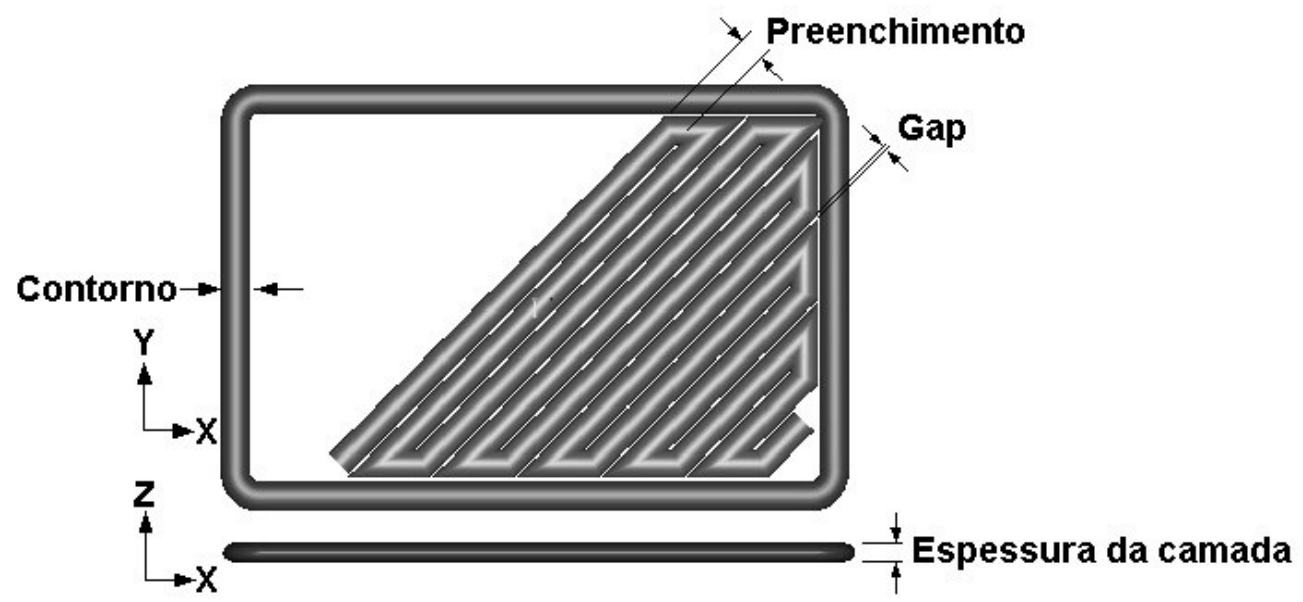

Figura 12 - Representação esquemática de uma camada de material sendo depositado no processo FDM com alguns dos parâmetros de controle (Volpato et al, 2007).

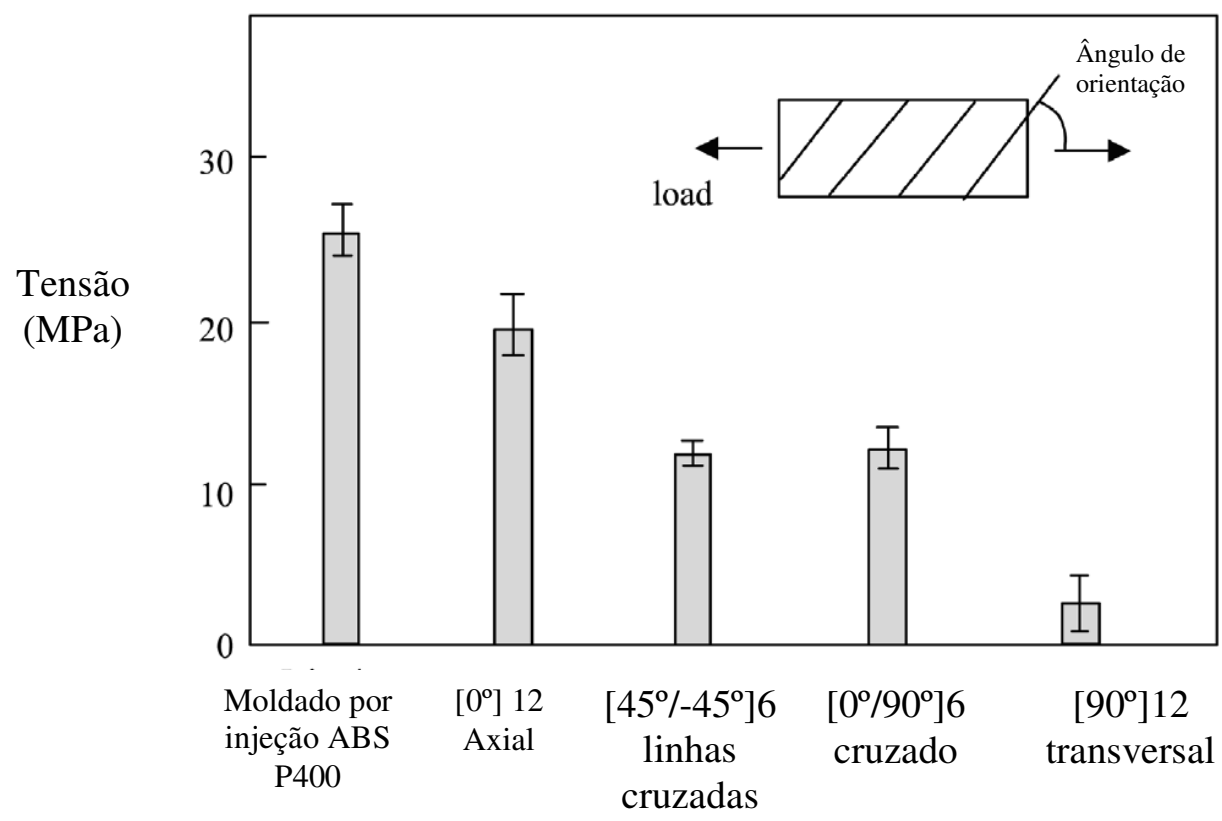

Figura 13 - Resultados comparativos entre peças injetadas e prototipadas em FDM (Ahn et al., 2002). 
Existem, porém, alguns parâmetros que são ignorados em virtude de possuírem os mesmos significados dos anteriores e não terem uma correlação relevante às propriedades finais do material como: temperatura do ar em volta da peça, altura de fatiamento, diâmetro do bico. Uma relação linear entre as principais variáveis de processo e resistência do protótipo é indicada na Figura 14, segundo Ahn et al. (2002).

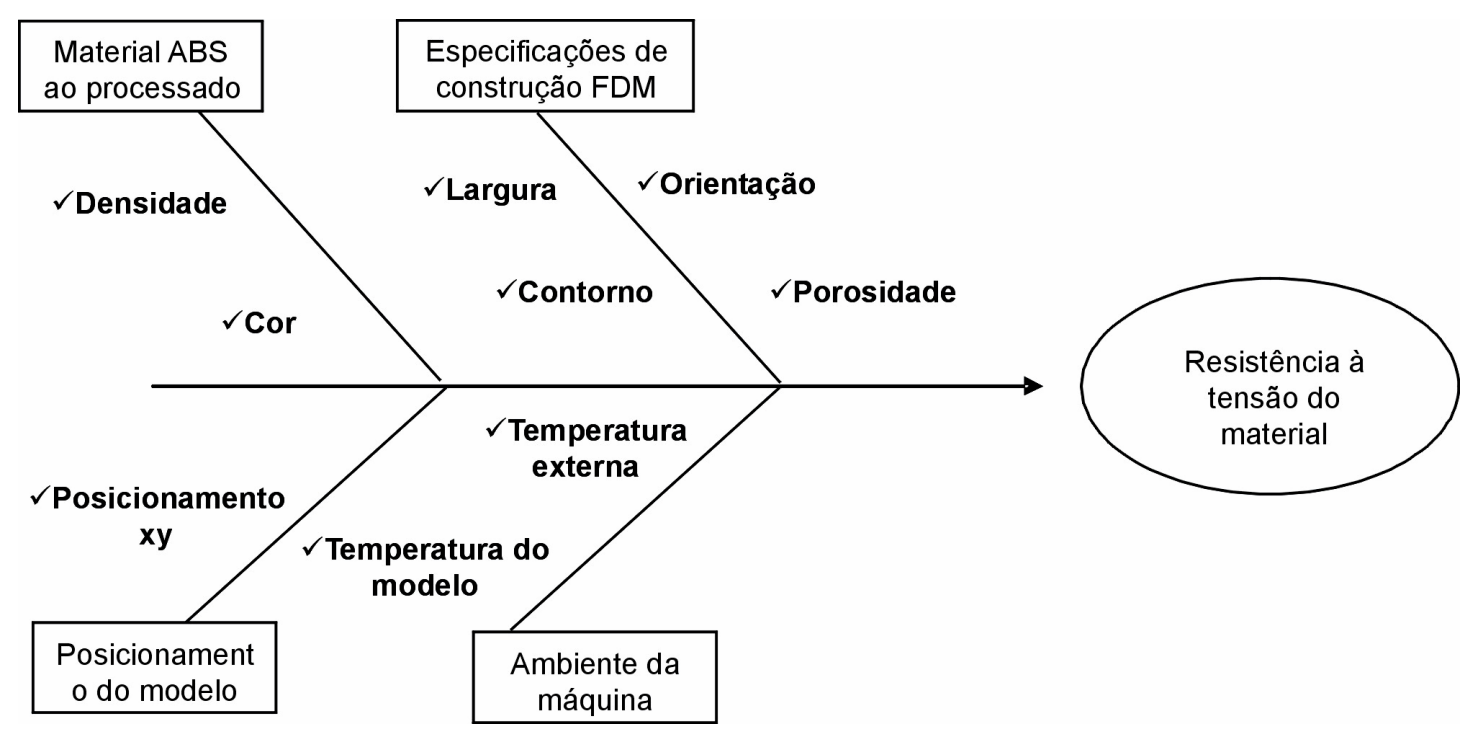

Figura 14 - Fatores de influência no processo de Prototipagem Rápida FDM (Ahn et al., 2002).

Ahn et al (2002) descreve ainda que as variáveis de processo, denominadas como parâmetros de configuração, afetam os protótipos construídos através da tecnologia FDM e podem ser divididos em:

- Parâmetros específicos da operação;

- Parâmetros específicos da máquina;

- Parâmetros específicos dos materiais;

- Parâmetros específicos da geometria.

Com relação aos parâmetros específicos de operação, algumas considerações são utilizadas como regras para construção de modelos: 
1 - Construir peças cuja direção da tensão de carga seja atuante axialmente no sentido longitudinal às fibras;

2 - Atentar para concentração de tensão que ocorre em áreas de cantos vivos ou entalhes, isto pelo fato de que as trajetórias de deposição apresentam descontinuidades ou transições acentuadas nessas regiões;

3 - Utilizar espaço entre as deposições ou ajuste de porosidade (air gaps) com valor negativo, o que aumenta resistência e dureza (porém pode alterar a precisão dimesnional do protótipo);

4 - Considerar os seguintes problemas na largura da linha:

- Pequenos valores de largura aumentam tempo de construção;

- Pequenos valores de largura melhoram qualidade da superfície;

- Espessura da parede da peça deve integrar largura da linha e porosidade (air gaps).

5 - Considerar os efeitos de precisão dimensional em relação à orientação de construção:

- Duas dimensões de corte aproximadas propagam a geometria (maior precisão);

- Três dimensões de camadas empilhadas criam aproximações lineares (menor precisão).

Como conclusão de estudos e experimentos já realizados por Ahn (2002 apud ANG et al 2006, p.100-105) pode verificar-se que peças realizadas com orientação ([0 / 90º $])$ e $\left(\left[45^{\circ} /\right.\right.$ $\left.\left.-45^{\circ}\right]\right)$ com ajuste de porosidade em $-0,003$ polegadas têm resistência medida em torno de 65 a 72 por cento se comparadas às peças injetadas com material ABS, sendo que para isso as peças devem ser construídas seguindo-se como base para ajustes das variáveis, as regras citadas acima.

Sabourin (1997) também ressalta que a necessidade de se reduzir o tempo para fabricar protótipos é altamente crítica uma vez que minimiza os gastos no desenvolvimento de novos produtos. Desta maneira, o gerenciamento dos parâmetros dentro do processo tem causado um aumento da fabricação por processos alternativos como o de formas livre (Freeform SFF) ou das tecnologias de prototipagem rápida criando uma oportunidade de reduzir tempos e custos 
no desenvolvimento dos protótipos e da produção. A maioria das técnicas utilizadas pelo autor foi limitada à utilização de materiais com baixa resistência à temperatura tais como papéis, polímeros, e ceras. As peças de cera e de polímero podem ser usadas também para produzir peças em metal e cerâmicas, uma vez que uma peça em cera pode servir como o positivo para molde de ligas metálicas.

Essencialmente, o cabeçote de extrusão no sistema FDM é similar a um cabeçote convencional, no qual o filamento age não somente como um material contínuo da alimentação para a extrusão, mas também como o pistão no sistema. Uma vez que um sistema foi desenvolvido para um material específico, a otimização apropriada das outras variáveis de processo determina a qualidade interna e externa das peças. Estas variáveis são dependentes entre si surgindo então a necessidade da otimização simultânea para fabricar as peças processadas com qualidade elevada. Estas variáveis de processo podem causar limitações e defeitos nas peças, sendo que alguns podem ainda existir mesmo após a completa otimização do processo. Para a completa eliminação destes defeitos, requer-se o desenvolvimento e a execução de estratégias de processamento em sistemas existentes de FDM com intuito de se atingir qualidades estruturais aceitáveis. As dimensões dos filamentos depositados são controladas pela taxa de fluxo que é controlada pela própria velocidade no contador de giros dos rolos. As dimensões da via (largura e espessura) junto com a velocidade do cabeçote determinam o fluxo do material extrudado.

Para que a maioria das imperfeições internas relacionadas possa ser evitada, é necessária a seleção da estratégia apropriada na configuração devido às funcionalidades disponíveis em sistemas comerciais de FDM. A maioria dos defeitos de superfície é devida às limitações atuais da tecnologia ou pela otimização indevida dos parâmetros da configuração no software de controle de FDM para um dado material. Com relação à espessura, a evolução dos softwares de operação da máquina tem possibilitado prototipar peças usando camadas 
mais finas ou mais espessas, aumentando ou diminuindo a taxa de deposição de material aplicado, conforme ilustrado nas figuras 14, 15 e 16.

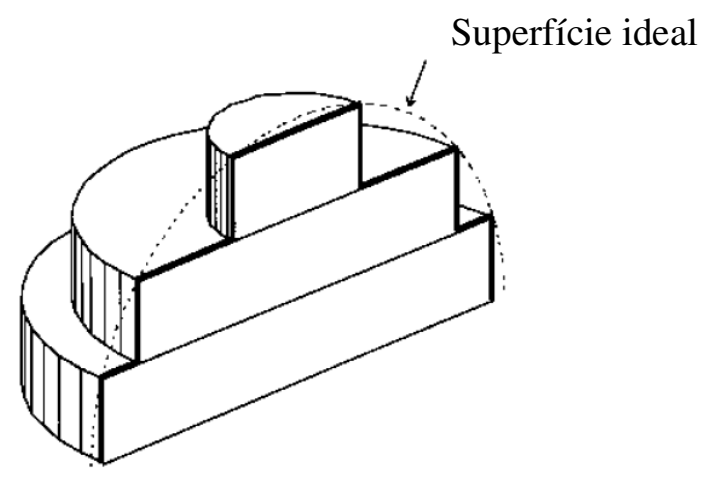

Figure 15 -_Tipo de construção de poucas camadas aproximando estruturas de formas complexas (Sabourin; Houser; Bohn, 1997).

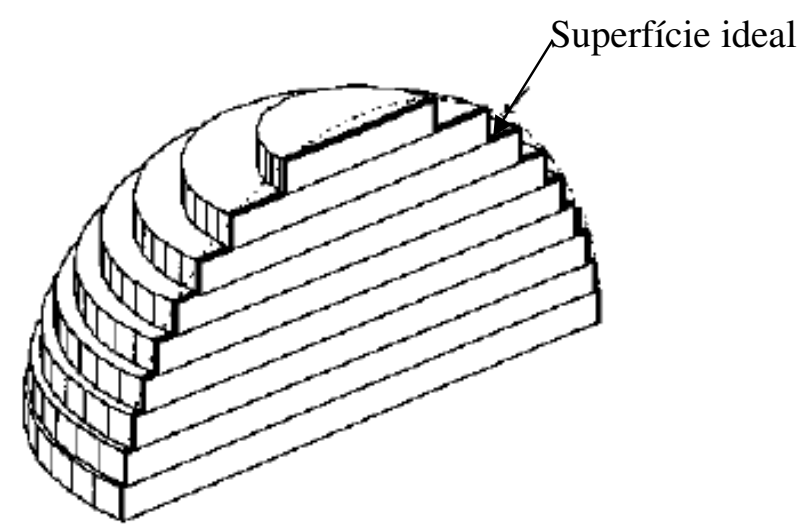

Figure 16 - Tipo de construção de muitas camadas melhores aproximando estruturas de formas complexas (Sabourin; Houser; Bohn, 1997). 


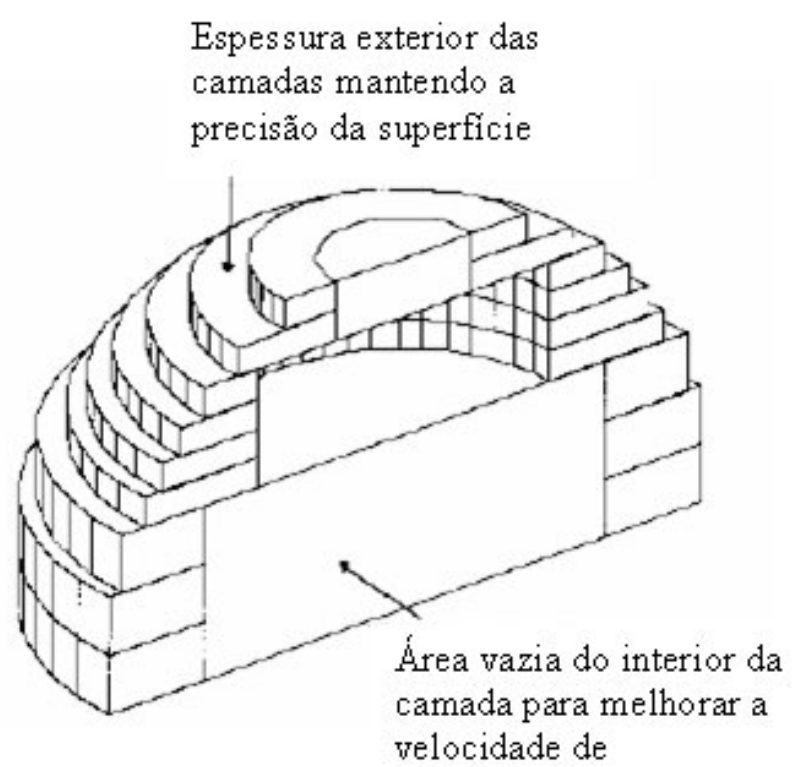

Figura 17 - Alteração da densidade no interior da camada (Sabourin; Houser; Bohn, 1997).

Existe ainda a possibilidade de adotar a construção da peça com uma área interna sem preenchimento. Tal procedimento reduz o tempo de fabricação, enquanto que a espessura exterior constrói camadas mantendo a precisão da superfície da peça (Figura 16).

- Ajustes de Contorno: denominado como o procedimento que separa as regiões exteriores das interiores da peça com interiores espessos, sendo relativamente simples de ser implementado. Primeiramente, os contornos do topo e base do bloco são projetados em um plano paralelo havendo uma intersecção para encontrar com as áreas comuns dos ajustes de contorno. Esta intersecção é então ajustada para criar um mínimo de região interior diferenciando região interior e superfície da peça. Ajustando o contorno interno pode-se criar auto-intersecções, geometrias complexas e regiões muito pequenas ou estreitas para a deposição de material.

Estes dois conjuntos de regiões da placa podem ser construídos em seqüência, primeiramente as regiões exteriores são construídas com finas camadas, então a região interior 
é feita de uma maneira simples, rápida, completando com uma área espessa, verificados nas figuras 17 e 18 .

- Profundidade: a divisão adaptativa na fabricação é um conceito que também auxilia, na qual a estratégia é proposta para seguir algumas restrições. As regiões externas das camadas devem, com folgas, aproximar-se das camadas interiores.

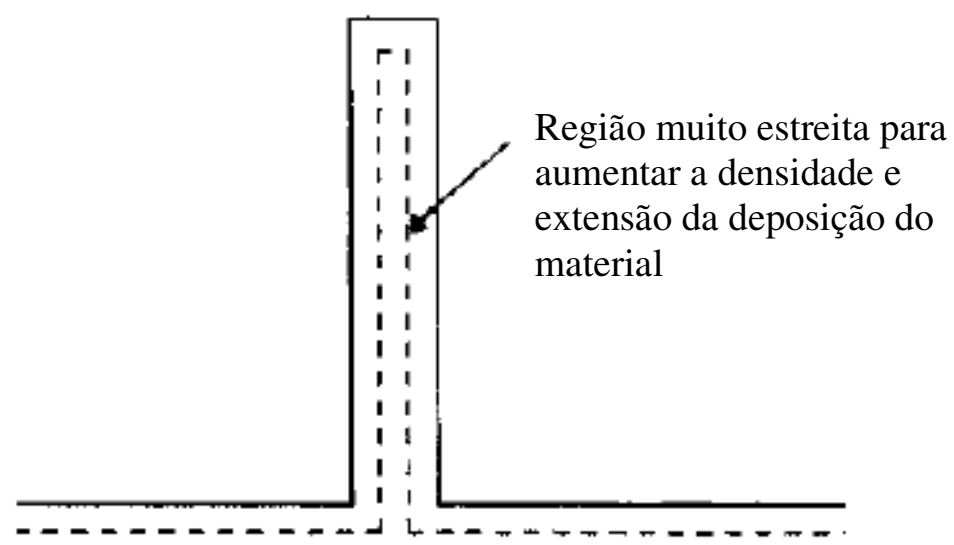

Figura 18 - Influência da densidade interna da peça (Sabourin; Houser; Bohn, 1997).

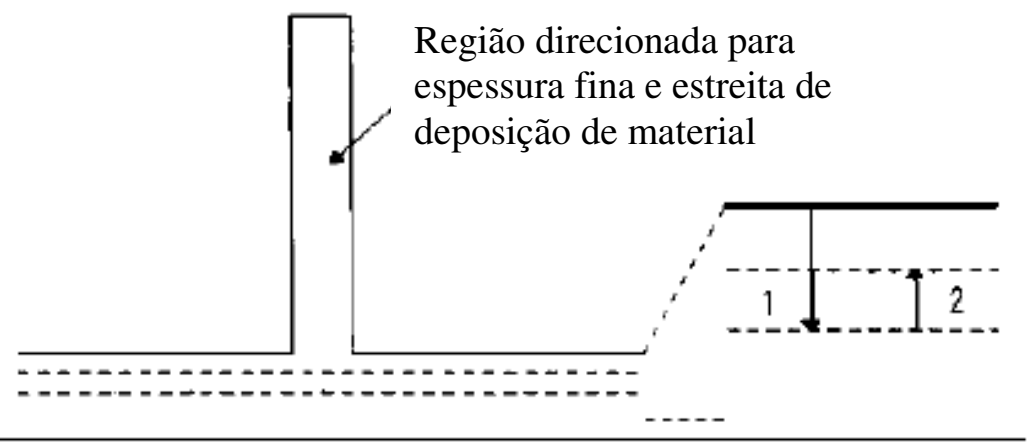

Figura 19 - Deposição de material em espessura fina (Sabourin; Houser; Bohn, 1997).

- Suporte: com relação à estrutura de suporte, alguns sistemas submetem à prova suportes implícitos (SLS, Impressão 3D, SGC) enquanto que outros são explícitos (Estereolitografia e FDM). Caso suportes explícitos sejam requisitados, a geometria deve ser 
gerada adicionando estes à geometria da peça. Esta combinação é então transposta para o código do software e para o controle de movimento do material no sistema durante a fabricação.

- Estruturas: além dos tipos de configurações previamente citadas, ANG et al (2006), mencionam uma variedade de técnicas atualmente disponíveis para a fabricação das estruturas internas da peça a ser construída, também conhecida como tecidos ou armações (Leong et al., 2003; Thomson et al., 2000 apud ANG et al 2006). Todavia, qualquer que seja a técnica utilizada, há sérias falhas que restringem o alcance da aplicação. Pode-se mencionar dentre alguns, a inconsistência na reprodução do tamanho do poro, irregularidades em sua distribuição, uso indispensável de solventes orgânicos tóxicos, trabalhos intensos e deficiência na resistência mecânica das malhas os quais são somente alguns problemas comuns associados com estas técnicas e suas conseqüentes falhas durante a fabricação (Yang et al., 2001; Sachlos and Czernuszka, 2003).

Com relação à porosidade, existem inúmeros parâmetros que necessitam ser especificados durante o processo de fabricação para se obter as propriedades desejadas. Estes parâmetros podem ser interdependentes e podem afetar a construção em diferentes graus, segundo relatado por Agarwal et al., 1996; Ahn et al., 2002; Montero et al., 2001; Weinmann et al., 2003 (apud AND et al 2006). Neste trabalho, as amostras de ABS foram fabricadas utilizando uma máquina FDM 1650, e todas as amostras foram construídas tendo suas dimensões de $12.5 \mathrm{~mm}$ (diâmetro) por $25 \mathrm{~mm}$ de (altura) conforme especificado na norma ASTM para métodos de testes D695-02 ${ }^{\mathrm{a}}$ (ASTM, 2002). As propriedades mecânicas foram analisadas utilizando a máquina Instron 5569 juntamente com o Software Instron Merlin (Série 5500), baseando-se nos métodos especificados pela norma ASTM D695-02a, cinco amostras com cada combinação de tratamento foram testadas em uma velocidade de teste de 1 $\mathrm{mm} / \mathrm{min}$ e com utilização de uma célula de carga de $10 \mathrm{kN}$. 
As medições referentes à porosidade revelaram que uma escala larga das estruturas apresentava porosidades diferentes, as quais poderiam ser fabricadas usando a técnica de FDM. A porosidade mais elevada foi conseguida quando as estruturas foram fabricadas usando uma combinação de ajuste entre a largura da quadriculação no ponto baixo e da abertura de ar no ponto mais elevado. Estes resultados podem ser visualmente analisados e verificados através da figura 20.

Variável

(A) Porosidade

(B) Largura

(C) Orientação

(D) Arranjo de deposição

(E) Construção de Camada
Baixo nível (-1)

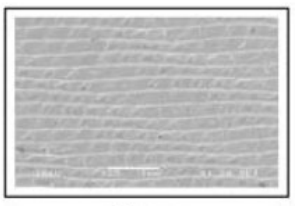

$0 \mathrm{~mm}$

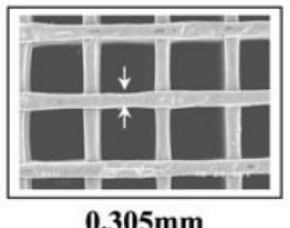

$0.305 \mathrm{~mm}$
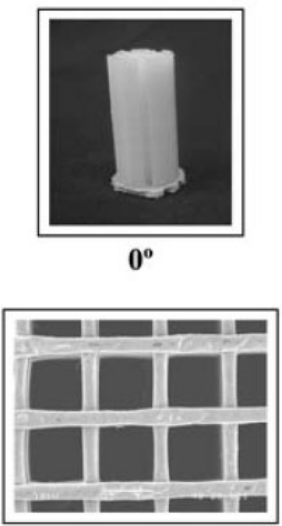

2 ângulos

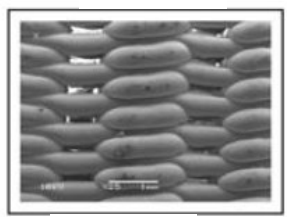

1 camada

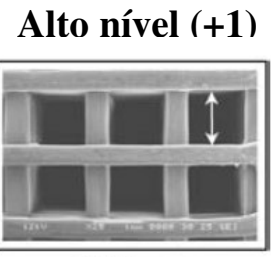

$1.27 \mathrm{~mm}$

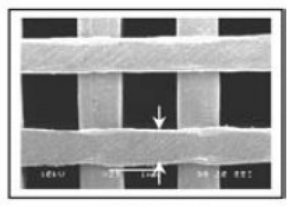

$0.98 \mathrm{~mm}$

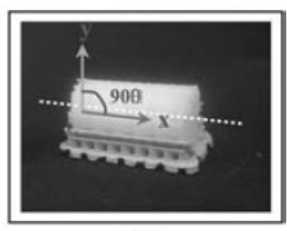

$90^{\circ}$

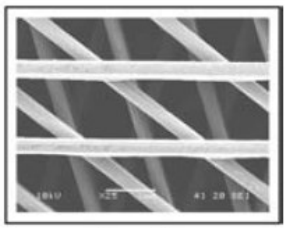

5 ângulos

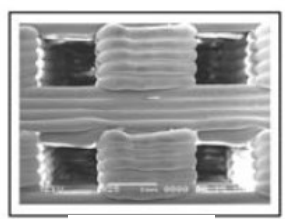

5 camadas

Figura 20 - Parâmetros de processo FDM de alto e baixo nível (Ang; Leong; Chua, 2006). 
As médias dos resultados dos experimentos incluíram as propriedades mecânicas e o modulo de compressão das amostras porosas, os quais estão apresentados na tabela 2.

Tabela 2 - Valores adotados para fatores mais relevantes no processo (Ang; Leong; Chua, 2006)

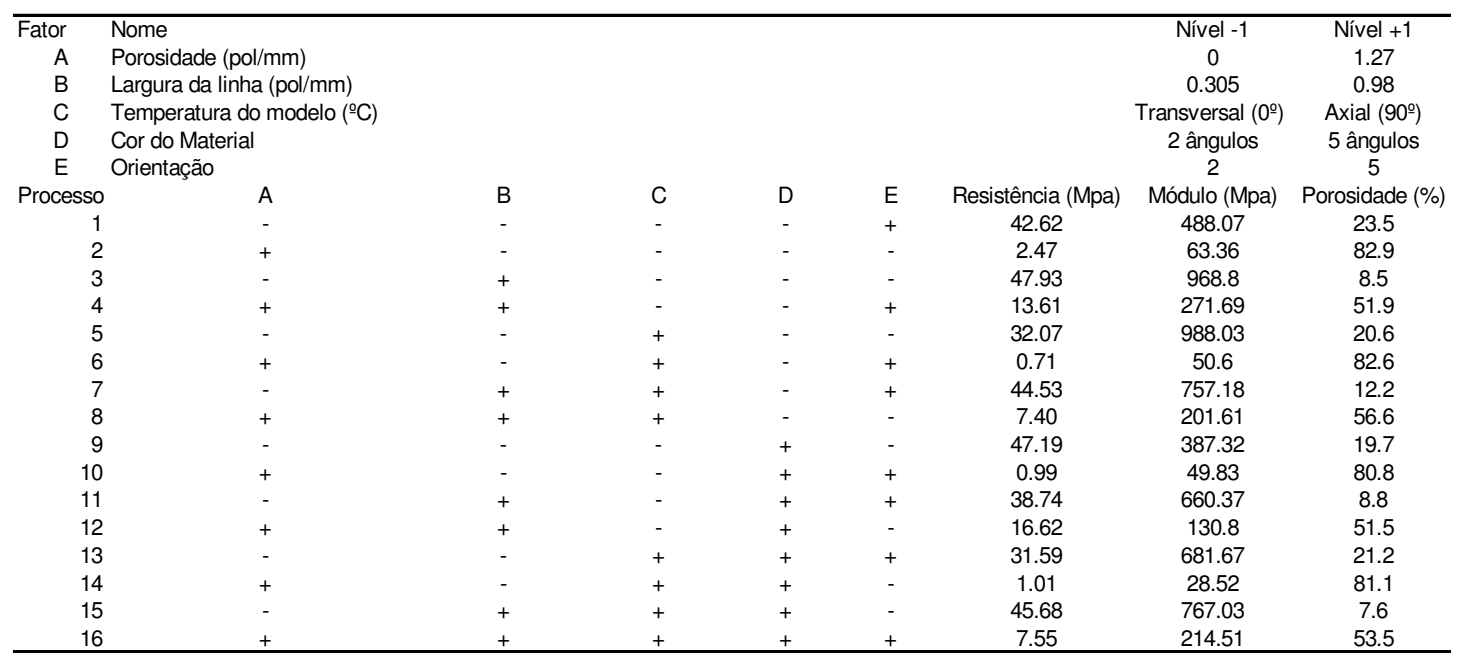

A tensão de compressão para as 16 amostras diferentes investigadas variou de 0.71 a 47.93 MPa visto que o módulo de compressão variou entre 28,52 e 988,03MPa. Verificou-se que as amostras que têm o módulo de compressão baixo possuem resistência também baixa.

A investigação dos efeitos da largura da quadriculação e da abertura dos poros em propriedades das estruturas exerce efeitos maiores nas propriedades das estruturas (porosidade e propriedades mecânicas) do que os outros parâmetros do processo. 
Tabela 3 - Influência da porosidade no comportamento mecânico da peça (Ang; Leong; Chua, 2006)

$\begin{array}{lccc}\text { Porosidade/largura }(\mathrm{mm} / \mathrm{mm}) & \text { Porosidade (por cento) } & \text { rendimento resistência compressão (MPa) } & \text { Modulo de compressão (MPa) } \\ 0.127 / 0.580 & 34.79 & 24.03 & 769.4 \\ 0.127 / 0.730 & 30.91 & 28.21 & 890.8 \\ 0.127 / 0.830 & 27.45 & 29.49 & 937.8 \\ 0.127 / 0.980 & 25.63 & 31.28 & 967.7 \\ 0.305 / 0.305 & 62.27 & 5.59 & 126.8 \\ 0.305 / 0.580 & 47.04 & 14.60 & 343.2 \\ 0.305 / 0.730 & 40.29 & 20.61 & 567.6 \\ 0.305 / 0.830 & 34.96 & 24.83 & 690.9 \\ 0.305 / 0.980 & 36.9 & 26.43 & 742.3 \\ 0.730 / 0.305 & 77.34 & 2.62 & 52.3 \\ 0.730 / 0.580 & 61.73 & 8.99 & 54.5 \\ 0.730 / 0.730 & 53.2 & 15.24 & 277.4 \\ 0.730 / 0.830 & 51.83 & 17.61 & 432.2 \\ 0.730 / 0.980 & 49.16 & 19.82 & 458.3 \\ 0.980 / 0.305 & 80.07 & 2.03 & 55.4 \\ 0.980 / 0.580 & 66.16 & 6.75 & 64.3 \\ 0.980 / 0.730 & 54.52 & 15.66 & 358.9 \\ 0.980 / 0.830 & 51.67 & 18.59 & 485.2 \\ 0.980 / 0.980 & 48.28 & 20.22 & 548.2 \\ 1.27 / 0.305 & 83.1 & 1.31 & 34.0 \\ 1.27 / 0.580 & 69.59 & 5.94 & 60.8 \\ 1.27 / 0.730 & 66.06 & 9.89 & 168.0\end{array}$

Relação entre propriedades mecânicas e a porosidade foi determinado por meio logarítmico, com as melhores propriedades mecânicas observadas nas estruturas de porosidade baixa.

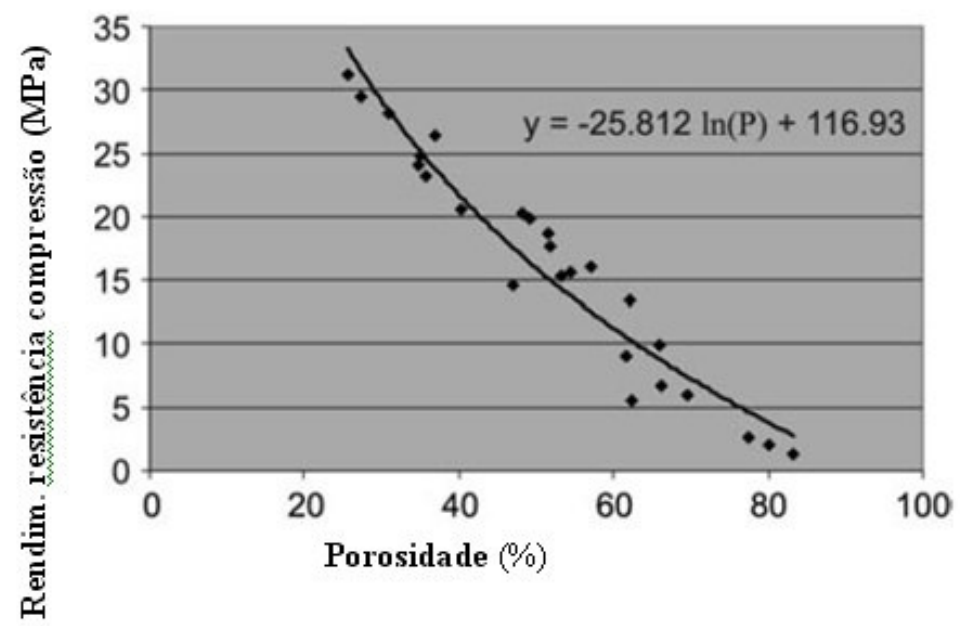

Figura 21 - Efeito da porosidade no rendimento da resistência à compressão para estruturas FDM

(Ang; Leong; Chua, 2006). 


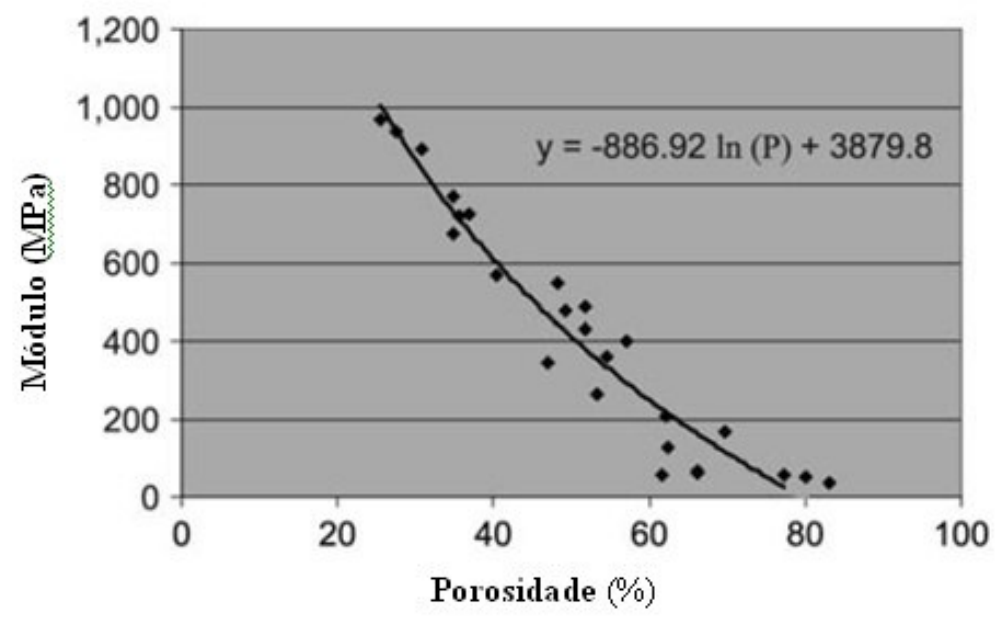

Figura 22 - Efeito da porosidade no módulo de compressão para estruturas FDM (Ang; Leong; Chua, 2006).

\subsection{MÓDULO DE ELASTICIDADE E PROPRIEDADES DO MATERIAL}

RODRÝGUEZ et al. (2003), descrevem que existe uma maneira essencial de modelamento utilizando material unidirecional FDM-ABS. Materiais unidirecionais são modelados com três dimensões homogêneas, lineares elásticas e ortotrópicas contínuas com um material na direção principal. Como proposta para as análises das propriedades mecânicas do material, deve-se considerar o modelo como um sólido com prismas alinhados e divididos por pequenos espaços, assumindo a característica de comprimento para se definir a seção transversal. Com este espaço determinado, o desenvolvimento das propriedades efetivas é transportado para o modelo.

Desta forma, cada ponto é associado com um tensor mesoestrutural variável chamado de densidade do poro dependente da magnitude na direção do plano definido em determinado ponto. A densidade do poro é definida para ser uniforme em qualquer plano através do sólido. Longitudinalmente, com esta hipótese, o esforço elementar e os campos de tensão são aplicados no material para obter as propriedades elásticas. 
Os módulos estimados para materiais ABS utilizados nas máquinas FDM mostram resultados similares em relação ao desempenho. No geral com 10 por cento a menos de diferença para propriedades elásticas em relação ao método experimental. Diferenças grandes e negativas ocorrem somente para o coeficiente de Poisson.

Muitos dos módulos encontrados em estudos são ignorados em virtude das alterações de propriedades mecânicas do material na linha de ABS durante a manufatura da peça (Rodrigues et al, 2001). De fato a redução do módulo de elasticidade e tensão do mono filamento de ABS ocorre após a extrusão devido à efeitos de orientação molecular. Em geral, em todas as investigações feitas com modelos encontra-se capacidade de prever anisotropia para o módulo de elasticidade em um determinado plano.

\subsection{PROCEDIMENTO EXPERIMENTAL}

A manufatura atual utilizando o processo FDM utiliza conhecimentos adquiridos na prática de modelamento, provenientes de estudos empíricos ou investigações analíticas.

Os sistemas geradores de dados de processo ajustam as variáveis e geram um prognóstico dos resultados. A divisão por camadas refere-se à situação na qual as espessuras de camadas variam em diferentes regiões da peça, permitindo camadas mais espessas e conseqüentemente a precisão da superfície não é importante, e camadas mais finas, o que se torna crucial para minimizar efeitos de degraus. Isto exige um compromisso entre o acabamento da superfície e o tempo de construção, que permite que uma peça seja construída rapidamente com precisão e funcionalidade, o que geralmente são características críticas, conforme descrito por Kulkarni e Dutta (1999 apud ZIEMIAN e CRAWN, 2001). 


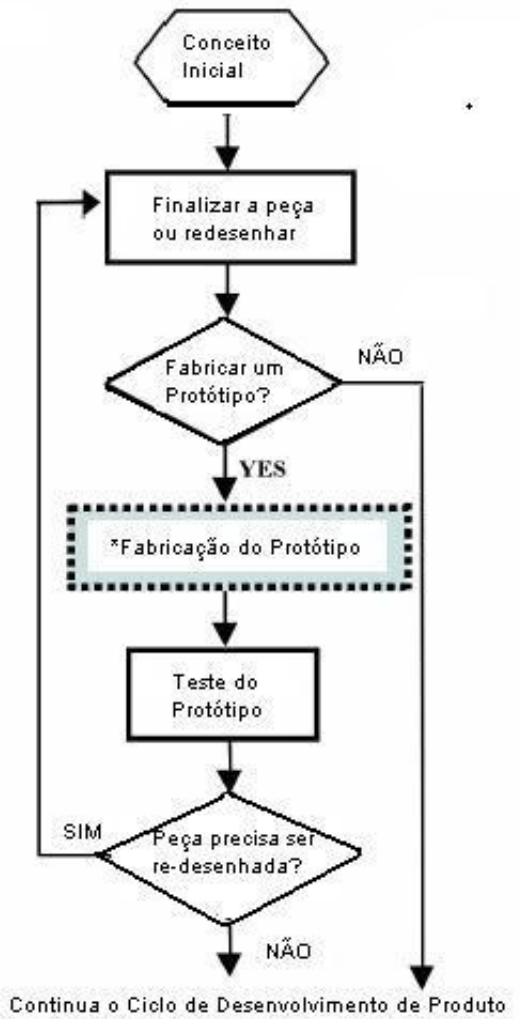

(a)

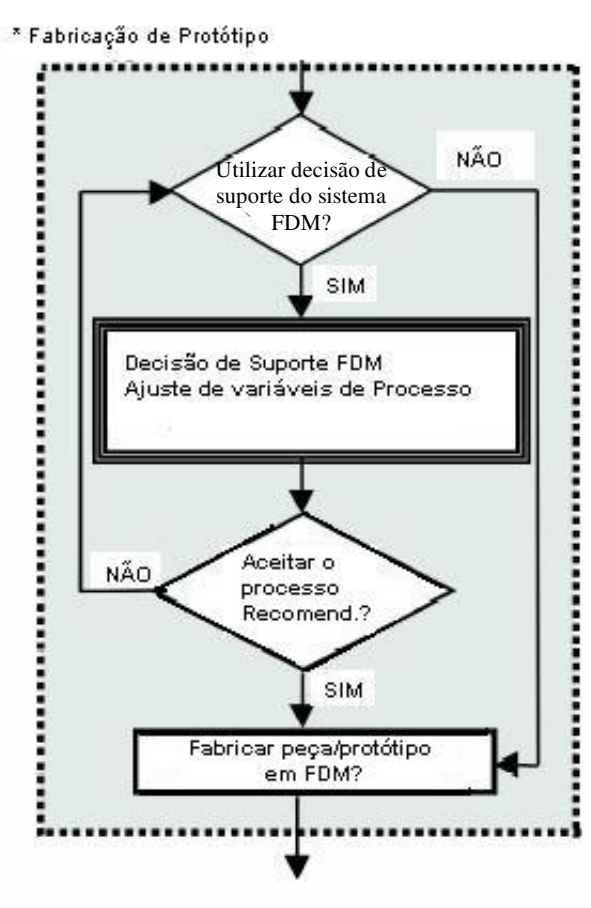

(b)

a) Colocação da fabricação do protótipo no processo de projeto

b) Decisão de suporte do sistema FDM usado na geração do protótipo

Figura 23 - Fabricação de um protótipo com o processo visto minimamente e a decisão do sistema de suporte usado (Ziemian; Crawn, 2001).

O tempo de pós processamento inclui a retirada da peça da base de espuma e a remoção dos suportes do material das superfícies. Superfícies de alto desempenho e qualidade com precisão em suas dimensões possibilitam que os componentes tornem-se fáceis para montagem e melhorem sua funcionalidade.

Sendo assim, todos os segmentos de superfície da peça que forem inclinados em relação à z possuirão algum efeito de degrau. Os meios para minimizar este efeito geralmente tentam expor menor número de superfícies inclinadas ou curvadas à linha central z. Pesquisas mostram que diminuir a espessura da camada nas regiões de curvatura elevada da de superfície, fornece uma diminuição considerável no efeito degrau (Lan et al., 1997 apud 
ZIEMIAN e CRAWN, 2001), sendo que o sistema de decisão de suporte aproxima uma medida relativa à qualidade da superfície computada analiticamente.

Como já comentado, as variáveis do processo FDM podem ser consideradas: orientação para construção, espessura da camada, largura da linha, estratégia de preenchimento interior.

A orientação de construção é somente uma variável com um estágio de CAD definido para o processo FDM. Esta orientação é variada pela rotação do arquivo STL em relação ao sistema de coordenadas da peça. Os aspectos importantes para a orientação incluem a altura no eixo z e o ângulo de cada superfície ou segmento com o plano x-y na mesa da máquina. A altura do eixo z pode variar entre os limites mínimos da camada física $(0.178 \mathrm{~mm})$ e a máxima altura de trabalho.

A espessura da camada refere-se à distância percorrida no eixo $\mathrm{z}$ entre as sucessivas camadas, e tem um impacto direto no tempo de construção e na qualidade da superfície. Cada um dos tipos de bicos tem uma associação com a escala recomendada para a espessura. Embora exista a capacidade do usuário em estabelecer uma espessura customizada, experimentos preliminares indicaram que o desempenho e a qualidade da superfície sofrem quando não utilizados os limites recomendados. Com relação à operação para deposição, pode-se incluir o caminho e a estratégia de preenchimento. O caminho refere-se à largura para deposição, relacionado ao tamanho do bico, sendo que o usuário pode selecionar largura com a escala recomendada. A estratégia de preenchimento refere-se em geral ao plano utilizado para preencher a porção interior de cada camada. O usuário pode escolher alguns tipos de preenchimento, como por exemplo: - sólido, contorno, peça rápida e transversal. Se a peça a ser prototipada não requerer alta densidade, o usuário pode diminuir o acúmulo de material e o tempo de construção. 
Outros parâmetros de construção que podem ser considerados comuns são: volume, superfície, fator de forma, material, temperatura de construção, tamanho do bico.

Para efeitos de estudo, a variável "estratégia de preenchimento interno", representa somente a qualidade, sendo que corresponde a algumas possíveis estratégias e representa um alto, médio e baixo nível de ajuste no volume de material a ser utilizado. Como exemplo, o bico T12 tem um diâmetro interno de $0.305 \mathrm{~mm}$ (0.012 polegadas), sendo uma espessura recomendada variando em uma escala de $0.178 \mathrm{~mm}$ a $0.35 \mathrm{~mm}$ com uma largura de linha entre 0.262 e 1.010 mm, utilizando material termoplástico ABS P400.

Os problemas encontrados no processo de FDM estão centrados na exatidão, no revestimento de superfície, na qualidade, no custo e no tempo de produção da peça, dependendo extremamente de diversos fatores que requerem o conhecimento, as habilidades e o julgamento por parte do projetista. Estes fatores são: criação de um modelo apropriado no CAD, melhor orientação do modelo STL, criação de suportes necessários, seleção da espessura de corte, edição do arquivo SLC, arquivo criado após STL com a espessura desejada, definição de ajustes, criação de caminhos, otimização de parâmetros do caminho e seleção do tamanho da ponta de FDM.

Outra situação, na qual um projetista utiliza boa parte de seu tempo é no julgamento dos estágios do pré-processamento como: uma peça maior do que o espaço de trabalho, uma peça a ser produzida em diversas etapas para o conjunto final, peças múltiplas a serem produzidas simultaneamente, seleção de materiais apropriados para uma peça, revestimento desejado de superfície e tipo de acabamento superficial, tempo de otimização da configuração selecionando ajustes e possibilidades de caminho e avaliação estimada do custo para a peça.

Além destes, há diversas outras dificuldades para a produtividade, que são confrontadas pelos usuários experientes de FDM e de outros processos de prototipagem rápida. Todos estes problemas podem ser agrupados nos seguintes quatro níveis de usuário. 
- $\quad$ Nível do projetista do produto:

Os projetistas de produto gastam geralmente um longo tempo para construir uma peça complexa como um modelo de superfície. Modelar peças mecânicas com sistemas CAD convencionais envolve a repetição elevada de características de projeto padrão tais como furos, entalhes, dobra e sustentações, em que os atributos não geométricos convencionais também são incluídos em características tais como a qualidade, o revestimento, estética, a superfície, a finalidade, as funções, os tipos de ajustes, tolerâncias geométricas e o desvio permissível do produto ou do protótipo resultante.

- $\quad$ Nível do planejamento do processo e nível de projeto para suportes:

O grau elevado de interação manual no processo de planejamento e interpretação com desenhistas é necessário a fim de definir os atributos como aparência, funcionalidades dos protótipos. Para que sejam discutidos e melhorados durante a execução, deve-se no planejamento do processo encontrar maneiras de orientar uma peça para conseguir um balanço entre o custo de produção e o nível desejado de qualidade e exatidão de superfície, abordando as variações e suas conseqüências em relação à orientação da peça, plano de construção bem como suas sustentações. Se a geração automática dos suportes não for apropriada, um grau elevado de interação manual é necessário para desenvolver o projeto e otimizar suportes. Com posicionamento a remoção apropriada dos suportes, é assegurado um bom revestimento de superfície e sem comprometer a textura da superfície do protótipo.

- Custos:

Um tempo intensivo de processo é considerado para decidir e estabelecer manualmente o número mínimo das camadas e conseguir a funcionalidade e a exatidão requeridas junto com uma redução no tempo de construção. A dificuldade em calcular custos com exatidão o uso de material, tempo de construção, o tempo da instalação, e esforços manuais como remover elementos de suporte e executar operações secundárias, dificulta o 
planejamento adequado de custos da peça. Os problemas secundários das operações ocorrem na colocação dos suportes para minimizar os esforços necessários no acabamento tais como lixar, rebarbar, e pintar o conjunto.

O cálculo de custos enfrenta dificuldades ao ser avaliado com relação ao grau de desempenho nos termos de atributos não geométricos tais como a qualidade, estética, revestimento da superfície, funcionalidade, tipos de tolerâncias aptas. A compreensão profunda dos problemas enfrentados pelo projetista e planejador do processo é requerida para avaliar o projeto proposto no total, sendo que a maior dificuldade é enfrentada para se conseguir um acordo racional entre as exigências do ponto de vista do cliente, do projetista e planejador do processo.

Gray et al (1998) descrevem os efeitos do processamento em aplicações de peças reforçadas com fibras, os quais são vistos como um grande auxílio para a melhoria das limitações das propriedades mecânicas dos polímeros utilizados para fabricação de peças em sistemas de prototipagem rápida. Muitos dos protótipos fabricados podem servir somente como réplicas geométricas do proposto para produção devido às propriedades mecânicas inadequadas. Os materiais que são comercialmente disponíveis para o sistema de FDM são ABS, e um copolímero de nylon e cera fundidos, sendo que o ABS tem o maior módulo de elasticidade e resistência.

Outro aspecto importante, segundo Massod (1996), está na necessidade de diversas áreas fazerem com que a tecnologia possa ser conduzida de forma mais eficiente e versátil sendo considerado como melhoria adicional ao ciclo de desenvolvimento do produto.

Os polímeros cristalinos líquidos termotrópicos (TLCPs) são uma classe de materiais que têm potencial para o uso em aplicações de FDM por diversas razões. Primeiramente, mostrou-se que TLCPs têm propriedades elásticas excelentes com módulos que variam de 50GPa a 100GPa para fibras puras. Também mostrou-se que, devido a estas propriedades de e 
devido às suas formas de fibras, os TLCPs têm sido usados para reforçar os termoplásticos (Baird, 1996; Handlos e Baird, 1995; Isayev, 1996 apud GRAY et al, 1998). O diâmetro das fibras de reforço dos TLCP é tipicamente uma ordem de grandeza menor do que aquelas de fibras típicas como as de vidro e ou de carbono, visto que, não se torna possível a extrusão de fibras do vidro ou de carbono através do cabeçote e ainda, manter as fibras elevadas em relação ao modelo devido ao diâmetro do capilar do material fundido ser pequeno.

As propriedades mecânicas finais de "TLCP" são baseadas em compostos, para os quais a morfologia da fibra de reforço é desenvolvida durante a etapa de processamento da base, e são diretamente dependentes das circunstâncias de processamento (Blizard e Baird, 1987; Handlos e Baird, 1995; Kohli et al., 1985; Viola et al., 1985). O fluxo de corte durante o processo para deformar partículas dispersadas de TLCP tem intenção de reforçar e gerar orientação molecular, que resulta em propriedades mecânicas melhoradas no sentido do fluxo.

Esta orientação preferida, das moléculas e das fibras, resulta em propriedades mecânicas anisotrópicas. Sabe-se que os campos do fluxo desenvolvem fibras melhores com relação ao aspecto de orientação molecular rendendo propriedades de mecânicas melhores do que o fluxo normal.

Segundo Bertold 1998, a metodologia para determinar a matriz de rigidez para uma peça construída com técnicas de FDM pode ser analisada de modo convencional de formulação de compósitos, com exemplo de orientação $\left[\begin{array}{llll}0 & 90 & +45 & -45\end{array}\right]$ e fabricadas utilizando material ABS. 


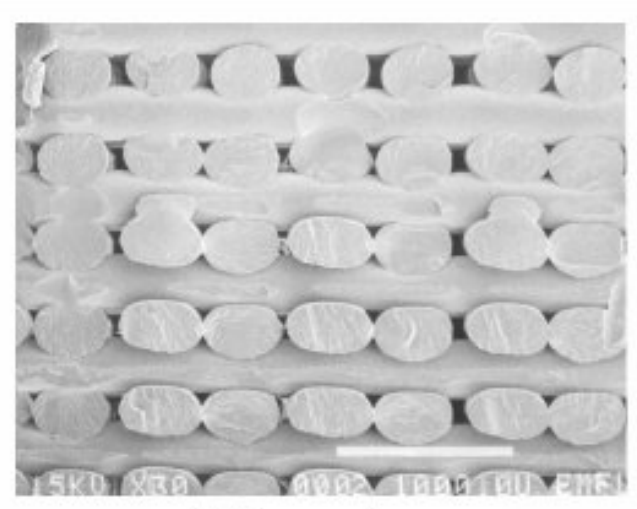

a) Vista total

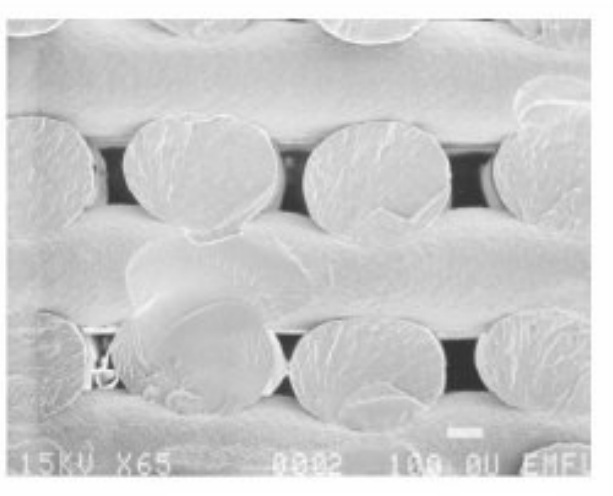

b) Vista aproximada

Figura 24 - Vista de seção transversal com peça construída em ABS e orientação de 0/90 (Bellini; Güçeri, 2003).

Para determinar completamente as propriedades do material, é assumido geralmente um comportamento linear do mesmo, em que os 36 componentes da matriz de flexibilidade [C] são conhecidos conforme teoria aplicada para materiais compósitos. Uma descrição mais detalhada da teoria envolvida é dada no Anexo B. Nas matrizes e equações mencionadas abaixo, são apresentadas apenas algumas equações principais.

$$
\left[\begin{array}{c}
\varepsilon_{1} \\
\varepsilon_{2} \\
\varepsilon_{3} \\
\gamma_{23} \\
\gamma_{13} \\
\gamma_{12}
\end{array}\right]=\left[\begin{array}{llllll}
S_{11} & S_{12} & S_{13} & S_{14} & S_{15} & S_{16} \\
S_{21} & \ldots & \ldots & & & \\
S_{31} & \ldots & \ldots & & & \\
S_{41} & & & \ldots & & \\
S_{51} & & & & \ldots & \\
S_{61} & & & & & \\
\sigma_{66}
\end{array}\right] \times\left[\begin{array}{c}
\sigma_{1} \\
\sigma_{2} \\
\tau_{23} \\
\tau_{13} \\
\tau_{12}
\end{array}\right]
$$

Onde a notação tensorial pode também ser expressa por:

$$
\underline{\varepsilon}=\underline{\underline{S}} \underline{\sigma}
$$


Devido à propriedade de simetria, da matriz $\mathrm{S}$, esta equação também pode ser reescrita nos termos de 21 componentes:

$$
\left[\begin{array}{c}
\varepsilon_{1} \\
\varepsilon_{2} \\
\varepsilon_{3} \\
\gamma_{23} \\
\gamma_{13} \\
\gamma_{12}
\end{array}\right]=\left[\begin{array}{llllll}
S_{11} & S_{12} & S_{13} & S_{14} & S_{15} & S_{16} \\
& S_{22} & \ldots & \ldots & \ldots & \ldots \\
& & S_{33} & \ldots & \ldots & \ldots \\
& & & S_{44} & \ldots & \ldots \\
& & & & & \\
& & & & & \\
& & & & & \\
& & & & & S_{66}
\end{array}\right] \times\left[\begin{array}{c}
\sigma_{1} \\
\sigma_{2} \\
\sigma_{3} \\
\tau_{23} \\
\tau_{13} \\
\tau_{12}
\end{array}\right]
$$

Para materiais ortotrópicos, os quais são definidos como materiais com três planos perpendiculares de simetria, a equação pode ser simplificada em termos de 9 componentes.

Considerando as constantes convencionais de engenharia nas três direções, nos termos do módulo de elasticidade E, Coeficiente de Poisson $V$ e módulo de cisalhamento G:

$$
\left[\begin{array}{c}
\varepsilon_{1} \\
\varepsilon_{2} \\
\varepsilon_{3} \\
\gamma_{23} \\
\gamma_{13} \\
\gamma_{12}
\end{array}\right]=\left[\begin{array}{cccccc}
\frac{1}{E_{1}} & \frac{-\nu_{12}}{E_{1}} & \frac{-\nu_{13}}{E_{1}} & 0 & 0 & 0 \\
& \frac{1}{E_{2}} & \frac{-\nu_{23}}{E_{2}} & 0 & 0 & 0 \\
& & \frac{1}{E_{3}} & 0 & 0 & 0 \\
& & & \frac{1}{G_{23}} & 0 & 0 \\
& & & & \frac{1}{G_{13}} & 0 \\
& & & & & \frac{1}{G_{12}}
\end{array}\right] \times\left[\begin{array}{c}
\sigma_{1} \\
\sigma_{2} \\
\sigma_{3} \\
\tau_{23} \\
\tau_{13} \\
\tau_{12}
\end{array}\right]
$$


Onde

$$
\nu_{12}=-\frac{\varepsilon_{2}}{\varepsilon_{1}}, \quad \nu_{13}=-\frac{\varepsilon_{3}}{\varepsilon_{1}}, \quad \nu_{23}=-\frac{\varepsilon_{3}}{\varepsilon_{2}}
$$

Substituindo;

$$
\begin{aligned}
& S_{11}=\frac{1}{E_{1}}, \quad S_{12}=\frac{-\nu_{12}}{E_{1}}=\frac{-\nu_{21}}{E_{2}}, \\
& S_{13}=\frac{-\nu_{13}}{E_{1}}=\frac{-\nu_{31}}{E_{3}}, \quad S_{22}=\frac{1}{E_{2}}, \\
& S_{23}=\frac{-\nu_{21}}{E_{2}}=\frac{-\nu_{12}}{E_{1}}, \quad S_{33}=\frac{1}{E_{3}}, \\
& S_{44}=\frac{1}{G_{23}}, \quad S_{55}=\frac{1}{G_{13}}, \quad S_{66}=\frac{1}{G_{12}} \\
& {\left[\begin{array}{c}
\varepsilon_{1} \\
\varepsilon_{2} \\
\varepsilon_{3} \\
\gamma_{23} \\
\gamma_{13} \\
\gamma_{12}
\end{array}\right]=\left[\begin{array}{cccccc}
S_{11} & S_{12} & S_{13} & 0 & 0 & 0 \\
& S_{22} & S_{23} & 0 & 0 & 0 \\
& & S_{33} & 0 & 0 & 0 \\
& & & S_{44} & 0 & 0 \\
& & & & S_{55} & 0 \\
& & & & & S_{66}
\end{array}\right] \times\left[\begin{array}{c}
\sigma_{1} \\
\sigma_{2} \\
\sigma_{3} \\
\tau_{23} \\
\tau_{13} \\
\tau_{12}
\end{array}\right]}
\end{aligned}
$$

Ou então, pode-se escrever:

$$
\underline{\sigma}=\underline{\underline{C}} \underline{\varepsilon}
$$


Ou na forma explícita:

$$
\left[\begin{array}{c}
\sigma_{1} \\
\sigma_{2} \\
\sigma_{3} \\
\tau_{23} \\
\tau_{13} \\
\tau_{12}
\end{array}\right]=\left[\begin{array}{cccccc}
C_{11} & C_{12} & C_{13} & 0 & 0 & 0 \\
& C_{22} & C_{23} & 0 & 0 & 0 \\
& & C_{33} & 0 & 0 & 0 \\
& & & C_{44} & 0 & 0 \\
& & & & C_{55} & 0 \\
& & & & & C_{66}
\end{array}\right] \times\left[\begin{array}{c}
\varepsilon_{1} \\
\varepsilon_{2} \\
\varepsilon_{3} \\
\gamma_{23} \\
\gamma_{13} \\
\gamma_{12}
\end{array}\right]
$$

Onde:

$$
\begin{aligned}
& C_{11}=\frac{S_{22} S_{33}-S_{23}^{2}}{S}, \quad C_{12}=\frac{S_{23} S_{13}-S_{12} S_{33}}{S} \\
& C_{13}=\frac{S_{12} S_{23}-S_{22} S_{13}}{S}, \quad C_{22}=\frac{S_{11} S_{33}-S_{13}^{2}}{S} \\
& C_{23}=\frac{S_{12} S_{13}-S_{11} S_{23}}{S}, \quad C_{33}=\frac{S_{11} S_{22}-S_{12}^{2}}{S} \\
& C_{44}=\frac{1}{S_{44}}, \quad S=S_{11} S_{22} S_{33}+2 S_{12} S_{23} S_{13}-S_{13}^{2} S_{22} \\
& -S_{23}^{2} S_{11}-S_{12}^{2} S_{33}
\end{aligned}
$$

Dessa forma, para definir o comportamento mecânico de uma peça ortotrópica, é necessário determinar 9 constantes independentes. A determinação experimental destas constantes é possível através da construção de seis amostras em diferentes orientações.

Deve-se notar que, de acordo com a lei de Hooke, o módulo de Young pode ser obtido através do diagrama de tensão versus deformação:

$$
E_{x}=\frac{\Delta \sigma_{x}}{\Delta \varepsilon_{x}}
$$


Coeficiente de Poisson v como:

$$
\nu_{x y}=-\frac{\varepsilon_{y}}{\varepsilon_{x}}
$$

O módulo de cisalhamento pode ser obtido a partir do teste com amostra unidirecional com orientação à $45^{\circ}$, de acordo com a equação:

$$
G_{a b}=\frac{E_{x}}{2\left(1+\nu_{x y}\right)}
$$

sendo que x é a direção da carga aplicada e y é a direção perpendicular a x. Além disso, a e b, sub-índices de G, correspondem a 1 e 2 para as amostras construídas no plano xy, 1 e 3 para as construídas no plano xz e 2 e 3 para àquelas construídas no plano yz.

Para obter os nove valores das constantes independentes na matriz, em relação à tensão, devem-se construir seis amostras com diferentes orientações para testes. (Zweben e Tsu-Wei Chou, 1996 apud BELLINI e GUÇERI, 2003).

De acordo com a norma ASTM C1341-97 (1997) foram realizados testes de flexão por três pontos, onde a máxima tensão ocorre na região central das amostras. Os resultados destes testes mencionados mostram que as amostras com orientação aleatória são mais frágeis, em geral $8 \%$ em relação às amostras fabricadas e medidas por empilhamento padrão. A flexão final de falha para as amostras com orientação aleatória é em geral muito menor que a deflexão registrada para amostras em empilhamento padrão. Como conseqüência da manufatura por camadas, as peças produzidas são ortotrópicas. Tem sido observado que as formas das linhas e a interação entre elas exercem influencia decisiva nas propriedades finais do protótipo fabricado. Em resumo, pode-se dizer que as propriedades mecânicas das peças finais dependem consideravelmente de duas importantes fases de modelamento:

- a escolha da direção de construção;

- a escolha do caminho. 
$\mathrm{O}$ fato de que as propriedades mecânicas dependem da orientação e do caminho torna crítico, quando se utiliza tecnologia FDM para produzir componentes diretamente para uso final. Neste caso, torna-se importante verificar com antecedência e projetar a construção do protótipo com tolerâncias e propriedades mecânicas desejadas.

Tata et al (1998) discute a possibilidade, com relação às falhas no interior das peças, ou seja, deve-se construir uma peça exatamente como um cubo empilhando-se as camadas, entretanto, os modelos contínuos não são curvados ou com superfícies inclinadas. Estas superfícies, quando cortadas e criadas em camadas resultantes, sofrerão uma perda inevitável de informação. Como conseqüência, as maneiras de se eliminar ou se reduzir têm sido investigadas através dos métodos para eliminação destas falhas, podenso-se facilmente deduzir que a diminuição da espessura da camada ajudaria na melhoria do resultado. Uma alternativa sugerida por Riley (1993) seria dar forma a cada camada ligeiramente menor em relação à seção transversal desejada e preencher as regiões vazias com diferentes materiais.

Outra maneira teoricamente mais indicada, é a utilização da orientação apropriada das peças (Frank e Fadel, 1995). Esta técnica, embora seja simples e não requeira nenhuma modificação no processo, está incompleta porque não é sempre possível eliminar o erro mudando a orientação. Quando considerando uma esfera ou um cone, por exemplo, o único método disponível seria reduzir a espessura da camada a um valor mínimo permitido pelo processo. Embora esta seja uma maneira adequada de reduzir o erro, o resultado também gera um aumento no número de camadas. Neste trabalho é mostrado que nem sempre é necessário sacrificar a qualidade para reduzir o tempo de processo, pelo contrário, os resultados provam conclusivamente que, quando comparadas às práticas existentes, as peças de qualidade superior podem ser produzidas com tempos reduzidos em sua configuração e desta maneira, as influências também podem ser extremas com relação à qualidade da superfície, erros no arquivo, tempo de preparação e o tempo real da configuração da máquina, visto que estes 
parâmetros têm menor influência. A velocidade, a precisão das camadas, as variações automáticas da espessura da camada, são parâmetros para conseguir um atributo de superfície pré-determinado, e o reconhecimento e a retenção das características chaves são as determinantes para um bom algoritmo.

Poucos pesquisadores dirigiram seus trabalhos à edição da espessura da camada. Chalasani (1992, apud TATA et al 1998) propôs um esquema seguindo do contorno, onde os contornos 2-D de uma altura particular fossem obtidos primeiramente recuperando todos as partes de superfície nessa altura da lista e então seguindo ao longo dos planos procurando os pontos de entrada e de saída. O algoritmo então criado pode ser executado com sucesso para divisão de camadas do arquivo STL em uma espessura da camada e diversas peças foram construídas.

Dolenc e Makala $(1992,1994)$ usaram o vértice de uma curva como um critério adaptável para a divisão de camadas dos arquivos STL. A detecção deste vértice foi realizada procurando contornos degenerados. Sreeram e Dutta (1994) desenvolveram um método para determinar a espessura variável para um objeto poliedro usando a otimização. Suh e Wozny (1994) desenvolveram um procedimento de divisão adaptável para as superfícies paramétricas onde a curvatura vertical em pontos diferentes é computada e a espessura calculada é baseada no máximo destas curvaturas verticais. Kulkarni e Dutta (1995) desenvolveram um procedimento para cortar as superfícies algébricas parametrizáveis de maneira adaptativa usando o critério da altura do vértice, onde a espessura da camada é determinada através do valor da curvatura máxima no sentido vertical. Recentemente, Sabourin et o al. (1996) e a Hole et o al. (1997) apresentaram também o trabalho para divisão adaptável. Tata (1995, 1996) desenvolveu um algoritmo de divisão adaptável de arquivos de STL.

A divisão por camadas gera fatias bidimensionais a partir de um modelo mosaico tridimensional, sendo os quatro componentes chave: 
1 - processador de segmentos de superfície para a velocidade computacional elevada;

2 - um identificador característico chave (KCI);

3 - uma calculadora da espessura para computar a espessura da camada;

4 - um fatiador para gerar contornos bidimensionais.

A arquitetura divisora proposta, mostra ao interior do fluxo de informação ao ser feita a divisão de camadas. A entrada é um arquivo STL, a saída para dados bidimensionais da camada. O processador do segmento de superfície recebe um arquivo STL e agrupa os seguimentos, posteriormente alimenta os dados processados a outros três membros. O KCI reconhece a presença das características chaves e emite sua posição à calculadora de espessura, que por sua vez alimenta essa informação junto com sua própria saída ao divisor. O divisor utiliza todos os dados recebidos para gerar fatias bidimensionais e entrega-as no formulário de um arquivo de dados de ou de uma exposição visual. A maneira mais fácil de encontrar o tipo de uma característica é estudando as camadas e os contornos dentro de cada fatia, onde as escalas fornecerão métodos para distinguir entre saliências e depressões. Estas escalas são simples, definitivas, sem ambigüidade e refletem o sólido.

Escala 1: Quando um plano imaginário corta um sólido, a fatia resultante pode conter um único ou um múltiplo, contornos fechados não-cruzados.

Escala 2: Se alguns únicos contornos vazios múltiplos forem cercados por um único contorno maior, todos os contornos internos representam características de depressão. Isto em um bloco retangular com diversos furos.

Escala 3: Se dois ou mais contornos forem aninhados dentro de si, todos os contornos numerados representam depressões.

Escala 4: Para características de forma e orientação uma vez que a posição e o tipo de uma característica esteja determinada, detalhes adicionais como a forma pode ser obtida estudando as características dos planos normais dos segmentos. (Tata; Fadel, 1996). 
O cálculo da espessura busca resolver os problemas fundamentais para melhorar o processo de planejamento e eventualmente para uma melhor eficiência (tempo e qualidade). Uma vez que o tempo de configuração aumenta com número das camadas, o objetivo de todo o processo deve ser construir as peças com qualidade superior e ao mesmo tempo diminuir a quantidade de camadas. O erro, função da espessura e do número de camadas (slices) da peça é o principal responsável pelas imperfeições de superfície e aspereza. A complexidade da superfície é considerada a partir do processo de manufatura, onde as superfícies podem ser classificadas em duas categorias:

1 - superfícies regulares: superfícies perpendiculares ao plano da camada que não exibem erro.

2 - superfícies não-regulares: as superfícies que caracterizam inclinações com relação à linha central da fatia são propícias à erros derivados de uma perda inevitável da informação durante o corte, sendo que, a quantidade de informação perdida é relacionada à inclinação e à espessura da camada. Para uma dada espessura da camada, o erro aumenta com a inclinação. Isto permite que se defina a complexidade de superfície nos termos da inclinação.

Em relação à complexidade de superfície, a espessura da camada deve ser escolhida tal que o tempo de fabricação desejado possa ser atingido, respeitando-se os parâmetros de processo. Por exemplo, a espessura máxima da camada no processo de estereolitografia é decidida pelo tipo de material, da potência do laser, e de outros parâmetros. No intuito de se minimizar todos os efeitos contrários aos bons resultados para a confecção de protótipos com qualidade, poder-se-ia desenvolver um sistema de prototipagem rápido inteligente, aplicado à tecnologia FDM, envolvendo as diferentes etapas do processo: criação do modelo do $\mathrm{CAD}$, o planejamento do processo, projeto de dispositivo para posicionamento, verificação e inspeção e operações para o preenchimento com interação prática do operador da máquina a fim de se produzir um protótipo exato e aceitável, conforme esquematizado na figura 24 . A 
idéia principal empregada é que o tempo total requerido antes da construção da peça poderia ser reduzido significativamente em todas as etapas se fossem integradas inteligentemente com sistemas baseados em conhecimento de fluxo e controle simultâneos de informação entre cada sistema e etapa. Acredita-se que este sistema seja bastante apropriado pelo fato de que certos cuidados seriam tomados e não somente na complexidade dos produtos, mas incluiria também as etapas relacionadas à finalização protótipo. O projeto e a execução bem sucedida de tal sistema envolvem o desenvolvimento de diversos conhecimentos inteligentes de sistemas baseados em tarefas específicas cada passo do desenvolvimento de um ambiente integrado a fim de coordenar e controlar então as atividades e a troca da informação e de dados. Acreditase que certos cuidados deveriam ser tomados não somente com relação à complexidade dos produtos, mas incluindo também as escalas relacionadas à finalização do protótipo. Dependendo das exigências e da funcionalidade do protótipo, o projetista tem que desenvolver um esquema apropriado e dispositivos de orientação que sejam baseados em conceitos de prototipagem rápida inteligente com a deposição de material fundido. Tal sistema inteligente executado com sucesso, dentro de um ambiente distribuído conseguiria os seguintes benefícios: nível de produtividade mais elevado e utilização de mais recursos; reduções no projeto, o planejamento, tempo e custos; economias nos termos da velocidade, uso de material e tempo de execução de cada etapa; exatidão e qualidade de produtos finais; incluindo também flexibilidade para se reagir mais rapidamente às demandas de cliente; melhores acesso e controle da informação através de todos os níveis; além de um ambiente eficaz para facilitar a cooperação entre todo o pessoal envolvido. 


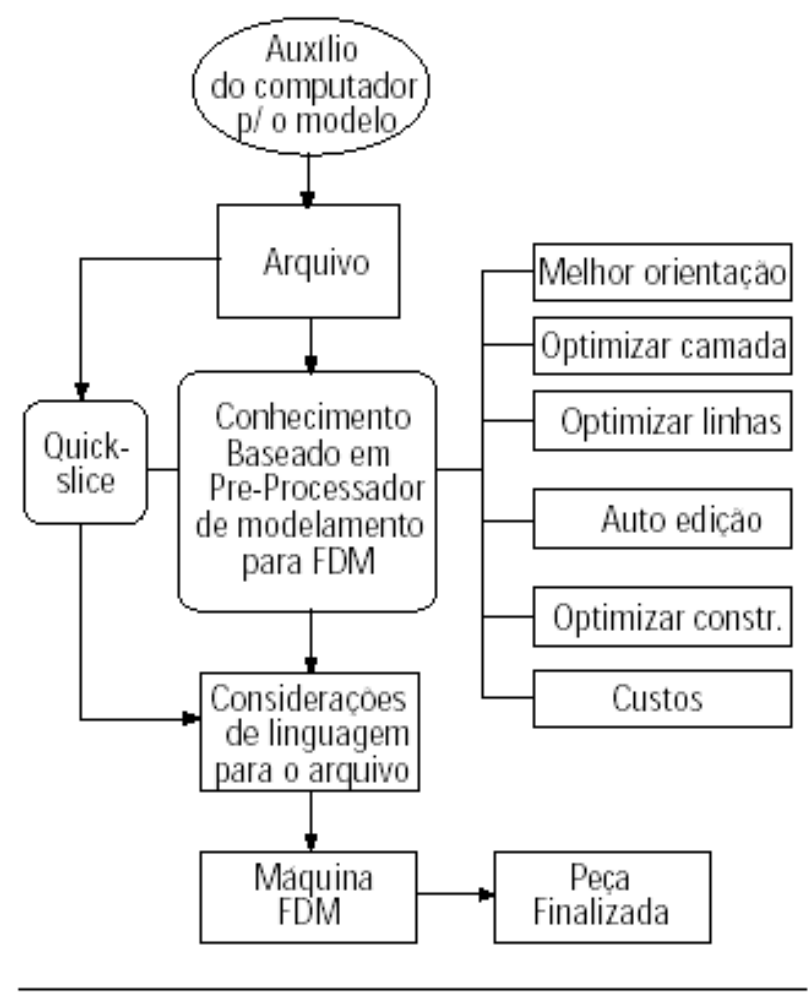

Figura 25 - Processo de pré-processamento em FDM (Masood, 1996).

Embora a metodologia de integrar diversas fontes do conhecimento esteja disponível, a aplicação desta técnica aos sistemas de prototipagem rápida é um fenômeno recente. A arquitetura foi aplicada eficazmente à manufatura integrando o computador ao controle do processo e ao planejamento de programação, onde os vários sistemas peritos cooperando entre si trabalham juntos para atingir o resultado final. Esta estrutura distribuída fornece uma plataforma eficaz para a integração, e o controle e a troca de informação simultânea com suas quatro fontes de conhecimento cooperando entre si. Uma outra vantagem importante, é que os dados necessários podem rapidamente ser gerados para o projetista ou cliente da peça, incluindo o desenho detalhado da peça e a informação referente ao projeto, lista de materiais, o provisão de custo, o nível de exatidão e da qualidade e volume de material. A habilidade de responder imediatamente a um pedido do cliente é atualmente um dos problemas principais nos ambientes de manufatura e de mercado, isto é atribuído na maior parte à falta de 
habilidade do coordenador em capturar e reter toda a informação necessária para atingir a expectativas do cliente, integrando um jogo de fontes de conhecimento na arquitetura do programa, sendo que o sistema inteligente será eficaz para resolver vários dos problemas relacionados à estes conflitos e referentes às estratégias da definição, peculiares à natureza de algumas das tecnologias de prototipagem rápida. Em sua maior parte deve-se este fato à falta de informação canalizada em tal ambiente no sentido correto, o que eliminaria também a necessidade de grandes e centralizadas bases de dados e que são frequentemente necessárias com sistema de manufatura convencional em sistemas prototipagem.

As conclusões referentes à estrutura de prototipagem rápida inteligente são de que este sistema fornece uma metodologia para melhorar a eficiência e a produtividade em sistema FDM com a aplicação de sistemas baseados em conhecimento e distribuí-se a tecnologia do controle do sistema. Tal estrutura facilita não somente a união de fontes cooperadas com o conhecimento, mas também a integração verdadeira de todas as atividades de projeto relacionadas para se desenvolver a proposta mais atrativa. Isto pode incluir a otimização do modelo, tornar dos modelos mais leves e reduzir material, e considerações relacionadas às operações secundárias e às aplicações tais como investimento em moldes, o que contribuirá decisivamente para a melhoria do desempenho econômico da empresa.

\subsection{ANÁLISE PELO MÉTODO DOS ELEMENTOS FINITOS}

Norton (2004) cita que no âmbito da Engenharia de Estruturas, o Método dos Elementos Finitos (MEF) é uma ferramenta poderosa para estudo de problemas do continuo, tem sido amplamente utilizado no estudo de tensões e deformações em componentes de geometria arbitrária sujeito a diferentes tipos de carregamentos. Este tipo de cálculo tem a designação genérica de análise de estruturas e surge, por exemplo, no estudo de edifícios, 
pontes, barragens, etc. Quando existe a necessidade de projetar uma estrutura, é habitual proceder-se a uma sucessão de análises e modificações das suas características, com o objetivo de se alcançar uma solução satisfatória, quer em termos econômicos, quer na verificação dos pré-requisitos funcionais e regulamentares. Neste texto apenas serão apresentados apenas alguns conceitos básicos relacionados à aplicação do método. Maiores detalhes são facilmente encontrados na literatura.

Todo elemento infinitesimal do material pode concebivelmente experimentar diferentes tensões ao mesmo tempo. Portanto, devemos olhar as tensões atuando elementos extremamente pequenos dentro do corpo. Esses elementos infinitesimais são tipicamente modelados como cubos. Considera-se que as componentes de tensão atuam sobre as faces destes cubos de duas maneiras diferentes. As tensões normais atuam na direção perpendicular à face do cubo e tendem a puxá-lo ou empurrá-lo. As tensões de cisalhamento atuam na direção paralela às faces dos cubos, em pares (binários) sobre faces opostas, o que tende a distorcer o cubo em um formato romboidal.

Segundo a PCE Engenharia (2007), o método permite que a peça em estudo tenha forma geométrica, carregamento e condições de contorno quaisquer. Ocorre uma semelhança física entre o modelo FEA (Finite Element Analysis) e a situação física real, não sendo o modelo uma abstração matemática difícil de ser visualizada. Inicialmente o MEF foi usado em cálculo estrutural (década de 60), hoje é largamente aplicado em problemas de campo (calor, fluidos, campo elétrico e magnético). Algumas das análises que podem serem executadas por softwares de elementos finitos:

- estática linear de tensões e deformações (edifícios, pontes, torres, componentes mecânicos em geral, tubulações industriais,...);

- dinâmica (modos de vibração e frequências naturais);

- não linear de tensões e deformações (conformação, grandes deformações); 
- térmica (transmissão de calor em regime permanente e transiente);

- tensões devido ao carregamento térmico (tubulações industriais);

- escoamento de fluídos (aerodinâmica, hidrodinâmica);

- campos elétricos (condutores, isolantes, eletrodeposição e corrosão) e magnéticos.

\subsubsection{ANÁLISE DINÂMICA E ESTÁTICA}

As ações sobre as estruturas são em geral dinâmicas, devendo ser consideradas as forças de inércia associadas às acelerações a que cada um dos seus componentes fica sujeito. Por este motivo, seria de esperar que a análise de uma estrutura, obrigatoriamente, considera os efeitos dinâmicos. Contudo, em muitas situações é razoável considerar que os carregamentos são aplicados de um modo suficientemente lento, tornando desprezáveis as forças de inércia. Nestes casos a análise designa-se estática. Nesta publicação apenas são considerados problemas em que se supõem válidas as simplificações inerentes a uma análise estática.

\subsubsection{ANÁLISE NÃO LINEAR OU LINEAR}

$\mathrm{Na}$ análise de uma estrutura sólida, é habitual considerar que os deslocamentos provocados pelas ações exteriores são muito pequenos quando comparados com as dimensões dos componentes da estrutura. Nestas circunstâncias, admite-se que não existe influência da modificação da geometria da estrutura na distribuição dos esforços e das tensões, isto é, todo o estudo é feito com base na geometria inicial não deformada. Se esta hipótese não for considerada, a análise é designada não linear geométrica.

É também freqüente considerar que, do ponto de vista do material que constitui a estrutura, a relação entre tensões e deformações é linear. Nos casos em que esta simplificação 
não é considerada, é necessário recorrer a algoritmos específicos de análise não linear material.

Segundo NORTON (2004), dentro do processo de análise por elementos finitos, é definido como CAE o uso geral de ferramentas que permitem que qualquer combinação de equações seja codificada de forma conveniente, as quais posteriormente podem manipular o grupo de equações para diferentes valores dos dados exibindo convenientemente, os resultados de forma tabular e gráfica.

O modelo de elementos finitos é composto por elementos conectados entre si por nós formando a malha de elementos finitos, conforme a Figura abaixo.

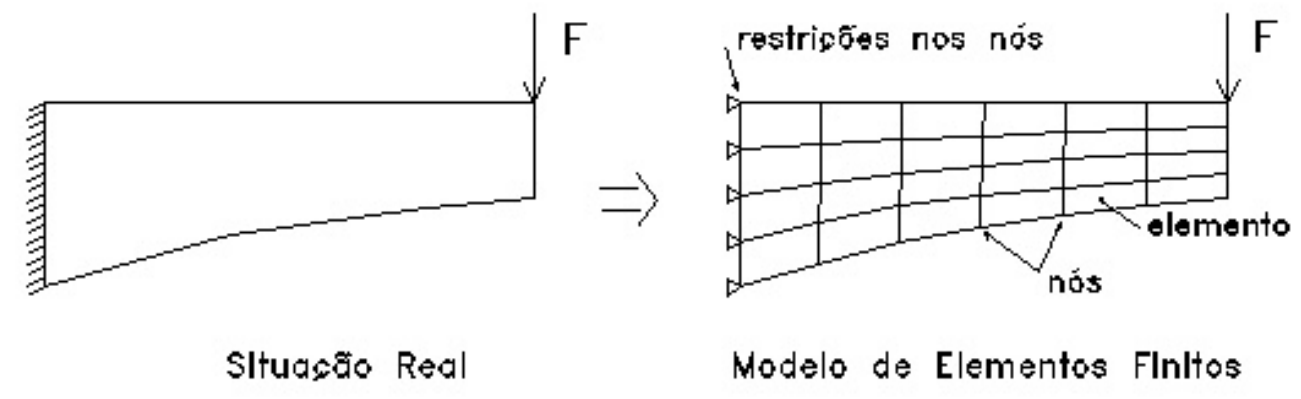

Figura 26 - Método dos elementos finitos (PCE Engenharia, 2007).

No caso de tensões/deformações cada nó pode possuir até 6 graus de liberdade (Degrees of Fredom) ou gdls (DOF's) em relação ao sistema de coordenadas cartesianas globais, dependendo do tipo de elemento. Um grau de liberdade é a possibilidade que um nó tem de rotacionar ou transladar em relação a um eixo coordenado.

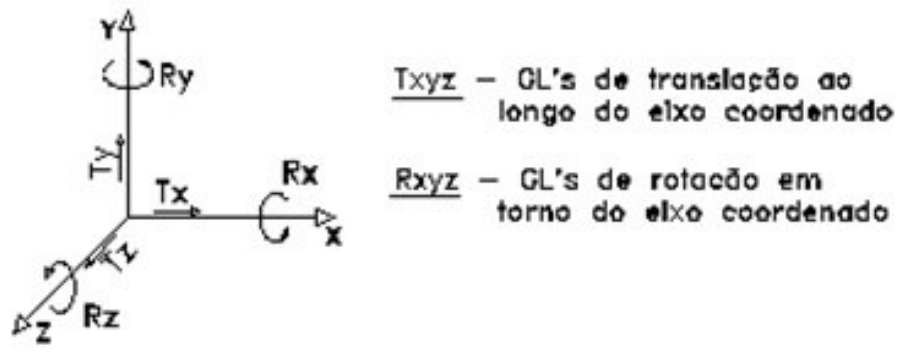

Figura 27 - Graus de liberdade (PCE Engenharia, 2006). 
As nove componentes de tensão que atuam sobre as superfícies deste elemento infinitesimal são: $\sigma_{\mathrm{xx}}, \sigma_{\mathrm{yy}}$ e $\sigma_{\mathrm{zz}}$ tensões normais, assim chamadas por que atuam, respectivamente, nas direções normais às superfícies $\mathrm{x}, \mathrm{y}$ e $\mathrm{z}$ do cubo. As componentes $\tau_{\mathrm{xy}} \mathrm{e}$

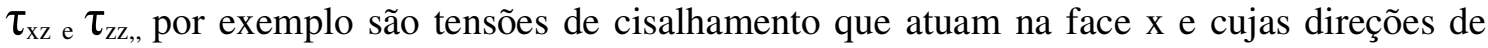
ação são paralelas aos eixos y e z, respectivamente. A matriz, nesse caso, apresenta configuração simétrica, na qual condição estas nove componentes são transformadas ou simplificadas em 6.

Os engenheiros civis foram os primeiros a utilizarem a análise por elementos finitos (FEA), conhecido como "Método de Análise Matricial de Estruturas". Dividir uma estrutura em elementos era quase natural nas estruturas em análise, principalmente em treliças e vigas rebitadas ou soldadas. A estrutura real é transformada matematicamente numa série de elementos do tipo "mola". A relação matemática que descreve força X deslocamento (Tensão x Deformação) são linearmente relacionadas pela lei de Hooke na região elástica da maioria dos materiais.

Considerando que, do ponto de vista de engenharia, a preocupação é projetar elementos de modo que os mesmos não falhem, e considerando que estas falhas ocorrem quando a tensão em algum ponto excede certo valor de segurança, é necessário encontrar as maiores tensões (tanto normal como de cisalhamento) que ocorrem em qualquer lugar no contínuo do material, dependendo do critério de falha utilizado para a análise.

\subsubsection{Pré-Processamento}

Basicamente o pré-processamento é realizado nas seguintes etapas:

- Modelamento: consiste no desenho em CAD da estrutura a ser calculada. Pode ser executado no próprio programa ou importado de outros CAD's. (figura 28) 


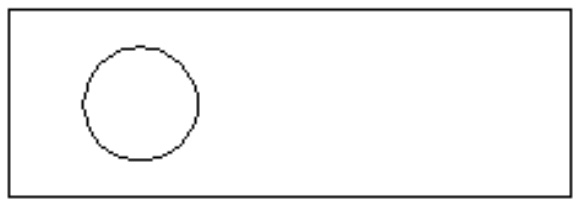

Figura 28 - Geração do modelo CAD (PCE Egenharia, 2007).

- Geração da malha de elementos finitos: Consiste na discretização da estrutura, ou seja, a sua divisão em elementos conectados por nós. (figura 29)

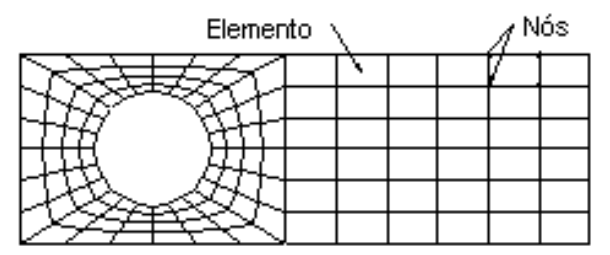

Figura 29 - Geração da malha (PCE Egenharia, 2007).

- Definição das condições de contorno e restrições - definem como a estrutura se relaciona com o meio em que está situada através de fixações e disposição das cargas. Neste mesmo conceito, define-se por carregamentos: as solicitações as quais a estrutura está submetida (Forças nodais, pressões, momentos, carga térmica, etc.) conforme mostrado na figura30.

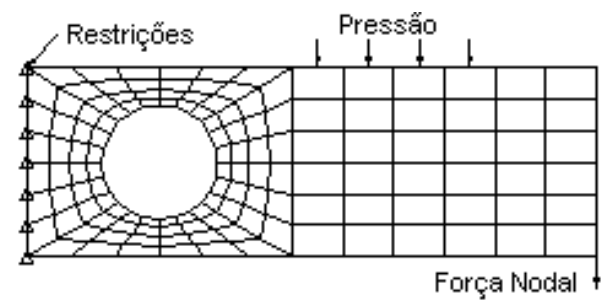

Figura 30 - Restrições e carregamentos (PCE Egenharia, 2007).

- Propriedades do material - Definição das características físicas do material a ser utilizado na estrutura. Módulo de Elasticidade, densidade, coeficiente de Poisson. 


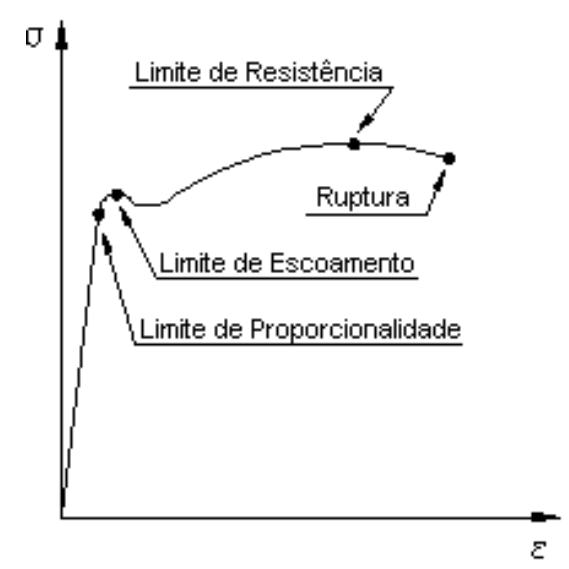

Figura 31 - Exemplo de comportamento de material (PCE Egenharia, 2007).

\subsubsection{Processamento}

Consiste na etapa de cálculo da matriz de rigidez, cálculo dos deslocamentos nodais e tensões. É uma etapa que, embora na maior parte das vezes seja “invisível” ao usuário, é a mais importante na solução do problema, uma vez que é a etapa na qual são realizados todos os cálculos.

\subsubsection{Pós- Processamento}

Nesta etapa podem ser visualizados os resultados globais da estrutura deformada, ou mesmo os deslocamentos individuais de cada nó. As tensões podem ser visualizadas na forma gráfica, em termos de direções principais, valores máximos e mínimos, Von Mises, ou outros. Podem ser visualizadas as regiões de maior concentração de tensões, que durante a vida útil da estrutura estarão mais propensas a apresentarem falhas (permitindo escolher futuros pontos de inspeção).

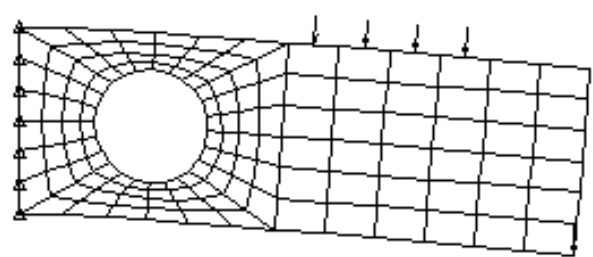

Figura 32 - Exemplo de resultados de deslocamentos (PCE Egenharia, 2007). 


\section{MATERIAIS E MÉTODOS}

\subsection{MATERIAIS}

Neste trabalho será utilizado material ABS P400, utilizado na máquina de prototipagem rápida FDM - 8000, da empresa americana Stratasys ${ }^{\circledR}$, com capacidade volumétrica de 457 x 457 × $609 \mathrm{~mm}$. Os dados gerados pelo sistema $C A D$ no formato $S T L$ foram interpretados pelo programa Insight ${ }^{\circledR}$ também desenvolvido pela mesma empresa. As análises pelo método dos elementos finitos foram realizadas no pacote ANSYS, versão 7.0. Os modelos CAD tridimensionais foram desenvolvidos no pacote SolidEdge v16.

\subsection{MÉTODOS}

Para uma análise adequada dos efeitos das diferentes trajetórias de preenchimento nas propriedades mecânicas do protótipo, optou-se por caracterizar o material utilizando ensaios de tração com diferentes trajetórias de preenchimento: longitudinal $\left(0^{\circ}\right)$, transversal $\left(90^{\circ}\right)$ e transversal $\left(+-45^{\circ}\right)$. Os resultados obtidos foram utilizados para validar também a ferramenta de simulação computacional utilizada. As propriedades mecânicas obtidas foram utilizadas posteriormente em dois estudos de caso: ensaio de flexão com diferentes orientações das trajetórias e componente real (válvula), ambos descritos capítulo 5. 


\subsubsection{Processamento EXPERIMENTAL}

Para a confecção dos corpos de prova $(\mathrm{CP})$ na máquina de prototipagem rápida, adotaram-se as especificações da norma ASTM D638-96 e ASTM D790-96a, para os testes de tração e flexão, respectivamente. Os CP's de tração adotados são do Tipo I, cujas dimensões estão mostradas na Figura 32. Para os CP's de flexão adotou-se o método de teste I (carregamento a três pontos) com a relação $\mathrm{L} / \mathrm{d}=16$, sendo que $\mathrm{L}$ é o comprimento do vão entre os apoios do CP e d é a espessura do corpo de prova. As dimensões do CP de flexão são mostradas na Figura 34.

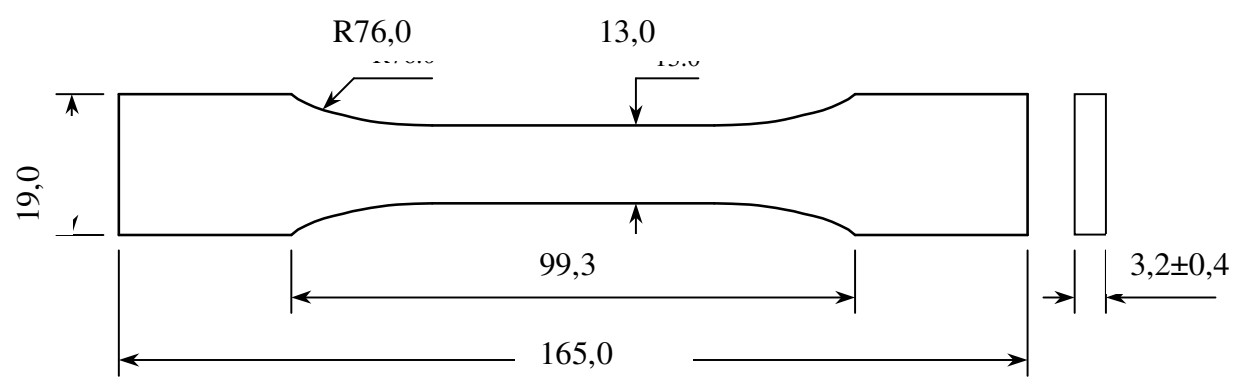

Figura 33 - Dimensões em milímetros do corpo de prova de tração - Tipo I (ASTM D638-96).

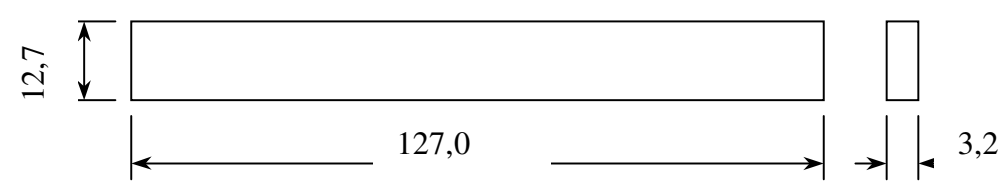

Figura 34 - Dimensões em milímetros do corpo de prova de flexão - Método I (ASTM D790-96a).

Para a confecção dos Corpos de Prova (CP's) foram utilizados os seguintes parâmetros de máquina: bico T16 ( 0,016 pol), espessura de camada de 0,3556, 9 camadas sucessivas para se atingir a espessura de $3,2 \mathrm{~mm}$. 
O carregamento aplicado foi de 100 N. Os resultados são mostrados na tabela 4.

Tabela 4 - Valores encontrados nos ensaios de tração dos protótipos.

\begin{tabular}{lc}
\hline \multicolumn{1}{c}{ PROPRIEDADES } & RESULTADOS \\
\hline Resistência à Tração no Limite de Escoamento [MPa] - $0^{\circ}$ & $21,5 \pm 0,3$ \\
Módulo de Elasticidade [GPa] - $0^{\circ}$ & $1,9 \pm 0,2$ \\
Resistência à Tração no Limite de Escoamento [MPa] - 90 & $14,5 \pm 0,3$ \\
Módulo de Elasticidade [GPa] - 90 & $1,7 \pm 0,2$ \\
Resistência à Tração no Limite de Escoamento [MPa] - +-45 & $17,5 \pm 0,3$ \\
Módulo de Elasticidade [GPa] - $+-45^{\circ}$ & $1,5 \pm 0,2$ \\
\hline
\end{tabular}

\subsubsection{Processamento NUMÉRICO}

O mesmo ensaio de tração foi simulado por elementos finitos, visando validar o procedimento adequado para modelagem das laminas no sistema. Os corpos de prova forma simulados utilizando o elemento com características ortotrópicas que possibilita a entrada das diferentes camadas do laminado. Os resultados são mostrados numericamente na Tabela 6 e graficamente nas Figuras 38, 39, 40, 41, 42 e 43, indicando uma boa concordância com aqueles obtidos experimentalmente.

Tabela 5 - Valores encontrados nas simulações dos ensaios de tração dos protótipos.

\begin{tabular}{lcc}
\hline \multicolumn{1}{c}{ PROPRIEDADES } & Experimentais & Numéricos \\
\hline Módulo de Elasticidade [GPa] $-0^{\circ}$ & $1,9 \pm 0,2$ & 2,10 \\
Módulo de Elasticidade [GPa] $-90^{\circ}$ & $1,7 \pm 0,2$ & 1,88 \\
Módulo de Elasticidade [GPa] $-+-45^{\circ}$ & $1,5 \pm 0,2$ & 1,48 \\
\hline
\end{tabular}




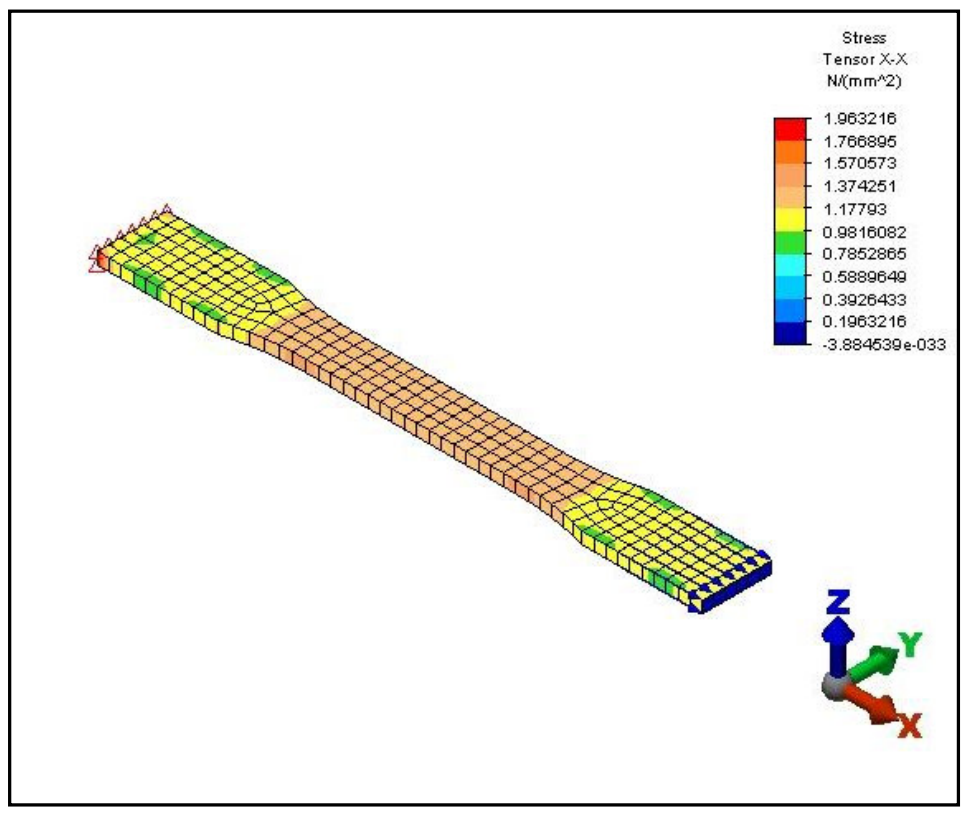

Figura 35 - Estado de tensões (direção axial) para trajetórias a $0^{\circ}$.

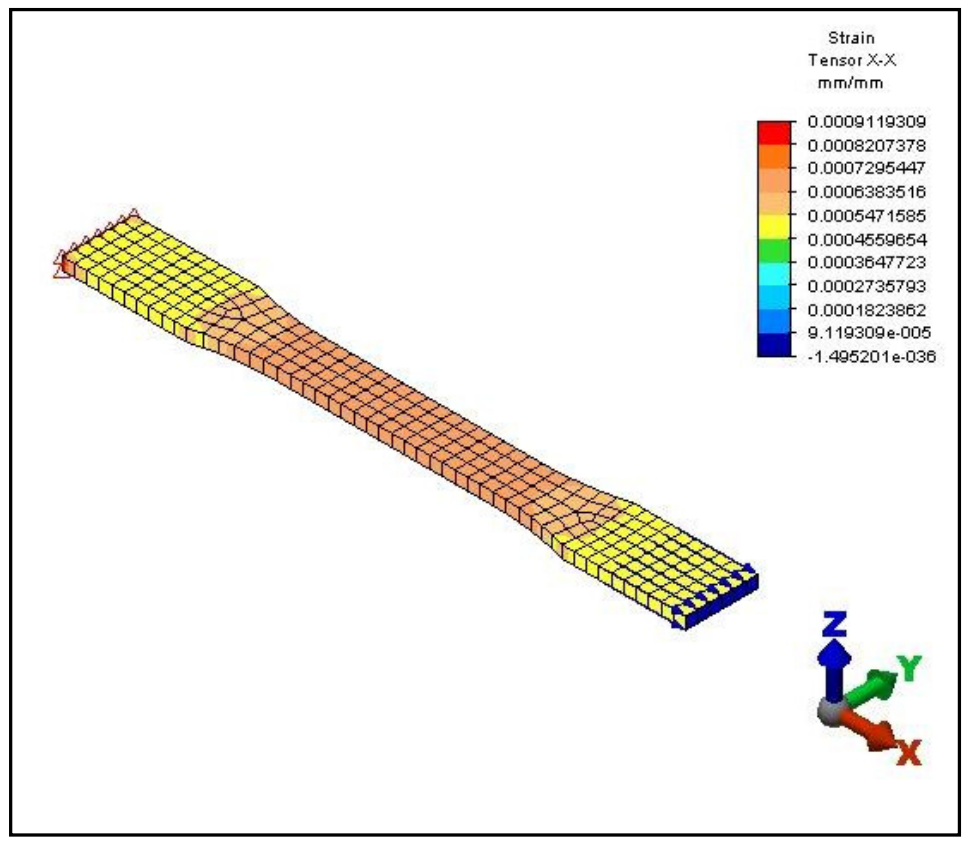

Figura 36 - Estado de deformações (axial) para trajetórias a $0^{\circ}$. 


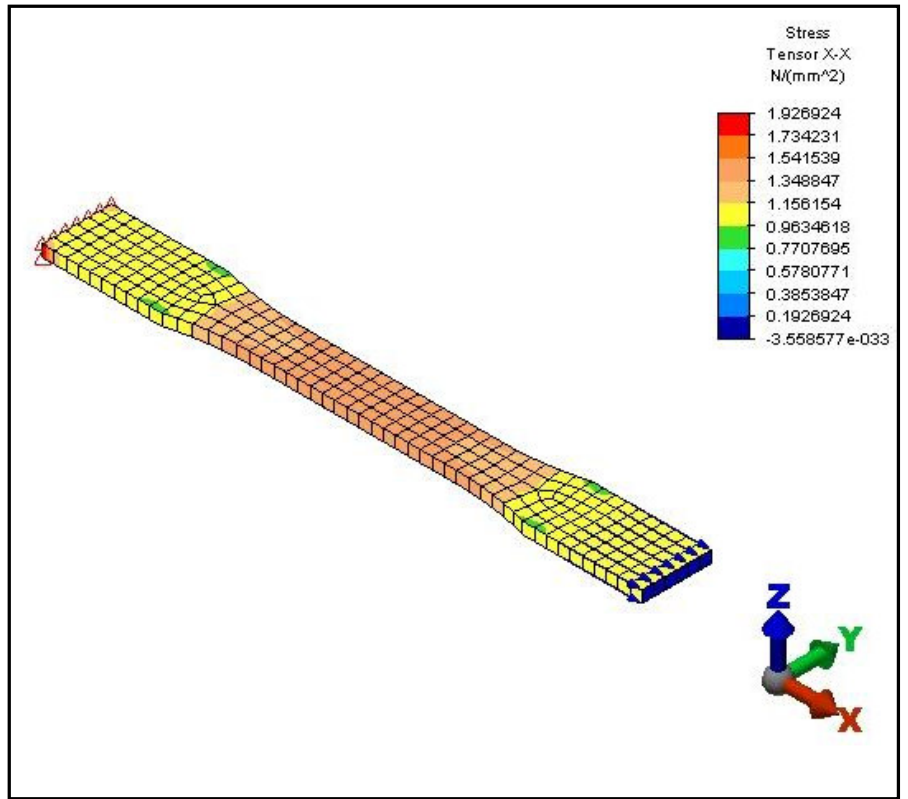

Figura 37 - Estado de tensões ( direção axial) para trajetórias a 90.

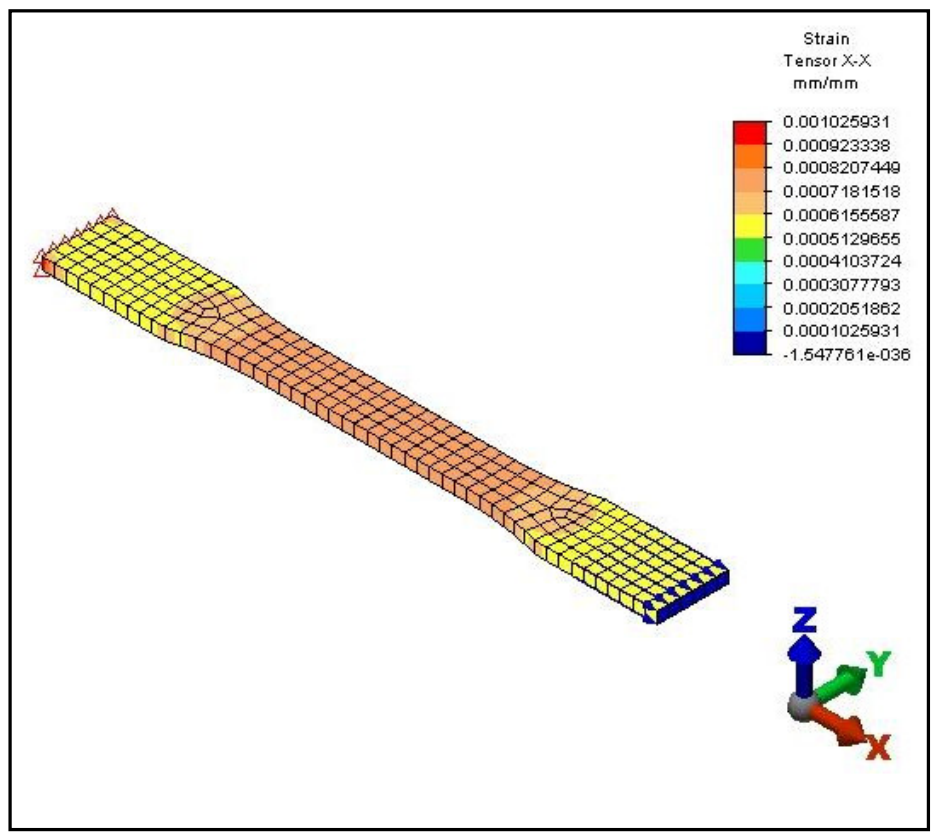

Figura 38 - Estado de deformações (axial) para trajetórias a $90^{\circ}$. 


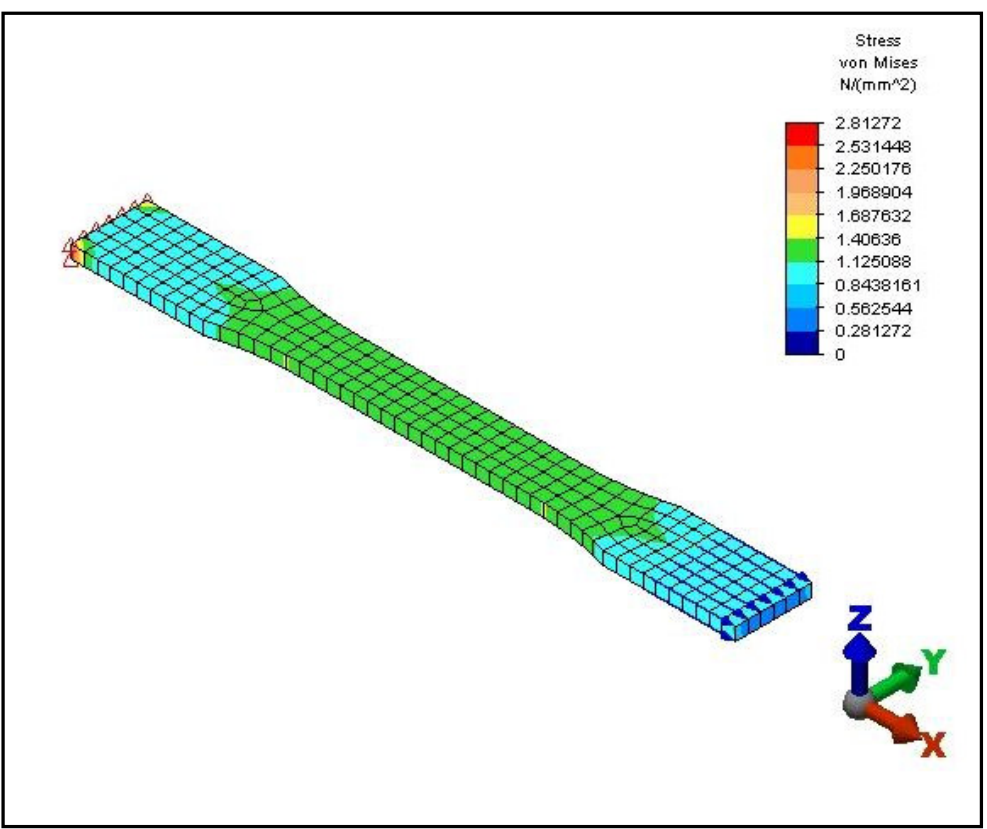

Figura 39 - Estado de tensões (direção axial) para trajetórias a $+-45^{\circ}$.

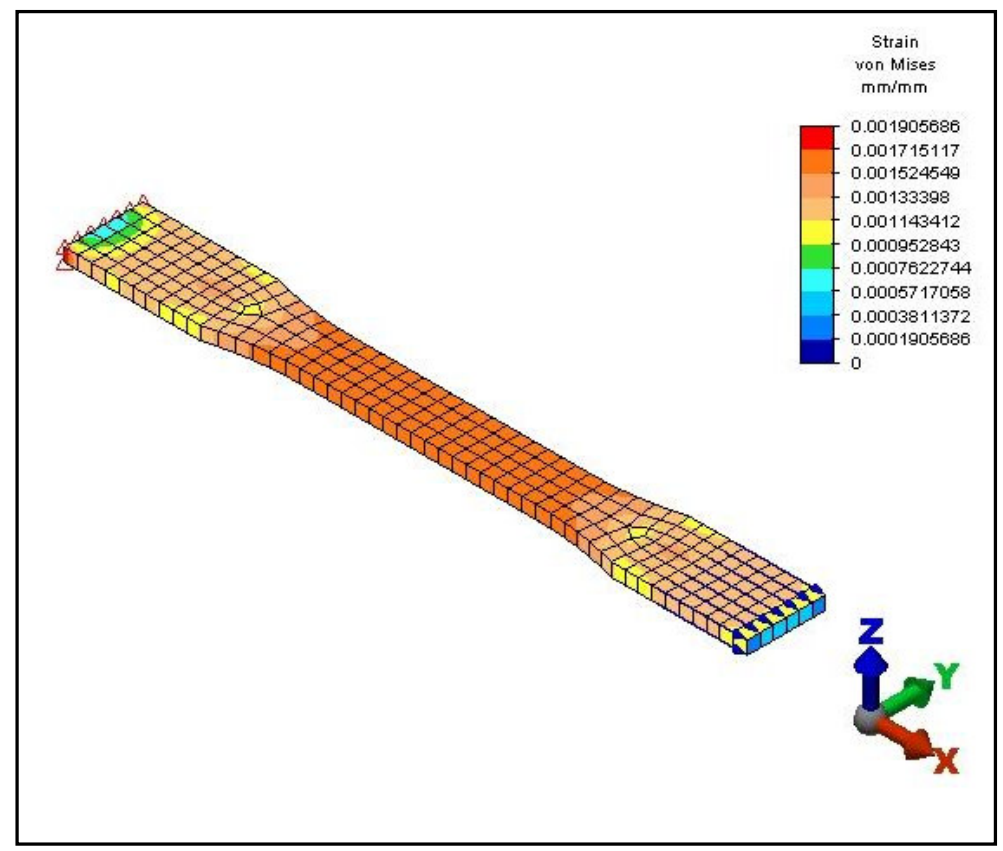

Figura 40 - Estado de deformações (axial) para trajetórias a +-45 . 


\section{ESTUDOS DE CASO}

Neste capítulo é abordada a realização dos ensaios computacionais de flexão a três pontos realizados nos corpos de prova com material ABS configurados em suas respectivas construções com as seguintes orientações descritas na tabela 6 para a sobreposição das camadas. Os mesmos corpos de prova confeccionados na máquina FDM8000 foram ensaiados segundo a norma ASTM D790-96 ${ }^{\mathrm{a}}$, conforme descrito no capítulo anterior, e os resultados tabelados em termos comparativos com os numéricos, conforme a tabela 5. Seguindo a metodologia de HUEBNER; THORNTON \& BYRON (1995) o problema foi dividido seguindo as etapas para a utilização do método dos elementos finitos: etapas de modelamento da geometria, modelagem matemática e criação da malha (pré-processamento) e de solução e etapa final de pós-processamento. Nestas análises utilizou-se o software ANSYS $^{\circledR}$ versao 7. Os resultados apresentados são as cargas (figuras 44, 46 e 48) e deslocamentos nodais (figuras 45, 47 e 49) do corpo de prova.

\subsection{CoRPo de Prova CP01}

Tabela 6: Especificações e Resultados Corpo de Prova CP01

\begin{tabular}{|l|l|l|l|l|l|l|}
\hline Material & Orientação & Carregamento & $\begin{array}{l}\text { Mód. } \\
\text { Elasticidade }\end{array}$ & Coef poisson & $\begin{array}{l}\text { Mod. } \\
\text { Cisalhamento }\end{array}$ & $\begin{array}{l}\text { Tensão } \\
\text { máxima }\end{array}$ \\
\hline ABS & Longitudinal & $100 \mathrm{~N}$ normal & $\mathrm{E} 12=1960$ & $\mathrm{v} 12=0,3200$ & $\mathrm{G} 12=552$ & 19,73 \\
\hline & ao eixo X $\left(0^{\circ}\right)$ & à superfíce & $\mathrm{E} 13=1710$ & $\mathrm{v} 13=0,2791$ & $\mathrm{~N} / \mathrm{mm}^{2}$ & $\mathrm{~N} / \mathrm{mm}^{2}$ \\
\hline & & $\mathrm{N} / \mathrm{mm}^{2}$ & & & \\
\hline
\end{tabular}

Sistema de Coordenadas: Global X $(\mathrm{X}, \mathrm{Y}, \mathrm{Z})$ 


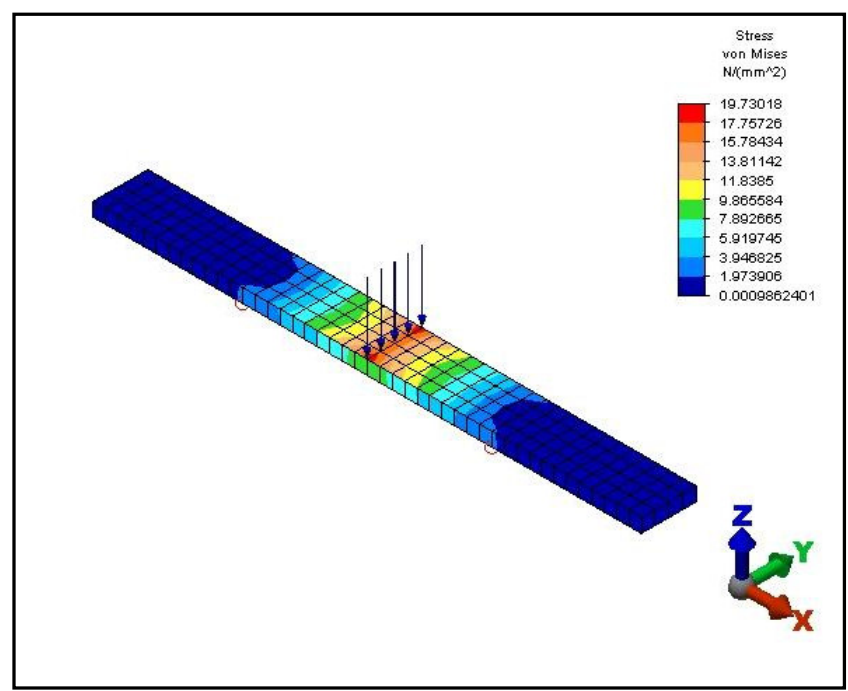

Figura 41 - Máxima tensão para CP01

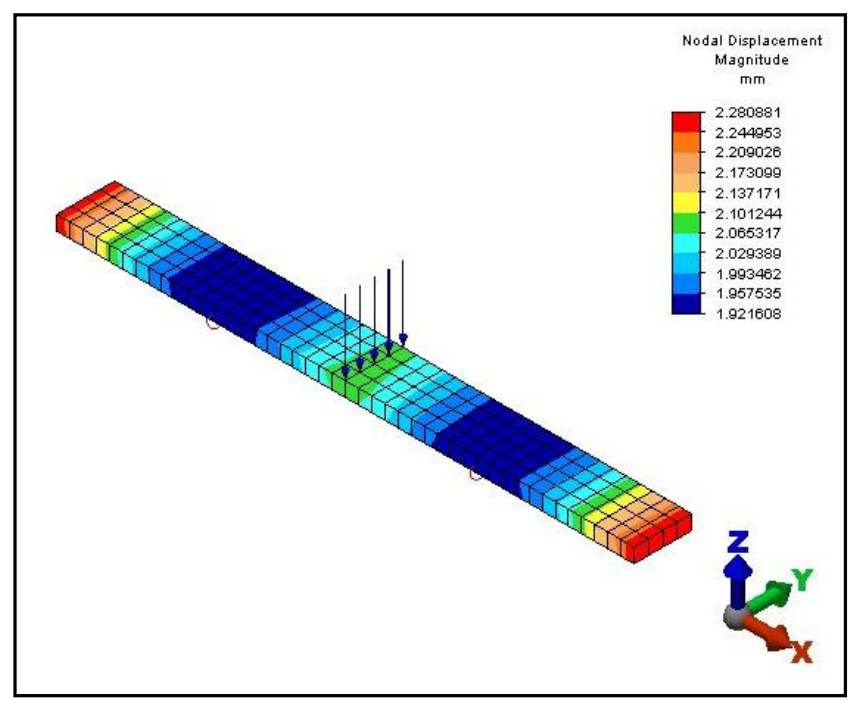

Figura 42 - Máximo deslocamento para CP01

\subsection{Corpo de Prova CP02}

Tabela 7: Especificações e Resultados Corpo de Prova CP02

\begin{tabular}{|l|l|l|l|l|l|l|}
\hline Material & Orientação & Carregamento & $\begin{array}{l}\text { Mód. } \\
\text { Elasticidade }\end{array}$ & Coef poisson & $\begin{array}{l}\text { Mod. } \\
\text { Cisalhamento }\end{array}$ & $\begin{array}{l}\text { Tensão } \\
\text { máxima }\end{array}$ \\
\hline ABS & Transversal & $100 \mathrm{~N}$ normal & $\mathrm{E} 12=1960$ & $\mathrm{v} 12=0,4391$ & $\mathrm{G} 12=554$ & 19,32 \\
\hline & eixo X $\left(90^{\circ}\right)$ & à superfíce & $\mathrm{E} 13=1710$ & $\mathrm{v} 13=0,2707$ & $\mathrm{~N} / \mathrm{mm}^{2}$ & $\mathrm{~N} / \mathrm{mm}^{2}$ \\
\hline & & $\mathrm{N} / \mathrm{mm}^{2}$ & & & \\
\hline $\begin{array}{l}\text { Máximo deslocamento (teórico): 1,403 } \mathrm{mm} \\
\text { Máximo deslocamento (experimental): } 1,50 \mathrm{~mm}\end{array}$ & & & & \\
\hline
\end{tabular}

Sistema de Coordenadas: Global X (X,Y,Z) 


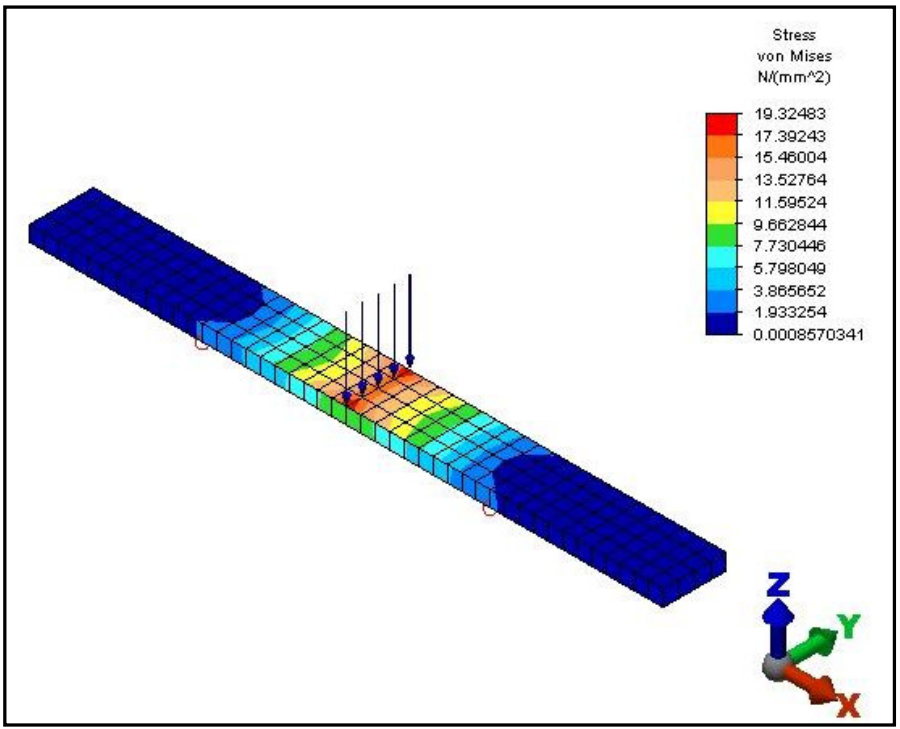

Figura 43 - Máxima tensão para CP02

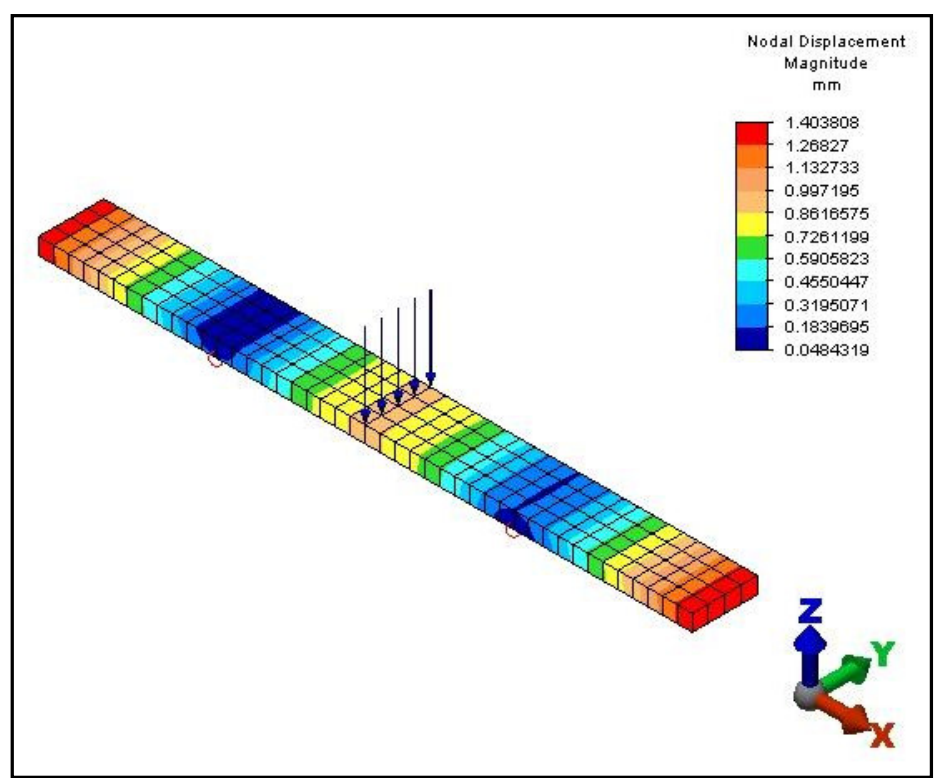

Figura 44 - Máximo deslocamento para CP02 


\subsection{Corpo de Prova CP03}

Tabela 8: Especificações e Resultados Corpo de Prova CP03

\begin{tabular}{|l|l|l|l|l|l|l|}
\hline Material & Orientação & Carregamento & $\begin{array}{l}\text { Mód. } \\
\text { Elasticidade }\end{array}$ & $\begin{array}{l}\text { Coef } \\
\text { poisson }\end{array}$ & $\begin{array}{l}\text { Mod. } \\
\text { Cisalhamento }\end{array}$ & $\begin{array}{l}\text { Tensão } \\
\text { máxima }\end{array}$ \\
\hline ABS & Combinada & $100 \mathrm{~N}$ normal & $\mathrm{E} 12=1478$ & $\mathrm{v} 12=04391$ & $\mathrm{G} 12=554$ & 17,08 \\
\hline & $45^{\circ},-45^{\circ}$ & à superfíce & $\mathrm{E} 13=1478$ & $\mathrm{v} 13=02707$ & $\mathrm{~N} / \mathrm{mm}^{2}$ & $\mathrm{~N} / \mathrm{mm}^{2}$ \\
\hline & & $\mathrm{N} / \mathrm{mm}^{2}$ & & & \\
\hline $\begin{array}{l}\text { Máximo deslocamento (teórico): } 1,507 \mathrm{~mm} \\
\text { Máximo deslocamento (experimental): } 1,60 \mathrm{~mm}\end{array}$ & & & & \\
\hline
\end{tabular}
Sistema de Coordenadas: Global X $(\mathrm{X}, \mathrm{Y}, \mathrm{Z})$

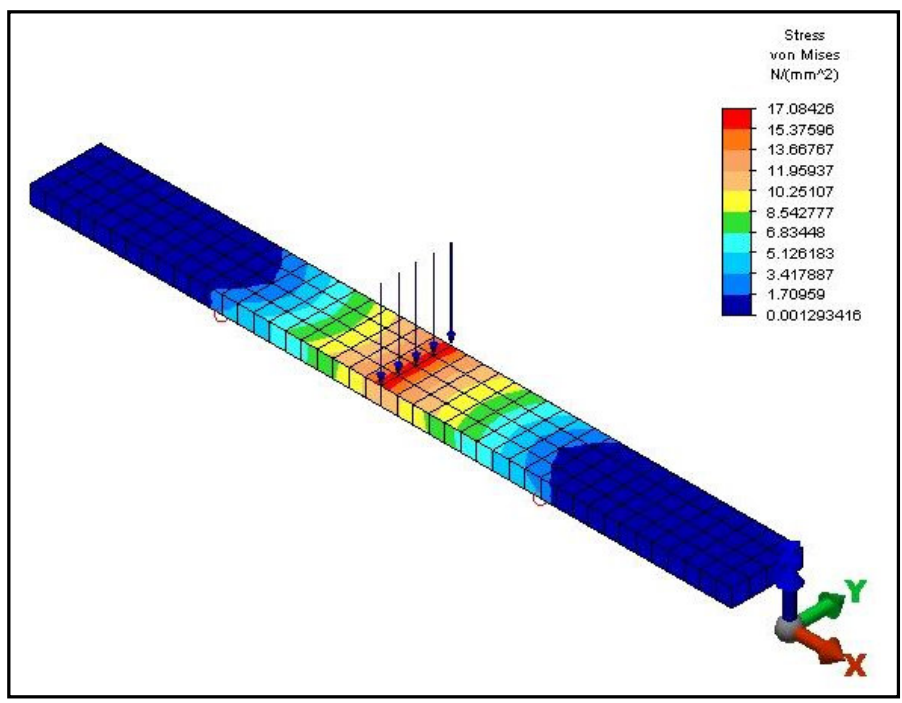

Figura 45 - Máxima tensão para CP03

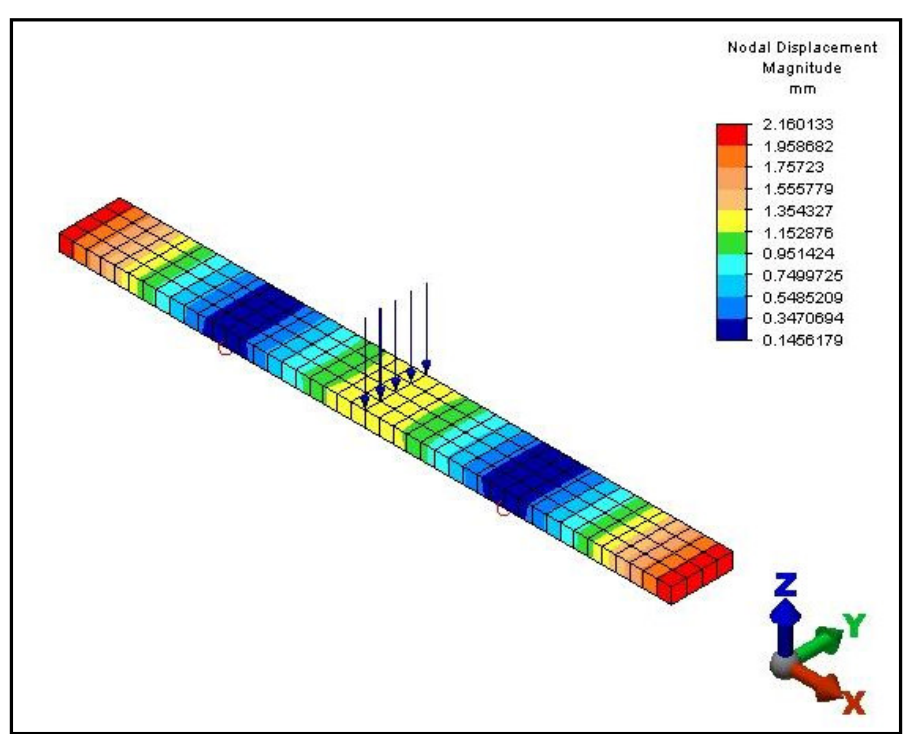

Figura 46 - Máximo deslocamento para CP03 
A partir destes ensaios realizados e confrontados com os ensaios físicos com as peças prototipadas em processo FDM, pode-se observar:

- Os maiores valores referentes às tensões máximas obtidas são observados nas peças com orientação longitudinal à "fibra", o que demonstra que os resultados se aproximam dos ensaios reais para a teoria de laminados em materiais ortotrópicos compósitos, diferenciando o material e forma de construção de protótipos por processo FDM de materiais convencionalmente utilizados e denominados isótropos em outros processos como injeção por molde.

- A construção das peças prototipadas com orientação combinada somente se mostra favorável para aplicação em peças com tensões aplicadas em diversas regiões e / ou em ângulos diferentes. As peças com orientação transversal, ou seja, $90^{\circ}$ em relação à extensão longitudinal da peça se mostraram consideravelmente mais frágeis se comparadas às peças com orientação de $0^{\circ}$.

\subsection{AlavanCA DE ACIONAMENTO}

Também com o intuito de demonstrar a funcionalidade dos protótipos em condições reais, foram realizados ensaios computacionais em uma alavanca de uma válvula de controle (figura 50), de fluxo com centro esférico, em toda o esforço para abertura e fechamento está concentrado na região externa da haste bem como nos pontos de apoio para fechamento. Desta forma, a peça foi vinculada na sua parte inferior e as cargas aplicadas na região de empunhadura para simular sua operação em que pode-se verificar a situação de torção do material: 
Aplicação: Válvula controladora de fluxo para sistemas hidrostáticos.

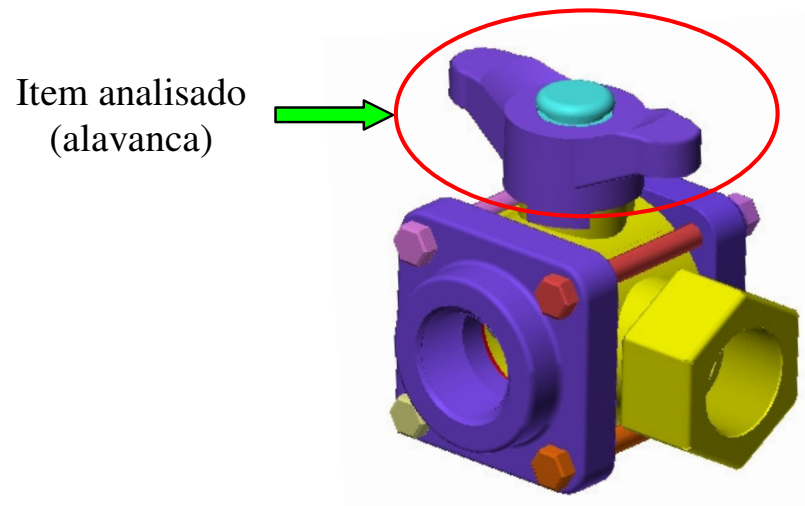

Figura 47 - Conjunto Válvula.

\subsubsection{Alavanca da Válvula, configuração V01}

Tabela 9: Especificações e Resultados Alavanca V01

\begin{tabular}{|l|l|l|l|l|l|l|}
\hline Material & Orientação & Carregamento & $\begin{array}{l}\text { Mód. } \\
\text { Elasticidade }\end{array}$ & $\begin{array}{l}\text { Coef } \\
\text { poisson }\end{array}$ & $\begin{array}{l}\text { Mod. } \\
\text { Cisalhamento }\end{array}$ & $\begin{array}{l}\text { Tensão } \\
\text { máxima }\end{array}$ \\
\hline ABS & Longitudinal ao & $100 \mathrm{~N}$ normal & $\mathrm{E} 12=1710$ & $\mathrm{v} 12=0,4391$ & $\mathrm{G} 12=552$ & 32,18 \\
\hline & Eixo X $\left(0^{\circ}\right)$ & às superfíces de & $\mathrm{E} 13=1960$ & $\mathrm{v} 13=0,2707$ & $\mathrm{G} 13=552$ & $\mathrm{~N} / \mathrm{mm}^{2}$ \\
\hline & & rotação funcional & $\mathrm{E} 23=1360$ & $\begin{array}{l}\mathrm{V} 23= \\
0,3209\end{array}$ & $\mathrm{G} 23=369,6$ & \\
\hline & & $\mathrm{N} / \mathrm{mm}^{2}$ & & $\mathrm{~N} / \mathrm{mm}^{2}$ & \\
\hline
\end{tabular}

Sistema de Coordenadas: Global Z (Z,X,Y)

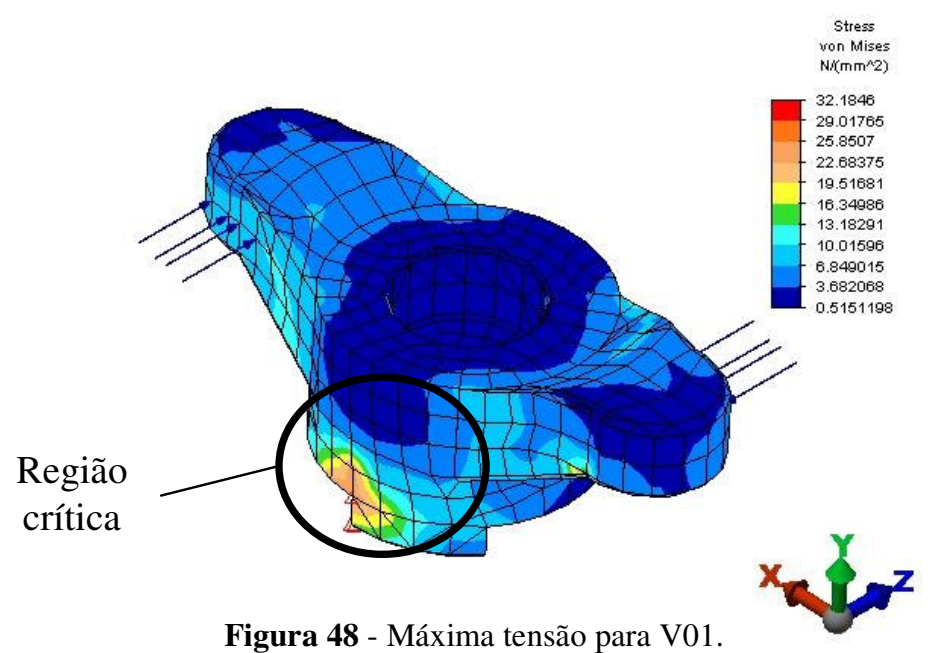

Figura 48 - Máxima tensão para V01. 


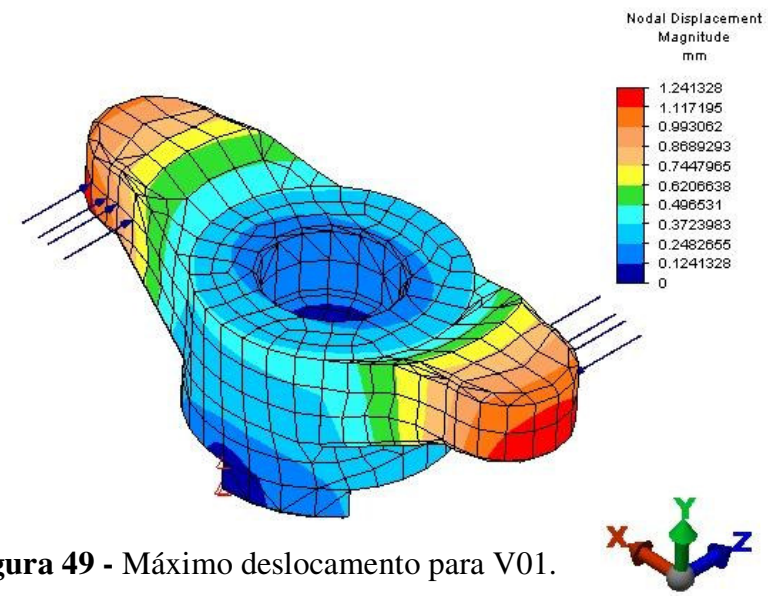

Figura 49 - Máximo deslocamento para V01.

\subsubsection{Alavanca da Válvula, configuração V02}

Tabela 10: Especificações e Resultados Alavanca V02

\begin{tabular}{|l|l|l|l|l|l|l|}
\hline Material & Orientação & Carregamento & $\begin{array}{l}\text { Mód. } \\
\text { Elasticidade }\end{array}$ & Coef poisson & $\begin{array}{l}\text { Mod. } \\
\text { Cisalhamento }\end{array}$ & $\begin{array}{l}\text { Tensão } \\
\text { máxima }\end{array}$ \\
\hline ABS & Combinada & 100 N normal & $\mathrm{E} 12=1478$ & $\mathrm{v} 12=0,2791$ & $\mathrm{G} 12=360$ & 30,38 \\
\hline & $45^{\circ},-45^{\circ}$ & às superfíces de & $\mathrm{E} 13=1478$ & $\mathrm{v} 13=0,3209$ & $\mathrm{G} 13=360$ & $\mathrm{~N} / \mathrm{mm}^{2}$ \\
\hline & rotação funcional & $\mathrm{E} 23=1360$ & $\mathrm{~V} 23=0,4391$ & $\mathrm{G} 23=369,6$ & \\
\hline & & $\mathrm{N} / \mathrm{mm}^{2}$ & & $\mathrm{~N} / \mathrm{mm}^{2}$ & \\
\hline
\end{tabular}

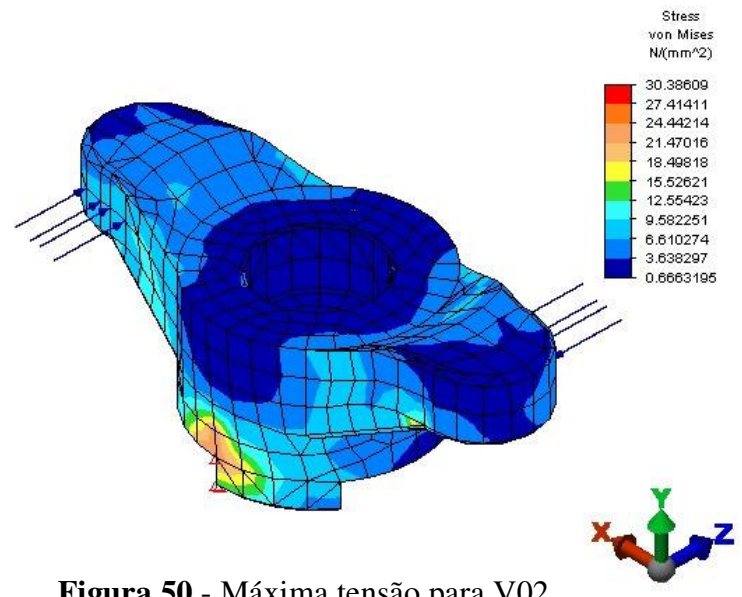

Figura 50 - Máxima tensão para V02. 


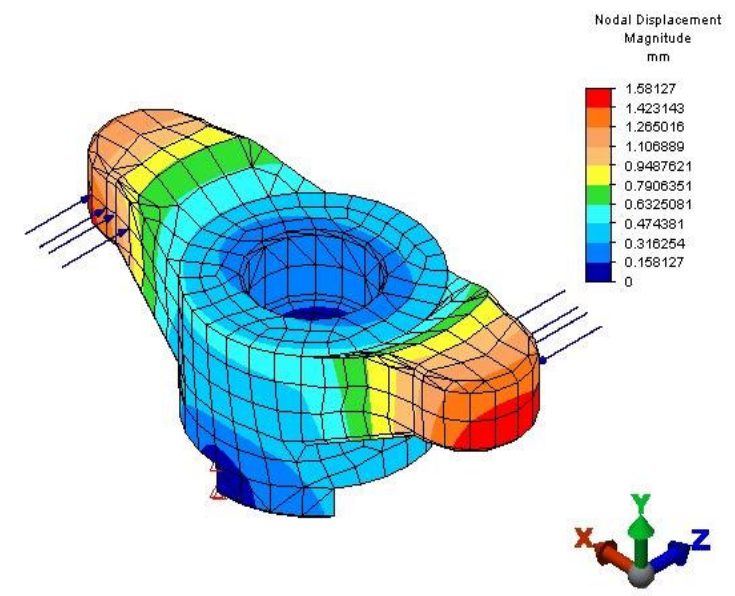

Figura 51 - Máximo deslocamento para V02.

Como conseqüência da manufatura por camada nas peças analisadas, as mesmas apresentam comportamento ortotrópico no material. Observa-se desta maneira que o caminho das linhas de material depositado e formato da peça interagem como uma ação de fortalecimento, afetando as propriedades e a performance do produto acabado.

Assim também, pode-se constatar que as propriedades das peças finais dependem consideravelmente de duas importantes fases, escolha da orientação e escolha do caminho de preenchimento das camadas, o que valida o procedimento de análise proposto neste trabalho. 


\section{CONCLUSÕES E SUGESTÕES}

\subsection{CONCLUSÕES}

Inicialmente, ressalta-se que os objetivos propostos no trabalho foram alcançados com resultados satisfatórios. Com relação aos objetivos inicialmente propostos, verificou-se que:

- o modelo de material ortotrópico utilizado para a análise do protótipo rápido produzido pela tecnologia FDM conduziu a bons resultados na análise, confirmando a observação já feita anteriormente por diversos outros autores. Isto já era esperado, uma vez que o próprio processo de extrusão do fio de $\mathrm{ABS}$, utilizado no processo FDM, induz ao aparecimento de um certo grau de anisotropia no material;

- pode-se utilizar a teoria clássica dos laminados para a análise numérica do material produzido, desde que observadas suas limitações, ou seja, a consideração de estado plano de tensões. Para componentes nas quais a componente de tensão fora do plano apresentar valores não negligenciáveis, embora não testado neste trabalho, os resultados numéricos poderão divergir dos experimentais;

- a utlização de diferentes trajetórias de preenchimento das camadas quando do projeto do protótipo fornece ao projetista um importante grau de liberdade quando do projeto de protótipos funcionais, utilizando por exemplo a Teoria Clássica dos Laminados (TCL). O uso criterioso das ferramentas de análise utilizadas possibilita que sejam obtidos prototipos funcionais que atendam adequadamente os requisitos de desempenho estrutural.

Dessa forma, conclue-se que a estratégia de otimização utilizada neste trabalho, a qual baseou-se em critérios de orientação segundo à teoria clássica dos laminados, representa 
uma importante contribuição ao projeto de protótipos funcionais, conduzindo a uma redução de custos e à produção de peças finais ( Manufatura rápida).

Em função do que foi apresentado, fica evidente a importância das tecnologias de prototipagem e ferramental rápido nos processos de desenvolvimento de produtos. A possibilidade de resultados rápidos para a análise e testes funcionais fornecem ao projetista uma vantagem competitiva em relação à concorrência pela considerável redução de tempo de desenvolvimento, custos e melhoria da produtividade. Neste contexto, ressalta-se a importância da análise criteriosa dos parâmetros dos diferentes processos, bem como o desenvolvimento de metodologias adequadas para a obtenção de protótipos que satisfaçam os requisitos estruturais de sua aplicação.

\subsection{SUGESTÕES PARA TRABALHOS FUTUROS}

Algumas sugestões para continuidade deste tema de pesquisa seriam:

- poder-se-ia trabalhar em termos de software para geração dos dados da máquina, possibilitando que numa mesma camada sejam utilizadas diferentes estratégias de preenchimento;

- uma vez desenvolvido o item anterior pode-se-ia desenvolver algoritmos de integração que possibilitassem a geração dos dados de material diretamente para o programa de elementos finitos, facilitando assim o trabalho de entrada de dados.

- estudar e implementar modelos de comportamento de material que modelem melhor o estado de tensões nos protótipos do que a teoria clássica dos laminados. Diversos modelos têm sido propostos na literatura, seria interessante que se estudassem os mais promissores e adequados para o uso na simulação de protótipos. 


\section{REFERÊNCIAS BIBLIOGRÁFICAS}

ADLER, DEBBIE. Rapid Prototyping Center. Histoy of RPC. Disponível em <http:// www.rpc.msoe.edu/history.php. Acesso em: 24 out 2005.

ANG , K.C.; LEONG K.F.; CHUA C.K. (2006). Investigation of the mechanical properties and porosity relationships in fused deposition modeling-fabricated porous structures. Rapid Prototyping Journal v. 12 .n 2. p.100-105.

AHN , S. H.; MONTERO, M.; ODELL, D.; ROUNDY, S.; WRIGHT, P. K. (2002). Anisotropic material properties of fused deposition modeling ABS. Rapid Prototyping Journal v. 08 .n 2. p.248-257.

BELLINI, A.; GUCERI, S. (2003). Mechanical characterization of parts fabricated using fused deposition modeling. Rapid Prototyping Journal. v. 9. n 4. p 252-264.

CAMARGO, DANIEL R.; SAKAI, RODRIGO M. R.; SAURA, CARLOS E.; SILVA, JORGE V. L.; CUNHA, FRANSÉRGIO L.; CLIQUET JR.; ALBERTO. Uso de Prototipagem Rápida na Concepção de uma Prótese Multifunção para membros Superiores. $3^{\circ}$ Congresso IberoAmericano IBERDISCAP. San José, C. R. 2004, p.238-243. ISBN 9968-31-335-1.

CARVALHO, J. Prototipagem rápida. Disponível em: < http://www.numa.org.br/conhecimentos_port/pag_conhec/prototipagem.html./>. Acesso em: 17 jun. 2005.

CRUZ, FERNANDO. (2005). Prototipagem Rápida Instituto Politécnico de Setúbal. Escola Superior de Tecnologia de Setúbal. Departamento de Engenharia Mecânica. Disponível em $<$ http://www.si.ips.pt. Acesso em: 17 jun. 2005

DOLENC, A. AND MÄKALÄ, I. (1994), Slicing procedure for layered manufacturing techniques, Computer Aided Design, Vol. 26 No. 2, pp. 119-26. 
DORF, R. C.; KUSIAK, A. Handbook of design, manufacturing and automation. ed. Wiley-Interscience Publication. New York. 1994. p. 23-171, 801-843.

FERREIRA, J. et al. Desenvolvimento integrado do produtos e ferramentas por metodologias de engenharia reversa e técnicas de prototipagem rápida. $3^{\circ}$ Congresso Brasileiro de Gestão de Desenvolvimento de Produto Florianópolis, SC - 25-27 Setembro de 2001, Disponível em: <http://www.ctc.ufsc.br/produto/Produto1/artigos/artigo4.pdf>. Acesso em: 17 jun. 2005.

FOGgiatto, JosÉ A., AHRENS, CARLOS H., SALMORIA, GEAN V. et al. Moldes de ABS construídos pelo processo de modelagem por fusão e deposição para injeção de PP e PEBD. Polímeros, Dez 2004, vol.14, no.5, p.349-353. ISSN 0104-1428

GRAY, ROBERT W.; BAIRD, DONALD G.; BOHN, JAN HELGE. (1998). Effects of processing conditions on short TLCP fiber reinforced FDM parts. Rapid Prototyping Journal, v.4, n.1, p.14-15.

GORNI, AUGUSTO A. Introdução a prototipagem rápida. Plástico Industrial. p. 230-239. Março 2001. Disponível em: <http://www.gorni.eng.br/protrap.html>. Acesso em 19 jun. 2005 .

GRIMM, TODD. (2003). Rapid Prototyping Benchmark.T. A. Grimm \& Associates Inc. Technical Report. 57p

HUBINGER, ALEXANDRE Z. Rapid Prototyping - Concepts, Techniques, Applications and Future Trends. $15^{\circ}$ Congresso Brasileiro de Engenharia Mecânica. Águas de Lindóia, S.P., Nov 1999.

Laboratório de Usinagem \& Automação CAD/CAM: Sistemas Integrados de Produção Visando Prototipagem Rápida Disponível em: <http://www.demec.ufmg.br/Grupos/Usinagem/CADCAM.htm. Acesso em: 17 jun. 2005.

LOBACH, B. Design Industrial: Bases para a configuração dos Produtos Industriais, Rio de Janeiro: Edgard Blucher Ltda, 2001. p.11-64. 
MASOOD, SYED H. · (1996) Intelligent rapid prototyping with fused deposition modeling. Rapid Prototyping Journal, v2. n 1. p 24-33.

MIETTI, MARCO A. (2005). O uso do sistema JPS 5 no ensino da prototipagem rápida. Disponível em <http:// www.profmietti.pop.com.br/downloads/jps5.pdf. Acesso em 24 out. 2005 .

NANTES, J.F.D. Projeto do Produto. São Carlos: UFSCar/Departamento de Engenharia de Produção, 2001. Material da disciplina do Curso Gestão da Produção.

PCE Engenharia Ltda. Simulação Computacional. Disponível em: < http://www.pce.com.br/intro_fea.htm/>. Acesso em: 04 abr. 2007.

QUATTER, Projetos, Consultoria \& Design. Prototipagem rápida, aplicação e vantagens. Disponível em: < http://www.quatter.com.br/vantagens.htm/>. Acesso em: 24 out. 2005.

RAPID PROTOTYPING CENTER. Fused deposition modeling. Disponível em <http://www.rpc.msoe.edu/machines_fdm.php. Acesso em: 24 out 2005.

RODRÝGUEZ J.F.; THOMAS J.P.; RENAUD J.E. (2003). Mechanical behavior of acrylonitrile butadiene styrene fused deposition materials modeling. Rapid Prototyping Journal, v. 9 n 4. .p. 219-230.

SABOURIN, E.; SCOTT, A.H.; BOHN, J. H. (1997). Accurate exterior, fast interior layered manufacturing. Rapid Prototyping Journal v. 3. n. 2.p. 44-52.

SILVA, DHIOGO C. et al. Mesa Posicionadora XY. $5^{\circ}$ Encontro Nacional dos Estudantes de Engenharia de Controle e Automação. Florianópolis, SC - 09-14 Outubro de 2005.

TATA, KAMESH. et al. (1998). Efficient slicing for layered manufacturing. Rapid Prototyping Journal. v. 4, n. 4, p. 151-167. 
VOLPATO N. et al (2007 ). Os principais processos de prototipagem rápida...Cap. 3, p. 3157.

ZIEMIAN, C.W.; CRAWN, P.M. 2001. Computer aided decision support for fused deposition modeling. Rapid Prototyping Journal, v 7 . n 3. p 138-147. 


\section{ANEXO A - TEORIA CLÁSSICA DOS LAMINADOS}

O modelo macro mecânico geralmente aceito para análise do laminado é a Teoria Clássica de Laminados (Classical Laminates Theory). Visto que, um laminado é constituído de várias lâminas empilhadas, a descrição do comportamento mecânico de uma única lâmina forma a base com a qual o comportamento mecânico do laminado é descrito, podendo-se assim obter uma formulação matemática que quantifique a rigidez estrutural do laminado.

Considerando uma lâmina de material compósito com as fibras alinhadas paralelamente à direção 1, como mostrado na Figura B.1, é prática comum no estudo de compósitos utilizar uma notação reduzida para a tensão e a deformação.

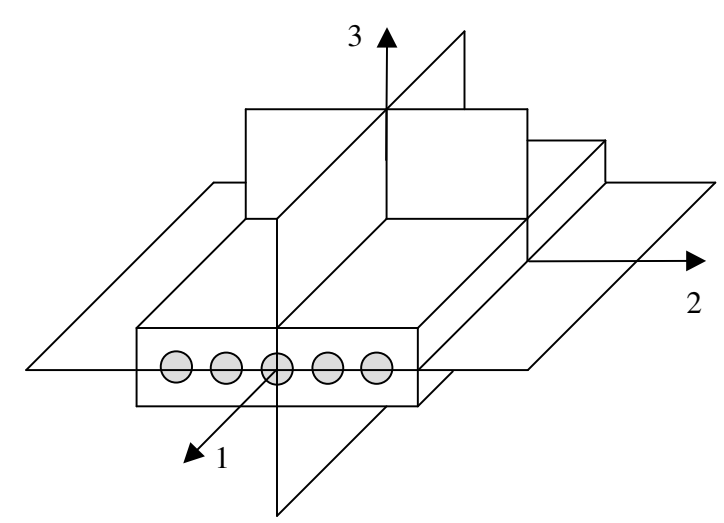

Figura B.1 - Planos de simetria ortogonais de uma lâmina.

Assim, definem-se as tensões e as deformações planas em termos das componentes do tensor das tensões e das deformações, respectivamente, como segue:

$$
\sigma=\left\{\begin{array}{l}
\sigma_{1} \\
\sigma_{2} \\
\sigma_{6}
\end{array}\right\}
$$

$$
\mathcal{E}=\left\{\begin{array}{l}
\varepsilon_{1} \\
\varepsilon_{2} \\
\varepsilon_{6}
\end{array}\right\}
$$

Onde $\sigma_{1}$ e $\sigma_{2}$ são as tensões nas direções dos eixos principais e $\sigma_{6}$ é a tensão de cisalhamento, e $\varepsilon_{1}, \varepsilon_{2}$ e $\varepsilon_{6}$ são as deformações correspondentes. 
As camadas individuais (lâmina) de um laminado são consideradas meios contínuos, homogêneos, elásticos e ortotrópicos com a equação constitutiva do material no sistema de coordenadas principal da forma:

$$
\left\{\begin{array}{l}
\varepsilon_{1} \\
\varepsilon_{2} \\
\varepsilon_{6}
\end{array}\right\}=\left[\begin{array}{ccc}
S_{11} & S_{12} & 0 \\
S_{12} & S_{22} & 0 \\
0 & 0 & S_{66}
\end{array}\right]\left\{\begin{array}{l}
\sigma_{1} \\
\sigma_{2} \\
\sigma_{6}
\end{array}\right\}
$$

onde $[\mathrm{S}]$ é a matriz de flexibilidade reduzida da lâmina. O termo reduzida é utilizado na relação da eq.(2) devido à hipótese do estado plano de tensões. A eq.(2) pode ser invertida e escrita como:

$$
\left\{\begin{array}{l}
\sigma_{1} \\
\sigma_{2} \\
\sigma_{6}
\end{array}\right\}=\left[\begin{array}{ccc}
Q_{11} & Q_{12} & 0 \\
Q_{12} & Q_{22} & 0 \\
0 & 0 & Q_{66}
\end{array}\right]\left\{\begin{array}{l}
\varepsilon_{1} \\
\varepsilon_{2} \\
\varepsilon_{6}
\end{array}\right\}
$$

onde $[\mathrm{Q}]=[\mathrm{S}]^{-1}$ é a matriz de rigidez reduzida para o estado plano de tensões. Os termos individuais da matriz de flexibilidade reduzida $[\mathrm{S}]$ podem ser expressos em termos das constantes de engenharia $E_{1}, E_{2}, v_{12} e G_{12}$ como:

$$
S_{11}=\frac{1}{E_{1}} \quad S_{12}=S_{21}=\frac{-v_{12}}{E_{1}} \quad S_{22}=\frac{1}{E_{2}} \quad S_{66}=\frac{1}{G_{12}}
$$


onde $E_{1} e E_{2}$ são os módulos de elasticidade na direção da fibra e na direção transversal à mesma, respectivamente; $v_{12}$ é o coeficiente de Poisson associado ao carregamento na direção 1, isto é:

$$
v_{12}=-\frac{\varepsilon_{2}}{\varepsilon_{1}}
$$

e $G_{12}$ é o módulo de cisalhamento no plano 1-2. A simetria da matriz de flexibilidade reduzida requer que:

$$
E_{1} v_{21}=E_{2} v_{12}
$$

onde $v_{21}$ é o coeficiente de Poisson associado ao carregamento na direção 2. As componentes de $[Q]$ podem ser expressas em termos das constantes de engenharia por meio de substituições apropriadas.

As matrizes de flexibilidade [S] e rigidez [Q] reduzidas relacionam as tensões e as deformações nas direções dos eixos principais da lâmina $(1,2)$. Normalmente, os eixos principais da lâmina não coincidem com os eixos de referência do laminado (x,y). Quando isto ocorre, as relações constitutivas de cada lâmina individual devem ser transformadas para os eixos de referência do laminado para que determinem as relações constitutivas do laminado. Na Figura B.2, dois sistemas de coordenadas são mostrados. 


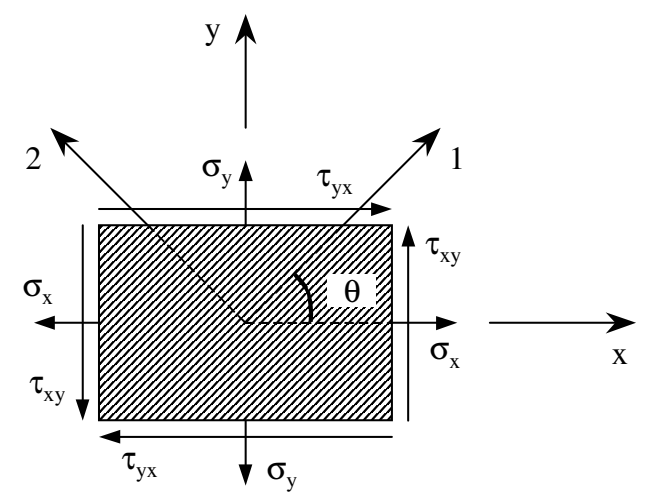

Figura B.2 - O sistema de coordenadas 1-2 refere-se à lâmina e o sistema x-y ao laminado.

As coordenadas 1-2 correspondem aos eixos principais da lâmina, enquanto as coordenadas x-y são arbitrárias e relacionam-se com as coordenadas 1-2 através da rotação em torno do eixo z. O ângulo $\theta$ é definido como a rotação do sistema arbitrário do laminado x-y para o sistema da lâmina 1-2 ( $\theta$ é positivo para uma rotação no sentido anti-horário).

A transformação das relações tensão-deformação do sistema 1-2 para o sistema x-y é:

$$
\left\{\begin{array}{c}
\sigma_{x} \\
\sigma_{y} \\
\tau_{x y}
\end{array}\right\}=\left[\begin{array}{lll}
\bar{Q}_{11} & \bar{Q}_{12} & \bar{Q}_{16} \\
\bar{Q}_{12} & \bar{Q}_{22} & \bar{Q}_{26} \\
\bar{Q}_{16} & \bar{Q}_{26} & \bar{Q}_{66}
\end{array}\right]\left\{\begin{array}{l}
\varepsilon_{x} \\
\varepsilon_{y} \\
\gamma_{x y}
\end{array}\right\}
$$

onde a matriz $[\bar{Q}]$ é denominada de matriz de rigidez reduzida transformada e é obtida por:

$$
[\bar{Q}]=[T]^{-1}[Q][T]^{-T}
$$


[T] na eq.(8) é a matriz de transformação de coordenadas, ou seja:

$$
[T]=\left[\begin{array}{ccc}
\cos ^{2} \theta & \operatorname{sen}^{2} \theta & 2 \operatorname{sen} \theta \cos \theta \\
\operatorname{sen}^{2} \theta & \cos ^{2} \theta & -2 \operatorname{sen} \theta \cos \theta \\
-\operatorname{sen} \theta \cos \theta & \operatorname{sen} \theta \cos \theta & \cos ^{2} \theta-\operatorname{sen}^{2} \theta
\end{array}\right]
$$

onde $[\mathrm{T}]^{-1}$ e $[\mathrm{T}]^{-\mathrm{T}}$ são a inversa e a transposta da inversa da matriz de transformação de coordenadas, respectivamente. A relação inversa da eq.(7) em termos de $[\bar{S}]$ apresenta o mesmo aspecto geral.

Percebe-se que a orientação da fibra influencia nas propriedades elásticas e consequentemente na matriz de rigidez da lâmina, onde se obtém a mais alta rigidez quando o carregamento estiver na mesma direção de orientação da fibra. Caso contrário, com a defasagem angular entre o carregamento e a orientação da fibra, o valor da matriz de rigidez diminui, chegando a um valor mínimo quando o carregamento for perpendicular à orientação da mesma.

Até agora, foram desenvolvidas as ferramentas necessárias para compreender a resposta elástica de uma lâmina individual. Sabendo-se que um compósito laminado é formado pelo empilhamento sistemático de várias lâminas, cada lâmina assume as hipóteses já discutidas e o laminado é analisado por meio da Teoria Clássica de Laminados. Da mesma forma, algumas hipóteses associadas à TCL são consideradas:

- Cada lâmina é considerada homogênea, ortotrópica e seus materiais constituintes têm comportamento elástico;

- Cada lâmina é analisada no estado plano de tensões;

- O deslocamento de cada lâmina segue uma regra restritiva de acordo com a hipótese de Kirchhoff; 
- Cada lâmina está perfeitamente unida à lâmina adjacente, assegurando a continuidade de deslocamentos.

Das hipóteses da TCL segue-se que as distribuições das deformações nas direções x e y variam linearmente através da espessura do laminado. Em termos das componentes de deformação no plano médio do laminado $\left\{\varepsilon^{o}\right\}$ e das componentes de rotação de corpo rígido medidas em relação ao plano médio do laminado $\left\{k^{o}\right\}$, as deformações podem ser expressas como:

$$
\left\{\begin{array}{l}
\varepsilon_{x} \\
\varepsilon_{y} \\
\gamma_{x y}
\end{array}\right\}=\left\{\begin{array}{c}
\varepsilon_{x}^{o} \\
\varepsilon_{y}^{o} \\
\gamma_{x y}^{o}
\end{array}\right\}+z \cdot\left\{\begin{array}{c}
k_{x}^{o} \\
k_{y}^{o} \\
k_{x y}^{o}
\end{array}\right\}
$$

As tensões para uma localização específica $z_{K}$, onde o subscrito $K$ denota a $K$ ésima lâmina do laminado, são obtidas das equações constitutivas (eq.7) e a deformação provém da hipótese de Kirchhoff, obtendo-se:

$$
\left\{\begin{array}{l}
\sigma_{x} \\
\sigma_{y} \\
\tau_{x y}
\end{array}\right\}_{K}=\left[\begin{array}{lll}
\bar{Q}_{11} & \bar{Q}_{12} & \bar{Q}_{16} \\
\bar{Q}_{12} & \bar{Q}_{22} & \bar{Q}_{26} \\
\bar{Q}_{16} & \bar{Q}_{26} & \bar{Q}_{66}
\end{array}\right]_{K}\left\{\left\{\begin{array}{c}
\varepsilon_{x}^{o} \\
\varepsilon_{y}^{o} \\
\gamma_{x y}^{o}
\end{array}\right\}+z\left\{\begin{array}{c}
k_{x}^{o} \\
k_{y}^{o} \\
k_{x y}^{o}
\end{array}\right\}\right)_{K}
$$

De um modo geral, a distribuição da tensão ao longo da espessura do laminado não é linear e as tensões são descontínuas na interface entre as lâminas. Visto que as tensões no compósito laminado variam de lâmina para lâmina, é conveniente definir as forças (esforços) normais $\{\mathrm{N}\}$ e os momentos fletores $\{\mathrm{M}\}$ que atuam, por unidade de comprimento, através da espessura $H$ do laminado, como: 


$$
\left\{\begin{array}{l}
N_{x} \\
N_{y} \\
N_{x y}
\end{array}\right\}=\int_{\frac{-H}{2}}^{\frac{H}{2}}\left\{\begin{array}{l}
\sigma_{x} \\
\sigma_{y} \\
\tau_{x y}
\end{array}\right\} d z \quad \text { e } \quad\left\{\begin{array}{l}
M_{x} \\
M_{y} \\
M_{x y}
\end{array}\right\}=\int_{\frac{-H}{2}}^{\frac{H}{2}}\left\{\begin{array}{l}
\sigma_{x} \\
\sigma_{y} \\
\tau_{x y}
\end{array}\right\}_{K} z d z
$$

Da integração das eqs.(12) provêem as equações fundamentais da Teoria Clássica de laminados:

$$
\left\{\begin{array}{l}
N_{x} \\
N_{y} \\
N_{x y}
\end{array}\right\}=\left[\begin{array}{lll}
A_{11} & A_{12} & A_{16} \\
A_{12} & A_{22} & A_{26} \\
A_{16} & A_{26} & A_{66}
\end{array}\right]\left\{\begin{array}{c}
\varepsilon_{x}^{o} \\
\varepsilon_{y}^{o} \\
\gamma_{x y}^{o}
\end{array}\right\}+\left[\begin{array}{lll}
B_{11} & B_{12} & B_{16} \\
B_{12} & B_{22} & B_{26} \\
B_{16} & B_{26} & B_{66}
\end{array}\right]\left\{\begin{array}{c}
k_{x}^{o} \\
k_{y}^{o} \\
k_{x y}^{o}
\end{array}\right\}
$$

$$
\left\{\begin{array}{l}
M_{x} \\
M_{y} \\
M_{x y}
\end{array}\right\}=\left[\begin{array}{lll}
B_{11} & B_{12} & B_{16} \\
B_{12} & B_{22} & B_{26} \\
B_{16} & B_{26} & B_{66}
\end{array}\right]\left\{\begin{array}{c}
\varepsilon_{x}^{o} \\
\varepsilon_{y}^{o} \\
\gamma_{x y}^{o}
\end{array}\right\}+\left[\begin{array}{lll}
D_{11} & D_{12} & D_{16} \\
D_{12} & D_{22} & D_{26} \\
D_{16} & D_{26} & D_{66}
\end{array}\right]\left\{\begin{array}{c}
k_{x}^{o} \\
k_{y}^{o} \\
k_{x y}^{o}
\end{array}\right\}
$$

onde as matrizes $A_{i j}, B_{i j}$ e $D_{i j}$ são definidas para um laminado com $n$ lâminas, como:

$$
\begin{aligned}
& A_{i j}=\sum_{K=1}^{n}\left(\bar{Q}_{i j}\right)_{K}\left(z_{K}-z_{K-1}\right) \\
& B_{i j}=\frac{1}{2} \sum_{K=1}^{n}\left(\bar{Q}_{i j}\right)_{K}\left(z_{K}^{2}-z_{K-1}^{2}\right) \\
& D_{i j}=\frac{1}{3} \sum_{K=1}^{n}\left(\bar{Q}_{i j}\right)_{K}\left(z_{K}^{3}-z_{K-1}^{3}\right)
\end{aligned}
$$


sabendo que para $A_{i j}, B_{i j}$ e $D_{i j}, i=1,2,6$ e $j=1,2,6 \mathrm{com} z_{K}$ iniciando na coordenada z até a K-ésima lâmina do laminado, como mostrado na Figura B.3 .
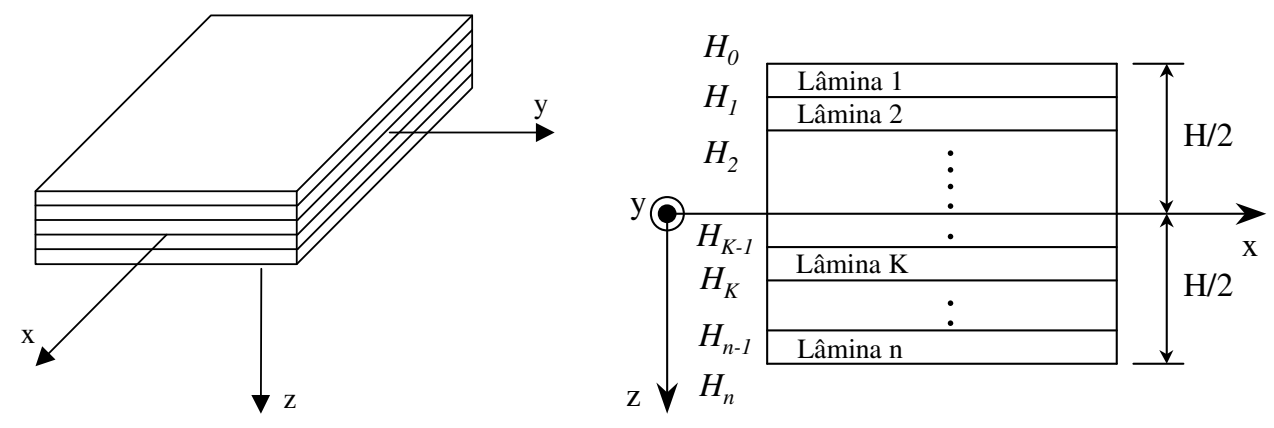

Figura B.3 - Nomenclatura do laminado (HYER, 1998).

Combinando as eqs.(13), o total de equações constitutivo do laminado é escrito da seguinte forma:

$$
\left\{\begin{array}{l}
N_{x} \\
N_{y} \\
N_{x y} \\
M_{x} \\
M_{y} \\
M_{x y}
\end{array}\right\}=\left[\begin{array}{llllll}
A_{11} & A_{12} & A_{16} & B_{11} & B_{12} & B_{16} \\
A_{12} & A_{22} & A_{26} & B_{12} & B_{22} & B_{26} \\
A_{16} & A_{26} & A_{66} & B_{16} & B_{26} & B_{66} \\
B_{11} & B_{12} & B_{16} & D_{11} & D_{12} & D_{16} \\
B_{12} & B_{22} & B_{26} & D_{12} & D_{22} & D_{26} \\
B_{16} & B_{26} & B_{66} & D_{16} & D_{26} & D_{66}
\end{array}\right]\left\{\begin{array}{c}
\varepsilon_{x}^{o} \\
\varepsilon_{y}^{o} \\
\gamma_{x y}^{o} \\
k_{x}^{o} \\
k_{y}^{o} \\
k_{x y}^{o}
\end{array}\right\}
$$

onde, a eq.(15) pode ser representada por uma notação simplificada, a saber:

$$
\left\{\begin{array}{l}
N \\
M
\end{array}\right\}=\left[\begin{array}{ll}
A & B \\
B & D
\end{array}\right] \cdot\left\{\begin{array}{l}
\varepsilon^{o} \\
k^{o}
\end{array}\right\}
$$


A equação da TCL pode ser invertida e expressa por:

$$
\left\{\begin{array}{l}
\varepsilon^{o} \\
k^{o}
\end{array}\right\}=\left[\begin{array}{ll}
A^{*} & B^{*} \\
C^{*} & D^{*}
\end{array}\right]\left\{\begin{array}{l}
N \\
M
\end{array}\right\}
$$

onde as quantidades (*) são apropriadamente definidas.

As equações fundamentais da TCL mostram que, em geral, existe um acoplamento entre a flexão e a tração através da matriz $B_{i j}$.

A matriz da eq.(15) formada pelos componentes $A_{i j}, B_{i j}$ e $D_{i j}$ com $i=1,2,6$ e $j=1,2,6$, é denominada de matriz de rigidez do laminado, também conhecida como matriz $\boldsymbol{A B D}$. A matriz $A$ representa a rigidez à tração e à compressão, a matriz $B$ é a matriz de acoplamento entre a rigidez planar e a rigidez à flexão e a matriz $D$ representa a rigidez à flexão. Esta matriz é fortemente influenciada pela seqüência de empilhamento (stacking sequence) das lâminas. Para representar a seqüência de empilhamento das lâminas, adota-se um sistema de convenção, utilizado na literatura, conhecido como "código do laminado" (laminate code) que simboliza a ordem dos ângulos de orientação das fibras de cada lâmina para especificar um laminado completo.

Os laminados apresentam uma gama de classificações conforme a sequiência de empilhamento utilizada e algumas destas classificações e seus efeitos sobre a matriz $A B D$ são encontradas em TSAI \& HAHN (1980), TSAI (1986), HYER (1998) entre outros. Quando um laminado é formado pelo empilhamento de várias lâminas ortotrópicas numa sequiência arbitrária de orientação, a matriz $A B D$ geralmente não possui termos nulos. Entretanto, é possível, e em muitos casos desejável, especificar a seqüência de empilhamento das lâminas para que vários termos da matriz $A B D$ possam ser nulos, simplificando a análise do laminado. 
Portanto, verifica-se a importância da disposição das fibras em cada lâmina do laminado. Esta característica exclusiva dos MCRF, concede a estes materiais um atrativo para o desenvolvimento de projetos. Principalmente em projetos que exijam uma estrutura de alta rigidez e alta resistência com baixo peso específico.

KEUNINGS (1992) apresenta um fluxograma, ilustrado na Figura B.4, que reúne todas as etapas necessárias para análise de um laminado, discutidas neste trabalho até agora.

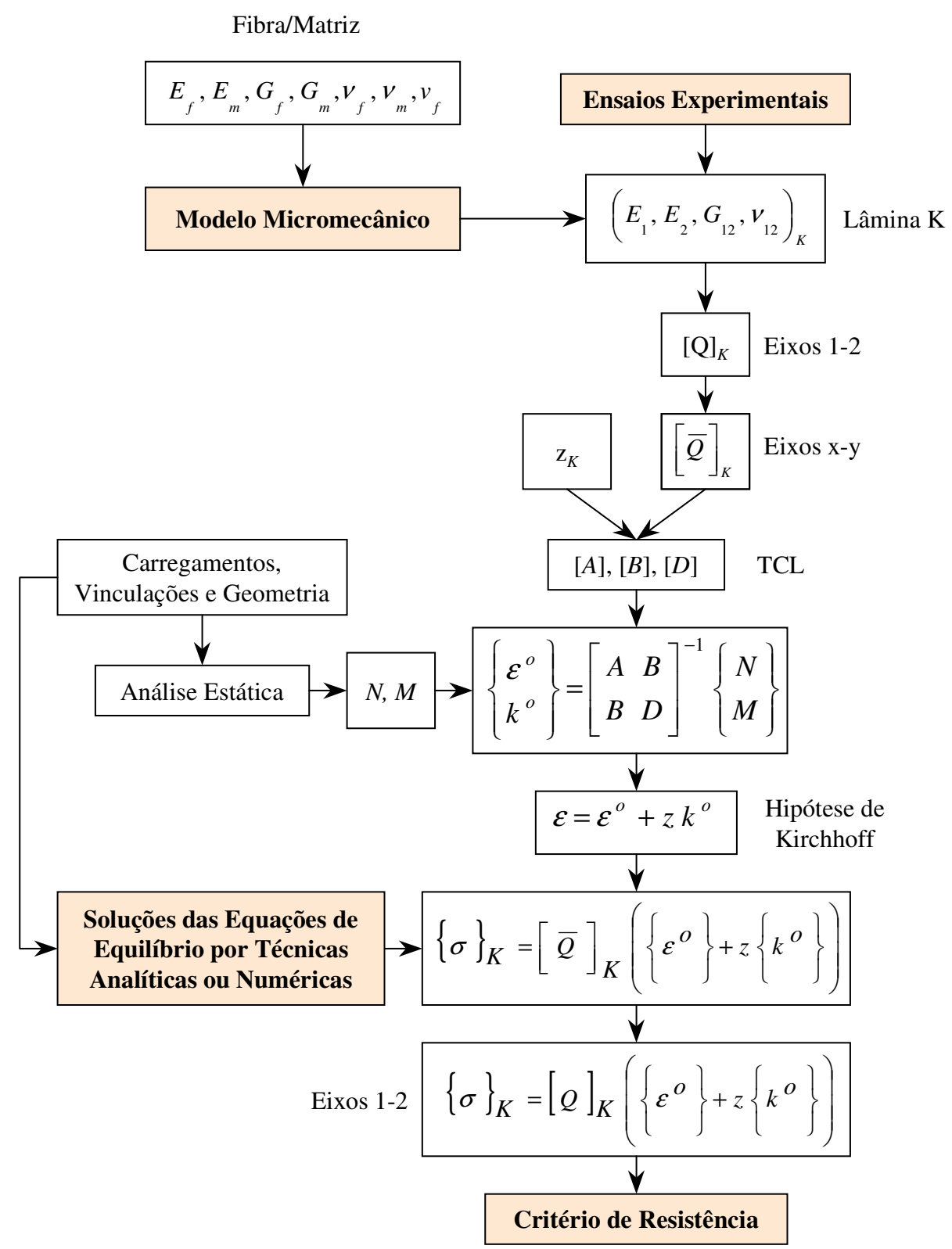

Figura B.4 - Fluxograma para determinação da rigidez e tensões atuantes no laminado. (KEUNINGS, 1992). 
Nota-se assim, que as propriedades elásticas $\left(E_{1}, E_{2}, G_{12}\right.$ e $\left.v_{12}\right)$ de uma lâmina podem ser obtidas por meio de um modelo micro mecânico baseado nas propriedades dos constituintes da lâmina (fibra e matriz) ou por meio de ensaios experimentais. Com isto, podese obter a matriz de rigidez $[\mathrm{Q}]_{\mathrm{K}}$ para uma lâmina tomando como referência os eixos 1-2. Caso haja uma defasagem $\theta_{K}$ na orientação das fibras de uma dada lâmina em relação ao eixo 1, aplica-se a matriz de transformação de coordenadas [T] sobre a matriz de rigidez. Assim, com a rigidez de cada lâmina e com a coordenada $z$ em relação ao plano médio do laminado $z_{K}$, pode-se com auxílio da Teoria Clássica de Laminados determinar as matrizes $[A],[B]$ e $[D]$. Com os esforços atuantes e a matriz de rigidez do laminado, têm-se as deformações desenvolvidas sob o mesmo. Tal cálculo pode ser executado por meio da TCL ou por técnicas numéricas, tais como o método das diferenças finitas, o método dos elementos finitos ou o método dos elementos de contorno. Utilizando-se das relações constitutivas para materiais compósitos, calculam-se as tensões $\sigma_{K}$ presentes em cada lâmina.

De acordo com KEUNINGS (1992), o uso de técnicas numéricas se faz necessário para uma melhor previsão das tensões nas regiões em que haja concentrações (regiões com mudança de seção), bem como a previsão das tensões interlaminares $\sigma_{x y}$. AGARWAL \& BROUTMAN (1990) confirmaram que as tensões de cisalhamento interlaminares são intensas porque há uma certa diferença entre os módulos de elasticidade das lâminas com diferentes orientações de fibras, segundo a seqüência de empilhamento. Diante disto, conclui-se que próximo às bordas do laminado ou em regiões em que haja mudança de seção, o comportamento do laminado não pode ser aproximado por um estado plano de tensões, mas sim por um estado triplo de tensões.

Por fim, nota-se que o fluxograma propõe o cálculo das tensões desenvolvidas em cada lâmina, isto ocorre porque os critérios de resistência para laminados estão na sua grande maioria baseados na falha de cada lâmina. Tal assunto será abordado em sessões posteriores. 
Conclui-se que um componente mecânico fabricado a partir de MCRF possui uma gama de opções para se obter um desempenho desejado. Pode-se escolher desde as propriedades dos seus constituintes (fibra e matriz), até a orientação e a distribuição das fibras em cada lâmina. Consequentemente modificar-se-á a rigidez do laminado final que depende da sequiência de empilhamento das lâminas (stacking sequence) e isto virá interferir diretamente na resistência do laminado bem como no seu comportamento dinâmico (freqüências naturais, modos de vibrar e fatores de amortecimento modal). Estas características únicas, presentes nos MCRF, fazem com que estes materiais, sejam atrativos no desenvolvimento de projetos. Principalmente em projetos que requerem um menor peso específico sem comprometer a sua resistência, como por exemplo, as estruturas aeronáuticas e automobilísticas.

\section{CARACTERIZAÇÃo MECÂNICA POR MÉTODOS EXPERIMENTAIS}

Segundo AGARWAL \& BROUTMAN (1990) a caracterização experimental referese à determinação das propriedades do material através de testes conduzidos por meio de corpos de prova preparados adequadamente.

Os dados obtidos a partir de testes são responsáveis pela avaliação das várias propriedades dos materiais que podem ser posteriormente utilizados no projeto e análise de componentes estruturais. $\mathrm{O}$ entendimento da resposta do material conforme a extensão total do carregamento é necessário, se procedimentos avançados de projeto são empregados para a utilização eficiente do material. No caso dos compósitos, pode ser desejável iniciar o projeto com as propriedades dos materiais constituintes e chegar às propriedades macromecânicas do compósito por meio das análises micromecânicas. Entretanto, a confiabilidade nas análises micromecânicas é confirmada por meio de ensaios experimentais. Outros propósitos da caracterização experimental são: verificar a conformidade dos procedimentos de fabricação; 
assegurar a uniformidade do material e comparar os valores das propriedades de vários materiais candidatos à seleção para utilização em projetos de engenharia.

Para caracterizar uma lâmina unidirecional por meio de ensaios experimentais são determinadas quatro constantes elásticas independentes: módulos de elasticidade na direção longitudinal e transversal $\left(\mathrm{E}_{1}\right.$ e $\left.\mathrm{E}_{2}\right)$; módulo devido ao cisalhamento no plano da lâmina $\left(\mathrm{G}_{12}\right)$ e o maior coeficiente de Poisson $\left(v_{12}\right)$. Assim como são determinadas cinco resistências, a saber: resistência à tração e à compressão na direção longitudinal e transversal e resistência ao cisalhamento no plano da lâmina. No caso de um laminado, a resistência ao cisalhamento interlaminar é também uma propriedade importante. É necessário estabelecer estas propriedades para uma caracterização mínima de uma lâmina unidirecional. Elas são geralmente estabelecidas quando corpos de prova adequados são submetidos a carregamentos no plano. Entretanto, um laminado em serviço é muitas vezes submetido à ação de carregamentos combinados, deste modo é necessário caracterizar a lâmina em relação a carregamentos de flexão em adição àquelas propriedades já mencionadas. Com todas as propriedades estabelecidas para uma lâmina, a Teoria Clássica de Laminados pode ser utilizada para calcular as propriedades do laminado.

No entanto, muitas vezes, as considerações práticas impedem a construção de corpos de prova com uma única lâmina. Assim, torna-se necessário conduzir os testes por meio de corpos de prova com várias lâminas e utilizar apropriadamente a TCL para simplificar os resultados em termos das propriedades da lâmina. Se o laminado é unidirecional, certamente, seu comportamento simula o comportamento da lâmina.

Os procedimentos de testes normalmente empregados para determinar as várias propriedades dos compósitos, como a seleção mais conveniente de um tipo particular de corpo de prova para cada método de teste, os métodos de redução dos dados experimentais, os detalhes de instrumentação e as técnicas de medição são discutidos fartamente na literatura. 
Além disso, discussões detalhadas podem ser encontradas em normas técnicas, tal como as normas da American Society for Testing and Materials - ASTM que têm sido muito utilizadas para testes em compósitos.

Contudo, CARVALHO (1996) descreve algumas particularidades relacionadas aos ensaios mecânicos em compósitos, tais como.

(a) Os ensaios mecânicos que são executados para a determinação das propriedades mecânicas dos materiais estão fundamentados na aplicação da teoria básica da mecânica. Tal teoria é aplicada satisfatoriamente para materiais elásticos homogêneos e isotrópicos, o que não é o caso dos compósitos reforçados por fibras, cuja anisotropia, não homogeneidade e não elasticidade dificultam a aplicação de tais conceitos.

(b) As grandes dificuldades na execução dos ensaios são devido a:

- Influência de "efeitos de borda" (end-effects) que induzem ao aparecimento de regiões com concentração de tensão próximas às arestas da amostra;

- Geração de níveis de carregamentos adequados sem causar danos ao material;

- Uso de dimensões apropriadas, principalmente a espessura, em relação à escala de heterogeneidade do material.

(c) A anisotropia conduz a problemas práticos, tais como:

- Intensifica os efeitos de borda, que dependem da geometria da amostra e do grau de anisotropia;

- Produz falha prematura em fixações ou em pontos de aplicação de carga;

- Favorece a delaminações prematuras em "arestas vivas" (free edges) ou aparecimento de outros mecanismos de falha;

- Aumenta a diferença entre as propriedades do material, como por exemplo, o módulo de elasticidade à tração, que é governado pelas propriedades da fibra e o módulo ao cisalhamento, governado basicamente pelas propriedades da matriz; 
(d) Os testes em compósitos são geralmente de alto custo, pois:

- Os materiais, na sua maioria, têm um preço alto;

- A fabricação de amostras e corpos de prova demanda atenção meticulosa a detalhes.

(e) Em determinados casos, as normas técnicas ASTM, ISO, DIN, etc. podem ser muito adequadas, enquanto que em outros casos podem ser totalmente inadequadas. 


\section{BIBLIOGRAFIA}

AGARWAL, B.D.; BROUTMAN, L.J. (1990). Analysis and performance of fiber composites, second edition. New York, John Wiley \& Sons, Inc.

CARVALHO, J. (1996). Computer integrated design optimization and manufacturing of filament wound parts. Tese (Doutorado) - Faculty of Applied Sciences, Division PMA, K.U. Leuven.

HYER, M. W. (1998). Stress analysis of reinforced composite materials. Singapore, WCB/McGraw-Hill.

KEUNINGS, R. (1992). Macromechanics of composites. Composites Science and Technology - European Postgraduate Education in Polymer and Composites Engineering (EUPOCO), K. U. Leuven, v.2, Module 4, p.1-67.

TSAI, S.W. (1986). Composites design 1986. Dayton, Think Composites.

TSAI, S.W.; HAHN, H.T. (1980). Introduction to composite materials. Lancaster, Technomic Publishing Company, Inc. 